\title{
Substitution Bias in Multilateral Methods for CPI Construction using Scanner Data
}

W. Erwin Diewert and Kevin J. Fox ${ }^{1}$

March 23, 2017

Discussion Paper 17-02, Vancouver School of Economics, The University of British Columbia, Vancouver, Canada, V6T 1L4.

\begin{abstract}
The use of multilateral comparison methods in a time series context is increasingly becoming an accepted approach for incorporating scanner data in a Consumer Price Index. The attractiveness stems from the ability to be able to control for chain drift bias. Consensus on two key issues has yet to be achieved: (i) the best multilateral method to use, and (ii) the best way of extending the resulting series when new observations become available. This paper presents theoretical and simulation evidence on the extent of substitution biases in alternative multilateral methods. The multilateral index number formulae studied include the GEKS, CCDI, Geary-Khamis and Weighted Time Product Dummy Methods as well as some price similarity linking methods. The paper also assesses alternative methods for extending non-revisable series, with particular regard to the possibility of introducing chain drift bias. Overall, our results suggest the use of the CCDI index with a new method, the "mean splice”, for updating.
\end{abstract}

\section{Key Words}

Consumer Price Indexes, superlative indexes, chain drift, scanner data, Time Product Dummy method, Geary-Khamis, GEKS and CCDI methods for making international comparisons, Rolling Year indexes, elementary indexes.

\section{Journal of Economic Literature Classification Numbers}

C43, E31.

W. Erwin Diewert: School of Economics, University of British Columbia, Vancouver B.C., Canada, V6T $1 \mathrm{Z1}$ and the School of Economics, UNSW Sydney, NSW 2052, Australia (erwin.diewert@ubc.ca) and Kevin J. Fox: School of Economics, UNSW Sydney, NSW 2052, Australia (K.Fox@unsw.edu.au). The first author gratefully acknowledges the financial support of the SSHRC of Canada, and both authors gratefully acknowledge the financial support of the Australian Research Council (DP150100830). 


\section{Introduction}

Several national statistical agencies are either using or considering the use of scanner data from retail outlets that collect data on weekly unit value prices and the corresponding quantities sold of specific products. This detailed data on prices and quantities can be used in order to construct consumer price indexes for various product groups. ${ }^{2}$ The 2004 International Labour Office Consumer Price Index Manual recommended that chained superlative indexes be used in constructing national Consumer Price Indexes (CPIs) when detailed price and quantity data were available. The reason why chaining was recommended over the use of fixed base indexes was the fact that more exact product matches will generally be found if chained indexes are constructed instead of fixed base indexes due to the fact that often one or two percent of products disappear from the marketplace each month in many countries. However, as more experience with the use of chained indexes has become available, it has been noticed that chained indexes frequently drift downwards as compared to corresponding fixed base indexes. It is a serious problem and this study will look at possible solutions to the problem.

Until recent times, CPIs were constructed by statistical agencies using bilateral index number theory; i.e., the prices and quantities for a group of commodities for the current period were compared to the same prices and quantities for a base period. Multilateral index number theory uses the prices and quantities for a group of commodities for multiple periods (say $\mathrm{T}$ periods) and simultaneously constructs a sequence of price indexes for all T periods. Ivancic, Diewert and Fox (2011) suggested that the use of multilateral indexes in the scanner data context can largely solve the chain drift problem. ${ }^{3}$ However, in recent years, there has been a considerable amount of additional research on the use of multilateral methods when detailed price and quantity data are available and we will attempt to review and extend this research in this study.

This chain drift problem will be explained in more detail in section 2. The GEKS multilateral method due to Gini (1931; 12), Eltetö and Köves (1964) and Szulc (1964) will be reviewed in section 3. The GEKS method uses the bilateral Fisher (1922) ideal index as a basic building block. Instead of using the Fisher index as the bilateral building block index, it is possible to use Gini's basic methodology but use the Törnqvist index as the bilateral building block index. This idea was used by Caves, Christensen and Diewert (1982) using distance functions and adapted to the price index context by Inklaar and Diewert (2016). This multilateral approach to price index theory will be explained in section 4. We will call this multilateral approach to index number theory the CCDI approach.

\footnotetext{
${ }^{2}$ See the Australian Bureau of Statistics (2016).

${ }^{3}$ Ivancic, Diewert and Fox (2009) (2011) used the GEKS and the Weighted Time Product Dummy multilateral methods which will be explained in sections 3 and 6. Khamis (1970; 83-85) (1972; 101) noted that the Geary-Khamis multilateral indexes could be applied in the time series context as well as in the international comparisons context. Balk (1981) also adapted Gini's basic methodology to the time series context using the Sato (1976) Vartia (1976) bilateral index number formula as the bilateral building block formula.
} 
A multilateral index number method will determine a sequence of price indexes or aggregate price levels for say $T$ periods where $T \geq 3$. When the data for period $T+1$ becomes available, CPI methodology typically does not allow for a revision of price levels that have already been determined for periods 1 to $\mathrm{T}$, so those initially determined price levels remain the same. If the multilateral method is used to form a new sequence of price levels for periods 2 to $\mathrm{T}+1$, the following question arises: how exactly should the new price levels be linked to the initial sequence of price levels? Various methods for accomplishing this linking have been suggest in the recent literature and in section 5 , we will study these alternative linking methods in the context of the CCDI multilateral indexes since this facilitates comparisons. It will emerge that it makes sense to link the results of the new window of price levels to the initial window of price levels by finding the period in the initial window that has the most similar structure of relative prices to the prices of period $\mathrm{T}+1$.

In sections 6-8, we continue to review multilateral methods that have been suggested in the recent literature to address the chain drift problem. Thus section 6 reviews and extends the Weighted Time Product Dummy (WTPD) method which is a generalization of Summer's (1973) Country Product Dummy method for making price comparisons across countries. Section 7 looks at the problem of linking windows in the context of the WTPD method. Section 8 reviews the Geary (1958) Khamis (1970) (1972) (GK) multilateral method.

Section 9 introduces Constant Elasticity of Substitution (CES) purchaser preferences as a basis for a target cost of living index. ${ }^{4}$ In recent years, statistical agencies have had difficulties in trying to determine which multilateral method should be used to aggregate price data when detailed price and quantity data are available for a stratum of their CPIs. The problem is that the "truth" is not known. Thus in the later sections of this study, we will assume that we know the "truth"; i.e., we will assume that purchasers have known CES preferences and thus we can construct the corresponding true cost of living indexes given an artificial data set. Then the various multilateral methods that have been suggested in the literature can be constructed using the artificial data set and compared with the corresponding true CES cost of living indexes. The assumption of CES preferences has been used in many economics and marketing studies. ${ }^{5}$

We present our first artificial data set in section 10. We assume given price data on four commodities for twelve periods along with total expenditures on the commodities. We assume CES preferences but we allow the elasticity of substitution parameter $\sigma$ to take on 6 separate values: $0,0.5,1,2,4$ and 10 . For each of these values of $\sigma$, we construct quantity data based on the CES functional form. Thus as $\sigma$ varies, the price data remain the same but the quantity data change in order to be consistent with the CES preferences. In section 10, we construct the six artificial data sets along with the true CES cost of living indexes and compare these true indexes with fixed base and chained Fisher and

\footnotetext{
${ }^{4}$ Balk's (1981) multilateral method, which adapted Gini's basic methodology using the Sato-Vartia bilateral price index as the basic building block, is exact for CES preferences.

${ }^{5}$ For economics studies, see e.g. Balk (1981), Feenstra (1994) and Ivancic, Diewert and Fox (2010), and Baltas (2001) for an example from the marketing literature.
} 
Törnqvist indexes as well as the single window GK, WTPD, GEKS and CCDI multilateral price levels. It turns out that the best approximations to the true indexes vary as the elasticity of substitution varies.

It turns out that the methodological approach taken in section 10 does not address the chain drift problem because it does not arise using the artificial data set. Chained superlative indexes performed well using the section 10 data set. Thus in section 11, we alter the data used in section 10 so that the altered data will reflect the chain drift problem. This problem is basically caused by heavily discounted prices. Purchasers stock up on a product when it goes on sale. In the period following the sale, consumers do not purchase the same amount of the product that they did in the pre-sale period. This behaviour is not consistent with the assumptions underlying the typical theory of the cost of living index which does not take into account the holding of stocks of consumer goods over multiple periods. ${ }^{6}$ The net effect of this stockpiling behaviour is to cause chained indexes to have a downward bias as compared to a corresponding fixed base index. The artificial data set introduced in section 10 has sales of products in four of the twelve periods. In section 11, we use the price data of section 10 but with the sales goods' quantity data adjusted downwards in the periods following a sale. ${ }^{7}$ Thus the CES true cost of living index is no longer a valid cost of living index for these four post sale periods. However, for the remaining 8 periods, we can still look at how well the various multilateral indexes approximate the true cost of living index.

In section 12, we used the adjusted artificial data set constructed in section 11 to study the window linking problem that was discussed in section 5 in theoretical terms.

In section 13, we again use the artificial data set constructed in section 11 in order to introduce two additional multilateral methods that are based on linking observations that have the most similar structure of relative prices. One of these price similarity linking methods worked very well for the artificial data sets that corresponded to elasticities of substitution in the range of 1 to 4 . This is a new method for linking observations and so there is no practical experience with its use but it seems promising. Section 14 concludes.

\section{The Chain Drift Problem}

More than a decade has passed since the Consumer Price Index Manual was published. ${ }^{8}$ There have been some significant developments that should be taken into account in the forthcoming revision of the Manual. The main problem that the Manual did not address adequately is the chain drift problem. ${ }^{9}$ In order to explain the nature of this problem, it

\footnotetext{
${ }^{6}$ In principle, this stockpiling activity could be modeled by treating the purchases as purchases of durable goods and constructing user costs.

${ }^{7}$ It will be seen that this adjustment to the data set does cause substantial downward drift in the chained superlative indexes.

${ }^{8}$ See the ILO/IMF/OECD/UNECE/Eurostat/The World Bank (2004). The Manual was written over the years 2000-2003. For brevity, in the future, we will refer to the CPI Manual as ILO (2004) or the Manual.

${ }^{9}$ Szulc (1983) (1987) demonstrated how big the chain drift problem could be with chained Laspeyres indexes but the authors of the Manual did not realize that chain drift could also be a problem with chained superlative indexes.
} 
will be useful to provide some introductory historical material on the construction of a CPI.

The first approach to the construction of a CPI that was suggested in the index number literature was the fixed basket approach. In this approach, a basket of commodities that is representative of the purchases of a group of households over a period of time is chosen. Suppose that the chosen group of households purchases $\mathrm{N}$ quantities in each of two periods and the representative basket is defined by the positive quantity vector $\mathrm{q} \equiv$ $\left[\mathrm{q}_{1}, \ldots, \mathrm{q}_{\mathrm{N}}\right]$. Given the price vectors for periods 0 and $1, \mathrm{p}^{0} \equiv\left[\mathrm{p}_{1}{ }^{0}, \ldots, \mathrm{p}_{\mathrm{N}}{ }^{0}\right]$ and $\mathrm{p}^{1} \equiv$ $\left[\mathrm{p}_{1}{ }^{1}, \ldots, \mathrm{p}_{\mathrm{N}}{ }^{1}\right]$ respectively, we can calculate the cost of purchasing this same basket in the two periods, $\mathrm{p}^{0} \cdot \mathrm{q} \equiv \sum_{\mathrm{n}=1}{ }^{\mathrm{N}} \mathrm{p}_{\mathrm{n}}{ }^{0} \mathrm{q}_{\mathrm{n}}$ and $\mathrm{p}^{1} \cdot \mathrm{q} \equiv \sum_{\mathrm{n}=1}{ }^{\mathrm{N}} \mathrm{p}_{\mathrm{n}}{ }^{1} \mathrm{q}_{\mathrm{n}}$. Then the ratio of these costs is a very reasonable indicator of pure price change over the two periods under consideration, provided that the basket vector q is "representative". This leads to the Lowe (1823) price index, $\mathrm{P}_{\mathrm{Lo}}$, defined as follows:

(1) $P_{L o}\left(p^{0}, p^{1}, q\right) \equiv p^{1} \cdot q / p^{0} \cdot q$.

As time passed, economists and price statisticians demanded a bit more precision with respect to the specification of the basket vector q. There are two natural choices for the reference basket: the period 0 commodity vector $\mathrm{q}^{0}$ that was actually purchase by the group of households or the corresponding period 1 commodity vector $q^{1}$. These two choices lead to the Laspeyres (1871) price index $\mathrm{P}_{\mathrm{L}}$ defined by (2) and the Paasche (1874) price index $\mathrm{P}_{\mathrm{P}}$ defined by (3):

(2) $\mathrm{P}_{\mathrm{L}}\left(\mathrm{p}^{0}, \mathrm{p}^{1}, \mathrm{q}^{0}, \mathrm{q}^{1}\right) \equiv \mathrm{p}^{1} \cdot \mathrm{q}^{0} / \mathrm{p}^{0} \cdot \mathrm{q}^{0}=\sum_{\mathrm{n}=1}{ }^{\mathrm{N}} \mathrm{s}_{\mathrm{n}}{ }^{0}\left(\mathrm{p}_{\mathrm{n}}{ }^{1} / \mathrm{p}_{\mathrm{n}}{ }^{0}\right)$;

(3) $\mathrm{P}_{\mathrm{P}}\left(\mathrm{p}^{0}, \mathrm{p}^{1}, \mathrm{q}^{0}, \mathrm{q}^{1}\right) \equiv \mathrm{p}^{1} \cdot \mathrm{q}^{1} / \mathrm{p}^{0} \cdot \mathrm{q}^{1}=\left[\sum_{\mathrm{n}=1}{ }^{\mathrm{N}} \mathrm{s}_{\mathrm{n}}{ }^{1}\left(\mathrm{p}_{\mathrm{n}}{ }^{1} / \mathrm{p}_{\mathrm{n}}{ }^{0}\right)^{-1}\right]^{-1}$

where the period t expenditure share on commodity $n, s_{n}{ }^{t}$, is defined as $p_{n}{ }^{t} q_{n}{ }^{t} / p^{t} \cdot q^{t}$ for $n=$ $1, \ldots, N$ and $t=0,1$. Thus the Laspeyres price index $P_{L}$ can be written as a base period expenditure share weighted average of the $\mathrm{N}$ price ratios (or price relatives), $\mathrm{p}_{\mathrm{n}}{ }^{1} / \mathrm{p}_{\mathrm{n}}{ }^{0}{ }^{10}$ The last equation in (3) shows that the Paasche price index $P_{P}$ can be written as a period 1 (or current period) expenditure share weighted harmonic average of the $\mathrm{N}$ price ratios. ${ }^{11}$

The problem with the Paasche and Laspeyres indexes is that they are equally plausible but in general, they will give different answers. This suggests that if a single estimate for the price change between the two periods is required, then an evenly weighted average of the two indexes should be chosen as the final estimate of price change between periods 0 and 1. Fisher (1922) suggested taking the geometric mean of the two indexes which leads to the Fisher ideal index, $\mathrm{P}_{\mathrm{F}}$, defined as

(4) $\mathrm{P}_{\mathrm{F}}\left(\mathrm{p}^{0}, \mathrm{p}^{1}, \mathrm{q}^{0}, \mathrm{q}^{1}\right) \equiv\left[\mathrm{P}_{\mathrm{L}}\left(\mathrm{p}^{0}, \mathrm{p}^{1}, \mathrm{q}^{0}, \mathrm{q}^{1}\right) \mathrm{P}_{\mathrm{P}}\left(\mathrm{p}^{0}, \mathrm{p}^{1}, \mathrm{q}^{0}, \mathrm{q}^{1}\right)\right]^{1 / 2} \cdot{ }^{12}$

\footnotetext{
10 This result is due to Walsh (1901; 428 and 539).

11 This expenditure share and price ratio representation of the Paasche index is described by Walsh (1901; 428) and derived explicitly by Fisher (1911; 365).

${ }^{12}$ For additional justifications for the Fisher price index, see the ILO (2004; Chapters 15-17).
} 
Another approach to index number theory is the stochastic approach. ${ }^{13}$ One of the most useful stochastic approaches is due to Theil (1967; 136-137). He argued as follows. Suppose price relatives (or ratios) are drawn at random in such a way that each dollar of expenditure in the base period has an equal chance of being selected. Then the probability that we will draw the nth price relative is equal to $\mathrm{s}_{\mathrm{n}}{ }^{0} \equiv \mathrm{p}_{\mathrm{n}}{ }^{0} \mathrm{q}_{\mathrm{n}}{ }^{0} / \mathrm{p}^{0} \cdot \mathrm{q}^{0}$, the period 0 expenditure share for commodity $\mathrm{n}$. Then the overall mean (period 0 weighted) logarithmic price change is $\sum_{n=1}{ }^{N} \mathrm{~s}_{n}{ }^{0} \ln \left(\mathrm{p}_{\mathrm{n}} / \mathrm{p}_{\mathrm{n}}{ }^{0}\right)$. Now repeat the above mental experiment and draw price relatives at random in such a way that each dollar of expenditure in period 1 has an equal probability of being selected. This leads to the overall mean (period 1 weighted) logarithmic price change of $\sum_{n=1}{ }^{N} s_{n}{ }^{1} \ln \left(p_{n}{ }^{1} / p_{n}{ }^{0}\right)$. Each of these measures of overall logarithmic price change seems equally valid so it is appropriate to take a symmetric average of the two measures in order to obtain a final single measure of overall logarithmic price change. Theil $(1967 ; 137)$ argued that a nice symmetric index number formula can be obtained if we make the probability of selection for the nth price relative equal to the arithmetic average of the period 0 and 1 expenditure shares for commodity n. Using these probabilities of selection, Theil's final measure of overall logarithmic price change was

(5) $\ln \mathrm{P}_{\mathrm{T}}\left(\mathrm{p}^{0}, \mathrm{p}^{1}, \mathrm{q}^{0}, \mathrm{q}^{1}\right) \equiv \sum_{\mathrm{n}=1}{ }^{\mathrm{N}}(1 / 2)\left(\mathrm{s}_{\mathrm{n}}{ }^{0}+\mathrm{s}_{\mathrm{n}}{ }^{1}\right) \ln \left(\mathrm{p}_{\mathrm{n}}{ }^{1} / \mathrm{p}_{\mathrm{n}}{ }^{0}\right)$.

Theil's price index $\mathrm{P}_{\mathrm{T}}\left(\mathrm{p}^{0}, \mathrm{p}^{1}, \mathrm{q}^{0}, \mathrm{q}^{1}\right)$ is obtained by exponentiating both sides of (5). ${ }^{14}$ This index number formula was also advocated by the economist Törnqvist.

A problem with the Lowe, Laspeyres and Paasche indexes is that they are subject to substitution bias. Typically, when the price of a commodity decreases, consumers purchase more of it and conversely when a price increases, consumers purchase less of it. The economic approach to index number theory, initiated by Konüs (1924), is able to deal with this problem of substitution bias. Diewert (1976) introduced the concept of a superlative index number formula. A superlative index number formula has the property that it is exactly equal to a Konüs true cost of living index provided that the purchasing households have preferences that can be represented by certain functional forms, where these functional forms can approximate arbitrary preferences to the accuracy of a second order approximation. It turns out that both the Fisher and Törnqvist indexes are superlative. Thus these indexes were recommended in the Manual as target indexes ${ }^{15}$ and were preferred to the Laspeyres and Paasche indexes, which are not superlative and are subject to substitution bias.

\footnotetext{
${ }^{13}$ Additional material on stochastic approaches to index number theory and references to the literature can be found in Selvanathan and Rao (1994), Diewert (1995) (2004) (2005), ILO (2004; 299-308), Clements, Izan and Selvanathan (2006) and Balk (2008; 32-36).

${ }^{14}$ This index first appeared explicitly as formula 123 in Fisher $(1922 ; 473)$. $\mathrm{P}_{\mathrm{T}}$ is generally attributed to Törnqvist (1936) but this article did not have an explicit definition for $\mathrm{P}_{\mathrm{T}}$; it was defined explicitly in Törnqvist and Törnqvist (1937); see Balk (2008; 26).

${ }^{15}$ In the Manual, these indexes were regarded as good ones not only from the viewpoint of the economic approach to index number theory but also from the viewpoint of test approach (for the Fisher index) and from the viewpoint of the stochastic approach (for the Törnqvist index).
} 
In order to explain the chain drift problem, it is first necessary to explain how chained indexes differ from fixed base indexes.

Suppose that we have decided on a "best" price index formula that compares the prices of period 0 with those of period 1 , say $\mathrm{P}\left(\mathrm{p}^{0}, \mathrm{p}^{1}, \mathrm{q}^{0}, \mathrm{q}^{1}\right)$. Suppose further that we have price and quantity data for 3 periods. The sequence of the price levels for the three periods under consideration, $\mathrm{P}^{0}, \mathrm{P}^{1}$ and $\mathrm{P}^{2}$, using fixed base (or direct) indexes can be constructed as follows:

(6) $\mathrm{P}^{0} \equiv 1 ; \mathrm{P}^{1} \equiv \mathrm{P}\left(\mathrm{p}^{0}, \mathrm{p}^{1}, \mathrm{q}^{0}, \mathrm{q}^{1}\right) ; \mathrm{P}^{2} \equiv \mathrm{P}\left(\mathrm{p}^{0}, \mathrm{p}^{2}, \mathrm{q}^{0}, \mathrm{q}^{2}\right)$.

Thus the prices in period $2, \mathrm{p}^{2}$, are compared directly with the prices in period $0, \mathrm{p}^{0}$.

The sequence of the three price levels, $\mathrm{P}^{0}, \mathrm{P}^{1}$ and $\mathrm{P}^{2}$, using chained indexes can be constructed as follows:

(7) $\mathrm{P}^{0} \equiv 1 ; \mathrm{P}^{1} \equiv \mathrm{P}\left(\mathrm{p}^{0}, \mathrm{p}^{1}, \mathrm{q}^{0}, \mathrm{q}^{1}\right) ; \mathrm{P}^{2} \equiv \mathrm{P}\left(\mathrm{p}^{0}, \mathrm{p}^{1}, \mathrm{q}^{0}, \mathrm{q}^{1}\right) \mathrm{P}\left(\mathrm{p}^{1}, \mathrm{p}^{2}, \mathrm{q}^{1}, \mathrm{q}^{2}\right)$.

Thus fixed base and chained price levels coincide for the first two periods but in subsequent periods t, the fixed base indexes compare the prices in period t directly to the prices in period 0 whereas the chained indexes simply update the price level in the previous period by multiplying by the period over period chain link index $\mathrm{P}\left(\mathrm{p}^{\mathrm{t}-1}, \mathrm{p}^{\mathrm{t}}, \mathrm{q}^{\mathrm{t}-1}, \mathrm{q}^{\mathrm{t}}\right)$.

The two methods of index construction will coincide if the bilateral price index formula $\mathrm{P}\left(\mathrm{p}^{0}, \mathrm{p}^{1}, \mathrm{q}^{0}, \mathrm{q}^{1}\right)$ satisfies the following test:

(8) Circularity Test: $\mathrm{P}\left(\mathrm{p}^{0}, \mathrm{p}^{1}, \mathrm{q}^{0}, \mathrm{q}^{1}\right) \mathrm{P}\left(\mathrm{p}^{1}, \mathrm{p}^{2}, \mathrm{q}^{1}, \mathrm{q}^{2}\right)=\mathrm{P}\left(\mathrm{p}^{0}, \mathrm{p}^{2}, \mathrm{q}^{0}, \mathrm{q}^{2}\right)$.

If there is only one commodity in the aggregate, then the price index $P\left(p^{0}, p^{1}, q^{0}, q^{1}\right)$ just becomes the single price ratio, $\mathrm{p}_{1}{ }^{1} / \mathrm{p}_{1}{ }^{0}$, and the circularity test becomes the equation $\left[\mathrm{p}_{1}{ }^{1} / \mathrm{p}_{1}{ }^{0}\right]\left[\mathrm{p}_{1}{ }^{2} / \mathrm{p}_{1}{ }^{1}\right]=\left[\mathrm{p}_{1}{ }^{2} / \mathrm{p}_{1}{ }^{0}\right]$, which is obviously satisfied. The equation in the circularity test illustrates the difference between chained index numbers and fixed base index numbers. The left hand side of (8) uses the chain principle to construct the overall inflation between periods 0 and 2 whereas the right hand side uses the fixed base principle to construct an estimate of the overall price change between periods 0 and $2 .^{16}$

It would be ideal if our preferred index number formulae, the Fisher and Törnqvist indexes $\left(\mathrm{P}_{\mathrm{F}}\right.$ and $\left.\mathrm{P}_{\mathrm{T}}\right)$, satisfied the circularity test but unfortunately, they do not satisfy (8). ${ }^{17}$ Hence, a statistical agency compiling a CPI has to choose between the two methods

\footnotetext{
${ }^{16}$ Fisher $(1911$; 203) introduced this fixed base and chain terminology. The concept of chaining is due to Lehr (1885) and Marshall (1887; 373).

${ }^{17}$ Alterman, Diewert and Feenstra $(1999 ; 61-65)$ showed that if the logarithmic price ratios $\ln \left(p_{n}{ }^{t} / p_{n}{ }^{t-1}\right)$ trend linearly with time $t$ and the expenditure shares $s_{i}{ }^{t}$ also trend linearly with time, then the Törnqvist index $\mathrm{P}_{\mathrm{T}}$ will satisfy the circularity test exactly. They extended this exactness result to cover the case when there are monthly proportional variations in prices and the expenditure shares have constant seasonal effects in addition to linear trends. However, when sales of products at irregular intervals occur, $\mathrm{P}_{\mathrm{T}}$ will no longer satisfy the circularity test.
} 
of index construction. The following quotation from the Manual explains why chaining was preferred:

"The question now arises: should the comparison month and the base month be adjacent months (thus leading to chained indices) or should the base month be fixed (leading to fixed base indices)? It seems reasonable to prefer chained indices over fixed base indices for two reasons:

- The set of seasonal commodities which overlaps during two consecutive months is likely to be much larger than the set obtained by comparing the prices of any given month with a fixed base month (like January of a base year). Hence the comparisons made using chained indices will be more comprehensive and accurate than those made using a fixed base.

- In many economies, on average 2 or 3 percent of price quotes disappear each month due to the introduction of new commodities and the disappearance of older ones. This rapid sample attrition means that fixed base indices rapidly become unrepresentative and hence it seems preferable to use chained indices which can more closely follow marketplace developments." ILO (2004; 407).

Thus the Manual recommended chained Fisher or Törnqvist indexes as target index concepts. As will be seen, this advice does not always work out too well.

Another advantage of using chained indexes is that if prices and quantities are trending relatively smoothly, chaining will reduce the spread between the Paasche and Laspeyres indexes. ${ }^{18}$ These two indexes each provide an asymmetric perspective on the amount of price change that has occurred between the two periods under consideration and it could be expected that a single point estimate of the aggregate price change should lie between these two estimates. Thus the use of either a chained Paasche or Laspeyres index will usually lead to a smaller difference between the two and hence to estimates that are closer to the "truth". Since annual data generally has smooth trends, the use of chained indexes is generally appropriate at this level of aggregation; see Hill (1993; 136-137).

However, the story is different at subannual levels; i.e., if the index is to be produced at monthly or quarterly frequencies. Hill (1993; 388), drawing on the earlier research of Szulc (1983) (1987) and Hill (1988; 136-137), noted that it is not appropriate to use the chain system when prices oscillate or "bounce" to use Szulc's $(1983 ; 548)$ term. This phenomenon can occur in the context of regular seasonal fluctuations or in the context of sales. The extent of the price bouncing problem or the problem of chain drift can be measured if we make use of the following test due to Walsh $(1901 ; 389),(1921 ; 540){ }^{19}$

(9) Multiperiod Identity Test: $\mathrm{P}\left(\mathrm{p}^{0}, \mathrm{p}^{1}, \mathrm{q}^{0}, \mathrm{q}^{1}\right) \mathrm{P}\left(\mathrm{p}^{1}, \mathrm{p}^{2}, \mathrm{q}^{1}, \mathrm{q}^{2}\right) \mathrm{P}\left(\mathrm{p}^{2}, \mathrm{p}^{0}, \mathrm{q}^{2}, \mathrm{q}^{0}\right)=1$.

Thus price change is calculated over consecutive periods but an artificial final period is introduced where the prices and quantities revert back to the prices and quantities in the very first period. The test asks that the product of all of these price changes should equal

\footnotetext{
${ }^{18}$ See Diewert (1978; 895) and Hill (1988) (1993; 387-388). Chaining under these conditions will also reduce the spread between fixed base and chained indexes using $\mathrm{P}_{\mathrm{F}}$ or $\mathrm{P}_{\mathrm{T}}$ as the basic bilateral formula.

${ }^{19}$ This is Diewert's (1993; 40) term for the test. Walsh did not limit himself to just three periods as in (9); he considered an indefinite number of periods.
} 
unity. If prices have no definite trends but are simply bouncing up and down in a range, then the above test can be used to evaluate the amount of chain drift that occurs if chained indexes are used under these conditions. Chain drift occurs when an index does not return to unity when prices in the current period return to their levels in the base period; see the ILO (2004; 445). Fixed base indexes that satisfy Walsh's test will not be subject to chain drift.

The Manual did not take into account how severe the chain drift problem could be in practice. ${ }^{20}$ The problem is mostly caused by periodic sales of products. An example will illustrate the problem. Suppose that we are given the price and quantity data for 2 commodities for 4 periods. The data are listed in Table 1 below. ${ }^{21}$

Table 1: Price and Quantity Data for Two Products for Four Periods

\begin{tabular}{lccrc}
\hline Period t & $\mathbf{p}_{\mathbf{1}}{ }^{\mathbf{t}}$ & $\mathbf{p}_{2}{ }^{\mathbf{t}}$ & $\mathbf{q}_{1}{ }^{\mathbf{t}}$ & $\mathbf{q}_{2}{ }^{\mathbf{t}}$ \\
\hline 1 & 1.0 & 1.0 & 10 & 100 \\
2 & 0.5 & 1.0 & 5000 & 100 \\
3 & 1.0 & 1.0 & 1 & 100 \\
4 & 1.0 & 1.0 & 10 & 100 \\
\hline
\end{tabular}

The first commodity is subject to periodic sales (in period 2), when the price drops to half of its normal level of 1 . In period 1 , we have a "normal" off sale demand for commodity 1 which is equal to 10 units. In period 2, the sale takes place and demand explodes to 5000 units. ${ }^{22}$ In period 3, the commodity is off sale and the price is back to 1 but most shoppers have stocked up in the previous period so demand falls to only 1 unit. ${ }^{23}$ Finally in period 4, the commodity is off sale but we are back to the "normal" demand of 10 units. Commodity 2 is dull: its price is 1 in all periods and the quantity sold is 100 units in each period. Note that the only thing that has happened going from period 3 to 4 is that the demand for commodity one has picked up from 1 unit to the "normal" level of 10 units. Also note that, conveniently, the period 4 data are exactly equal to the period 1 data so that for Walsh's test to be satisfied, the product of the period to period chain links must equal one.

Table 2 lists the fixed base Fisher, Laspeyres and Paasche price indexes, $\mathrm{P}_{\mathrm{F}(\mathrm{FB})}, \mathrm{P}_{\mathrm{L}(\mathrm{FB})}$ and $\mathrm{P}_{\mathrm{P}(\mathrm{FB})}$ and as expected, they behave perfectly in period 4, returning to the period 1 level of 1. Then the chained Fisher, Törnqvist, Laspeyres and Paasche price indexes, $\mathrm{P}_{\mathrm{F}(\mathrm{CH})}, \mathrm{P}_{\mathrm{T}(\mathrm{CH})}$,

\footnotetext{
${ }^{20}$ Szulc (1983) (1987) demonstrated how big the chain drift problem could be with chained Laspeyres indexes but the authors of the Manual did not realize that chain drift could also be a problem with chained superlative indexes.

${ }^{21}$ This example is taken from Diewert (2012). It is based on a similar example due to de Haan and van der Grient (2009; 39).

${ }^{22}$ This example is based on an actual example that used Dutch scanner data. When the price of a detergent product went on sale at approximately one half of the regular price, the volume sold shot up approximately one thousand fold; see de Haan (2008). This paper brought attention to the magnitude of volume fluctuations due to sales.

${ }^{23}$ Feenstra and Shapiro (2003) also looked at the chain drift problem that was caused by sales and restocking dynamics. Their suggested solution to the chain drift problem was to use fixed base indexes.
} 
$\mathrm{P}_{\mathrm{L}(\mathrm{FB})}$ and $\mathrm{P}_{\mathrm{P}(\mathrm{FB})}$ are listed. Obviously, the chained Laspeyres and Paasche indexes have chain drift bias that is extraordinary but what is interesting is that the chained Fisher has a $2 \%$ downward bias and the chained Törnqvist has a close to 3\% downward bias.

Table 2: Fixed Base and Chained Fisher, Törnqvist, Laspeyres and Paasche Indexes

\begin{tabular}{clllllll}
\hline Period & $\mathbf{P}_{\mathbf{F}(\mathrm{FB})}$ & $\mathbf{P}_{\mathbf{L}(\mathrm{FB})}$ & $\mathbf{P}_{\mathbf{P}(\mathrm{FB})}$ & $\mathbf{P}_{\mathbf{F}(\mathrm{CH})}$ & $\mathbf{P}_{\mathbf{T}(\mathrm{CH})}$ & $\mathbf{P}_{\mathbf{L}(\mathbf{C H})}$ & $\mathbf{P}_{\mathbf{P}(\mathbf{C H})}$ \\
\hline 1 & 1.000 & 1.000 & 1.000 & 1.000 & 1.000 & 1.000 & 1.000 \\
2 & 0.698 & 0.955 & 0.510 & 0.698 & 0.694 & 0.955 & 0.510 \\
3 & 1.000 & 1.000 & 1.000 & 0.979 & 0.972 & 1.872 & 0.512 \\
4 & 1.000 & 1.000 & 1.000 & 0.979 & 0.972 & 1.872 & 0.512 \\
\hline
\end{tabular}

If the above data were monthly, and they repeated themselves three times over the year, the overall chain drift bias would build up to the 6 to $8 \%$ range, which is significant.

The problem is this: when commodity one comes off sale and goes back to its regular price in period 3, the corresponding quantity does not return to the level it had in period 1: the period 3 demand is only 1 unit whereas the "normal" period 1 demand for commodity 1 was 10 units. It is only in period 4 that demand for commodity one recovers to the period 1 level. However, since prices are the same in periods 3 and 4, all of the chain links show no change (even though quantities are changing) and this is what causes the difficulties. If demand for commodity one in period 3 had immediately recovered to its "normal” period 1 level of 10, then there would be no chain drift problem. ${ }^{24}$

There are at least three possible solutions to the chain drift that is associated with the use of a superlative index in a situation where monthly scanner data is available to the statistical agency for components of the CPI: ${ }^{25}$

- Stick to the usual annual basket Lowe index that uses annual expenditure weights from a past year;

- Pick a base month and use fixed base superlative indexes relative to the chosen month;

- Use a Rolling Window multilateral index number approach adapted to the time series context.

\footnotetext{
${ }^{24}$ De Haan $(2015 a$; 14) noted the root cause of the chain drift problem: "The drift is mainly due to quantities spiking when storable goods are on sale.”

${ }^{25}$ There is a possible fourth method to avoid chain drift within a year when using a superlative index and that is to simply compute a sequence of 12 year over year monthly indexes so that say January prices in the previous year would be compared with January prices in the current year and so on. Handbury, Watanabe and Weinstein (2013) use this methodological approach for the construction of year over year monthly superlative Japanese consumer price indexes using the Nikkei point of sale data base. This data base has monthly price and expenditure data covering the years 1988 to 2010 and contains 4.82 billion price and quantity observations. This type of index number was recommended in the ILO (2004; chapter 22) as a valid year over year index that would avoid seasonality problems. However, central banks and other users require month to month CPIs in addition to year over year monthly CPIs and so the approach of Handbury, Watanabe and Weinstein does not solve the problems associated with the construction of superlative month to month indexes.
} 
The problem with the first method is that the Lowe index is subject to a small amount of upper level substitution bias, usually in the range of 0.15 to 0.40 percentage points per year. ${ }^{26}$ The widespread use of the Lowe index is due to its practical nature and the fact that the amount of substitution bias is generally not all that large. ${ }^{27}$ The problem with the second method is that picking a base month and calculating superlative indexes relative to this base is an asymmetric procedure and gives too much weight to the chosen base. Moreover, some commodities may not be available in the chosen base month and some commodities disappear in the later months of the comparison and thus not all of the monthly price and quantity information is used in a fixed base method. Thus in the remainder of this paper, we will concentrate on the use of multilateral indexes as potential solutions to the chain drift problem. ${ }^{28}$

\section{GEKS Multilateral Indexes}

The GEKS method for making international index number comparisons between countries is due to Gini $(1931 ; 12)$. It was derived in a different fashion by Eltetö and Köves (1964) and Szulc (1964) and thus the method is known as either the GEKS or EKS method for making multilateral comparisons. Of course, it can also be adapted to making comparisons between multiple time periods.

The GEKS method in the time series context works as follows. Suppose we have price and quantity information for a component of the CPI on a monthly basis for a sequence of 13 consecutive months. Now pick one month (say month $\mathrm{k}$ ) in this augmented year as the base month and construct Fisher price indexes for all 13 months relative to this base month. Denote the resulting sequence of Fisher indexes as $P_{F}(1 / k), P_{F}(2 / k), \ldots, P_{F}(13 / k){ }^{29}$ The final set of GEKS indexes for the 13 months is simply geometric mean of all 13 of the specific month indexes; i.e., the final set of GEKS indexes for the months in the augmented year is any normalization of the following sequence of indexes: ${ }^{30}$

(10) $\left[\prod_{\mathrm{k}=1}^{13} \mathrm{P}_{\mathrm{F}}(1 / \mathrm{k})\right]^{1 / 13},\left[\prod_{\mathrm{k}=1}{ }^{13} \mathrm{P}_{\mathrm{F}}(2 / \mathrm{k})\right]^{1 / 13}, \ldots,\left[\prod_{\mathrm{k}=1}{ }^{13} \mathrm{P}_{\mathrm{F}}(13 / \mathrm{k})\right]^{1 / 13}$.

The above GEKS indexes have a number of important properties: ${ }^{31}$

\footnotetext{
${ }^{26}$ For recent retrospective studies on upper level substitution bias for national CPIs, see Armknecht and Silver (2013), Diewert, Huwiler and Kohli (2009) and Huang, Wimalaratne and Pollard (2017). For studies of lower level substitution bias for a Lowe index, see Diewert, Finkel and Artsev (2009) and Diewert (2013a).

${ }^{27}$ Recent Canadian research has indicated that the substitution bias can be reduced substantially by more frequent updating of the annual basket; see Huang, Wimalaratne and Pollard (2017).

${ }^{28}$ For a recent paper that takes a systematic look at the use of multilateral methods to aggregate scanner data, see the Australian Bureau of Statistics (2016).

${ }^{29}$ Using scanner data, it is not trivial to construct these Fisher indexes. The problem is that for each pair of months, it is necessary to determine the list of products that sold in both months so that the relevant Fisher index between those two months can be constructed.

${ }^{30}$ Balk (1981; 74) derived the GEKS parities using this type of argument rather than the usual least squares derivation of the GEKS parities; see Balk (1996) and Diewert (1999) for these alternative derivations.

${ }^{31}$ The basic idea of adapting a multilateral method to the time series context is due to Balk (1981) who set up a framework that is very similar to the one explained here (which follows Ivancic, Diewert and Fox
} 
- They satisfy Walsh's multiperiod identity test so that if any two months in the augmented year have exactly the same price and quantity vectors, then the above index values will coincide for those two months; i.e., the above indexes are free from chain drift.

- The above indexes do not asymmetrically single out any single month to play the role of a base period; all possible base months contribute to the overall index values. $^{32}$

- The above indexes make use of all possible bilateral matches of the price data between any two months in the augmented year. That is, we are using what Ivancic, Diewert and Fox $(2011 ; 26)$ called a "flexible basket" approach that incorporates new items as they become available.

- Strongly seasonal commodities make a contribution to the overall index values.

The last property explains why the augmented year should include at least 13 consecutive months, so that strongly seasonal commodities ${ }^{33}$ can make a contribution to the overall index.

The major problem with the GEKS indexes defined by (28) is that the indexes change as the data for a new month becomes available. A headline CPI cannot be revised from month to month due to the fact that many contracts are indexed to a country's headline consumer price index. A solution to this problem was proposed by Ivancic, Diewert and Fox (2011). Their method added the price and quantity data for the most recent month to the augmented year and dropped the oldest month from the old augmented year in order to obtain a new augmented year. The GEKS indexes for the new augmented year are calculated in the usual way and the ratio of the index value for the last month in the new augmented year to the index value for the previous month in the new augmented year is used as an update factor for the value of the index for the last month in the previous augmented year. The resulting indexes are called Rolling Window GEKS indexes, or for a thirteen month window, Rolling Year GEKS indexes.

Numerical experiments with Australian and Dutch scanner data from grocery chains showed that the Rolling Year GEKS indexes seem to work reasonably well; see Ivancic, Diewert and Fox (2011), de Haan and van der Grient (2011), Johansen and Nygaard (2011), van der Grient and de Haan (2011) and Krsinich (2011). In particular, adding and dropping a month of data and recomputing the GEKS indexes does not seem to change

(2011) more closely). Balk (1981) used an index number formula due to Vartia (1976) in place of maximum overlap bilateral Fisher indexes as his basic building blocks and he considered augmented years of varying length instead of a 13 month augmented year but the basic idea of adapting multilateral methods to the time series context is certainly due to him.

${ }^{32}$ Thus the above GEKS procedure seems to be an improvement over the suggestion of Feenstra and Shapiro (2003) who chose only a single base month.

${ }^{33} \mathrm{~A}$ strongly seasonal commodity is one that is not present in the marketplace for all months of the year. 
past index values very much. ${ }^{34}$ Basically, the method seems to control chain drift quite well. $^{35}$

There are two additional issues with using Rolling Window GEKS in the scanner data context:

- How long should the window length be? As indicated above, the window length should be at least 13 months (or 5 quarters if a quarterly CPI is compiled) in order to allow for the influence of strongly seasonal commodities but what are the advantages and drawbacks of increasing this "standard" window length?

- When a new window is computed, how should the index results from the new window be linked to the previous index values? Ivancic, Diewert and Fox (2011) (IDF) suggested that the movement of the indexes for the last two periods in the new window be linked to the last index value generated by the previous window. However Krsinich (2016) in a slightly different context suggested that the movement of the indexes generated by the new window over the entire new window period be linked to the previous window index value for the second period in the previous window. Krsinich called this a window splice as opposed to the IDF movement splice. De Haan (2015a; 27) suggested that perhaps the linking period should be in the middle of the old window which the Australian Bureau of Statistics $(2016 ; 12)$ terms a half splice.

We will return to these questions after we have studied our second multilateral method in the following section.

\section{CCDI Multilateral Indexes}

It is convenient to introduce some alternative notation at this point. We assume that the vector of positive ${ }^{36}$ period $\mathrm{t}$ (unit value) prices is $\mathrm{p}^{\mathrm{t}} \equiv\left[\mathrm{p}_{\mathrm{t} 1}, \ldots, \mathrm{p}_{\mathrm{tN}}\right]$ and the corresponding

${ }^{34}$ Balk (1981; 77) also observed the same phenomenon as he computed his GEKS indexes using successively larger data sets. Diewert (2013) also found that Rolling Year GEKS estimates were quite close to their GEKS counterparts for his small data set on Israeli seasonal commodities.

${ }^{35}$ Ivancic, Diewert and Fox (2011; 33, footnote 19): "While a RWGEKS index, such as the RYGEKS, will not satisfy transitivity in practice and hence will be potentially subject to chain drift, comparisons within each window are transitive. Using this approach, chain drift is therefore unlikely to be a significant problem in any context likely to be faced by a statistical agency. Also, alternative approaches to linking the indexes could be investigated, such as using different overlapping periods for doing the linking, taking the geometric mean of overlapping comparisons in multiple windows, and so forth. The most obvious approach is pursued in this paper and works well in our empirical applications. An investigation into alternative approaches is left for future research.” We return to this issue explicitly in section 11. The Australian Bureau of Statistics (2016) plans to use RYGEKS or some other multilateral method for some components of its Consumer Price Index. Statistics Netherlands also computed RYGEKS indexes for some components of its CPI on an experimental basis with good results but they did not implement the method officially; see de Haan and van der Grient (2011) and de Haan (2015a) (2015b). Statistics New Zealand have implemented a version of RYGEKS, with adjustments for quality change, for consumer electronics scanner data; see Krsinich (2015).

${ }^{36}$ The restriction that all prices in each period are positive is a restrictive assumption. Implicitly, we assume that if say commodity $\mathrm{n}$ is not available in period $\mathrm{t}$ so that $\mathrm{q}_{\mathrm{tn}}=0$, then there is a positive reservation price $\mathrm{p}_{\mathrm{nt}}>0$ that will induce potential purchasers to demand a zero amount of the commodity. 
nonnegative period $t$ quantity vector is $\mathrm{q}^{\mathrm{t}} \equiv\left[\mathrm{q}_{\mathrm{t} 1}, \ldots, \mathrm{q}_{\mathrm{tN}}\right]$ with the inner product, $\mathrm{p}^{\mathrm{t}} \cdot \mathrm{q}^{\mathrm{t}} \equiv \Sigma_{\mathrm{n}=1}{ }^{\mathrm{N}}$ $\mathrm{p}_{\mathrm{tn}} \mathrm{q}_{\mathrm{tn}}>0$ for $\mathrm{t}=1, \ldots, \mathrm{T}$. Define the expenditure share for commodity $\mathrm{n}$ in period $\mathrm{t}$ as $\mathrm{s}_{\mathrm{tn}} \equiv$ $\mathrm{p}_{\mathrm{tn}} \mathrm{q}_{\mathrm{tn}} / \mathrm{p}^{\mathrm{t}} \cdot \mathrm{q}^{\mathrm{t}}$ for $\mathrm{n}=1, \ldots, \mathrm{N}$ and $\mathrm{t}=1, \ldots, \mathrm{T}$. We now denote the Törnqvist price index for period t relative to period $\tau$ as $\mathrm{P}_{\mathrm{T}}(\mathrm{t} / \tau)$. Using our new notation, the logarithm of $\mathrm{P}_{\mathrm{T}}(\mathrm{t} / \tau)$ is defined as follows:

(11) $\ln \mathrm{P}_{\mathrm{T}}(\mathrm{t} / \tau) \equiv \sum_{\mathrm{n}=1}{ }^{\mathrm{N}}(1 / 2)\left(\mathrm{s}_{\mathrm{tn}}+\mathrm{s}_{\tau \mathrm{n}}\right)\left(\ln \mathrm{p}_{\mathrm{tn}}-\ln \mathrm{p}_{\tau \mathrm{n}}\right)$;

$\mathrm{t}, \tau=1, \ldots, \mathrm{T}$.

The above bilateral index can be used to form a system of "star" indexes where we choose each country in term as the base, calculate a sequence of indexes for each base and then take the geometric mean of the resulting star sequences. Thus a preliminary price level for period $t$ using this methodology is $\pi_{\mathrm{t}}$ defined as follows:

(12) $\pi_{\mathrm{t}} \equiv\left[\prod_{\tau=1}^{\mathrm{T}} \mathrm{P}_{\mathrm{T}}(\mathrm{t} / \tau)\right]^{1 / \mathrm{T}}$;

$\mathrm{t}=1, \ldots, \mathrm{T}$.

The normalized sequence of price levels is defined as the sequence $\pi_{t} / \pi_{1}$ for $t=1, \ldots, T$. Obviously, this methodology is entirely similar to Gini's methodology which led to the sequence of GEKS (unnormalized) price levels defined by (10) in the previous section: the only difference is that the Törnqvist bilateral price index formula, $\mathrm{P}_{\mathrm{T}}(\mathrm{t} / \tau)$, is used as the basic building block rather than the Fisher formula, $\mathrm{P}_{\mathrm{F}}(\mathrm{t} / \tau){ }^{37}$

Substituting definitions (11) into (12) shows that the logarithm of $\pi_{\mathrm{t}}$ is equal to the following expression:

(13) $\ln \pi_{\mathrm{t}}=(1 / \mathrm{T}) \sum_{\tau=1}^{\mathrm{T}} \sum_{\mathrm{n}=1}^{\mathrm{N}}(1 / 2)\left(\mathrm{s}_{\mathrm{tn}}+\mathrm{s}_{\tau \mathrm{n}}\right)\left(\operatorname{lnp} \mathrm{ptn}_{\mathrm{tn}}-\ln \mathrm{p}_{\tau \mathrm{n}}\right)$;

$\mathrm{t}=1, \ldots, \mathrm{T}$.

The expressions (13) that define the (unnormalized) price levels $\pi_{t}$ can be simplified. Define the sample average expenditure share for commodity $n$, $s_{\bullet n}$, and the sample average of the logarithms of the prices for commodity n, lnp•n, as follows:

(14) $\mathrm{S}_{\bullet n} \equiv(1 / \mathrm{T}) \Sigma_{\mathrm{t}=1}^{\mathrm{T}} \mathrm{S}_{\mathrm{tn}} ; \operatorname{lnp} \bullet \equiv(1 / \mathrm{T}) \Sigma_{\mathrm{t}=1}^{\mathrm{T}} \ln \mathrm{p}_{\mathrm{tn}}$;

$\mathrm{n}=1, \ldots, \mathrm{N}$.

Definitions (14) can be used in order to define a new system of (unnormalized) price levels $\rho_{t}$ for the T periods; i.e., define the logarithm of $\rho_{t}$ as follows:

(15) $\ln \rho_{\mathrm{t}} \equiv \sum_{\mathrm{n}=1} \mathrm{~N}(1 / 2)\left(\mathrm{s}_{\mathrm{tn}}+\mathrm{s}_{\bullet \mathrm{n}}\right)\left(\ln \mathrm{p}_{\mathrm{tn}}-\ln \mathrm{p}_{\bullet \mathrm{n}}\right)$;

$\mathrm{t}=1, \ldots, \mathrm{T}$.

This methodological approach to new and disappearing goods follows Hicks (1940; 114). The practical problem facing price statisticians is: how exactly are these reservation prices to be determined?

${ }^{37}$ De Haan and van der Grient (2011; 41) call the indexes (12) that use (11) as the bilateral building block GEKS-Törnqvist indexes. Feenstra, Ma and Rao (2009; 171-172) also noted that Törnqvist bilateral price indexes could be used in place of Fisher price indexes in the Gini methodology. Fox and Syed (2016; 401) call the indexes defined by (12) CCD indexes. Caves, Christensen and Diewert (1982) used the GEKS methodology in the quantity context; i.e., they used bilateral Törnqvist quantity indexes as their basic building block rather than bilateral Törnqvist price indexes. 
The sequence of normalized or final price levels for the $T$ observations in the sample is $\rho_{t} / \rho_{1}$ for $t=1, \ldots, T$. Note the similarity in structure of (11) and (15): the regular Törnqvist index $\mathrm{P}_{\mathrm{T}}(\mathrm{t} / \tau)$ compares the level of prices in period $t$ with the corresponding level in period $\tau$ whereas $\rho_{\mathrm{t}}$ can be thought of comparing the level of prices in period $t$ with the corresponding level of prices in an "average" observation which has expenditure shares equal to the sample average expenditure shares $s_{\bullet n}$ and sample average prices $p_{\bullet n}=\left[\Pi_{n=1}{ }^{T}\right.$ $\left.\mathrm{p}_{\mathrm{tn}}\right]^{1 / \mathrm{T}}$.

The price levels $\pi_{\mathrm{t}}$ defined by (13) are closely related to the price levels $\rho_{\mathrm{t}}$ defined by (15); i.e., substituting definitions (14) into (15) and using definitions (13) leads to the following relationship between the logarithms of $\pi_{\mathrm{t}}$ and $\rho_{\mathrm{t}}$ :

(16) $\ln \pi_{\mathrm{t}}=\ln \rho_{\mathrm{t}}+\alpha$; $\mathrm{t}=1, \ldots, \mathrm{T}$

where the constant $\alpha$ is defined as follows:

(17) $\alpha \equiv \Sigma_{\mathrm{n}=1}{ }^{\mathrm{N}}(1 / 2) \mathrm{s} \cdot \mathrm{m} \operatorname{lnp} \bullet \mathrm{m}-(1 / 2 \mathrm{~T}) \Sigma_{\mathrm{t}=1}^{\mathrm{T}} \Sigma_{\mathrm{n}=1}{ }^{\mathrm{N}} \mathrm{s}_{\mathrm{tn}} \ln \mathrm{p}_{\mathrm{tn}}$.

Equations (16) mean that the normalized price levels using the $\pi_{\mathrm{t}}$ and $\rho_{\mathrm{t}}$ coincide; i.e., we have:

(18) $\pi_{\mathrm{t}} / \pi_{1}=\rho_{\mathrm{t}} / \rho_{1}$

$\mathrm{t}=1, \ldots, \mathrm{T}$.

Comparing (13) to (15), it can be seen that making multilateral comparisons of prices across the T periods using the price levels $\rho_{\mathrm{t}}$ defined by (15) is analytically simpler than using the price levels $\pi_{\mathrm{t}}$ defined by (13). Caves, Christensen and Diewert (1982; 78) introduced the artificial country comparison idea into multilateral index number theory except that they introduced the idea in the context of making quantity comparisons across production units using distance functions. Inklaar and Diewert (2016; 429) extended the CCD methodology to making price comparisons across production units and derived equations (16). Thus we will call the multilateral price comparison method that uses the price levels $\rho_{\mathrm{t}}$ defined by (15) the CCDI method.

Using definitions (15) to define the (unnormalized) price levels $\rho_{t}$, it can be seen that the CCDI normalized price level in period t relative to period $\mathrm{r},\left(\rho_{\mathrm{t}} / \rho_{1}\right) /\left(\rho_{\mathrm{r}} / \rho_{1}\right)$, is independent of the choice of the normalizing period; i.e., $\left(\rho_{\mathrm{t}} / \rho_{1}\right) /\left(\rho_{\mathrm{r}} / \rho_{1}\right)=\left(\rho_{\mathrm{t}} / \rho_{\mathrm{s}}\right) /\left(\rho_{\mathrm{r}} / \rho_{\mathrm{s}}\right)$ for any period s. ${ }^{38}$ As was pointed out by de Haan and van der Grient $(2011 ; 40)$, this is a major advantage of a multilateral method. CCD referred to the earlier work of Fisher (1922) and noted that there is a tradeoff between transitivity (or circularity) and characteristicity:

\footnotetext{
${ }^{38}$ The price levels $\rho_{\mathrm{t}}$ defined by (15) also satisfy the following version of Walsh's multiperiod identity test (9): for periods $r, s$ and $t$, we have $\left(\rho_{\mathrm{r}} / \rho_{\mathrm{s}}\right)\left(\rho_{\mathrm{t}} / \rho_{\mathrm{r}}\right)\left(\rho_{\mathrm{s}} / \rho_{\mathrm{t}}\right)=1$. The price levels $\rho_{\mathrm{t}}$ also satisfy the time reversal test and the circularity test. A less obvious test that the price level $\rho_{\mathrm{t}}$ also satisfies is the following price proportionality test: $\rho_{\mathrm{t}}\left(\lambda \mathrm{p}^{t}\right)=\lambda \rho_{\mathrm{t}}\left(\mathrm{p}^{\mathrm{t}}\right)$ for arbitrary scalar $\lambda>0$ where $\rho_{\mathrm{t}}\left(\mathrm{p}^{\mathrm{t}}\right)$ is the function $\rho_{\mathrm{t}}\left(\mathrm{p}^{1}, \ldots, \mathrm{p}^{\mathrm{T}}, \mathrm{q}^{1}, \ldots, \mathrm{q}^{\mathrm{T}}\right)$ defined by (15) regarded as a function of the period $\mathrm{t}$ price vector, $\mathrm{p}^{\mathrm{t}}$. Note that the period $t$ share vector $\mathrm{s}^{\mathrm{t}}$ and the sample average share vector $\mathrm{s}_{\bullet} \equiv\left[\mathrm{s}_{\bullet}, \ldots, \mathrm{s}_{\bullet}\right]$ also depends on $\mathrm{p}^{\mathrm{t}}$.
} 
"In essence Fisher's discomfort with the circularity test was due to the fact that it conflicted with using value shares weights that are specific to the two entities being compared. Dreschler (I973) has used the term 'characteristicity' to indicate the degree to which weights are specific to the comparison at hand. The Fisher Ideal index utilises weights that are perfectly characteristic. Dreschler $(1973 ; 17)$ succinctly summarised Fisher's dilemma: '...characteristicity and circularity are always ... in conflict with each other.' The implication is that some degree of characteristicity must be sacrificed to obtain circularity.” Douglas Caves, Laurits Christensen and W. Erwin Diewert (1982; 74).

The logarithm of the direct bilateral comparison of price level of period t relative to period $\tau$ using the Törnqvist formula (11) is

(19) $\ln \mathrm{P}_{\mathrm{T}}(\mathrm{t} / \tau)=\sum_{\mathrm{n}=1} \mathrm{~N}(1 / 2)\left(\mathrm{s}_{\mathrm{tn}}+\mathrm{s}_{\tau \mathrm{n}}\right)\left(\ln \mathrm{P}_{\mathrm{tn}}-\ln \mathrm{P}_{\tau \mathrm{n}}\right)$

This bilateral direct index depends only on the prices and expenditure shares pertaining to periods $\tau$ and $t$. The corresponding multilateral comparison of the price level in period $t$ to period $\tau$ is: ${ }^{39}$

$$
\text { (20) } \begin{aligned}
\ln \left(\rho_{t} / \rho_{\tau}\right) & =\sum_{n=1}{ }^{N}(1 / 2)\left(s_{t n}+s_{\bullet n}\right)\left(\operatorname{lnp}_{t n}-\operatorname{lnp} \bullet_{n}\right)-\sum_{n=1}{ }^{N}(1 / 2)\left(s_{t n}+s_{\bullet n}\right)\left(\operatorname{lnp} p_{\tau n}-\operatorname{lnp} \bullet_{\bullet}\right) \\
& =\sum_{n=1} N(1 / 2)\left(s_{t n}+s_{\bullet n}\right)\left(\operatorname{lnp} p_{t n}-\ln p_{\bullet n}\right)+\sum_{n=1}^{N}(1 / 2)\left(s_{\tau n}+s_{\bullet n}\right)\left(\operatorname{lnp} \bullet_{\bullet n}-\ln p_{\tau n}\right) .
\end{aligned}
$$

Using (19), the prices of period $t$ are compared directly to the prices in the base period $\tau$ whereas in (20), the prices in period $t$ are compared to the prices in the artificial "average" period and then the prices in the "average" period are compared to the prices in the base period $\tau$. Thus if there are smooth trends in prices and expenditure shares, chaining the bilateral indexes defined by (19) would probably be preferable (since chaining tends to reduce the spread between superlative indexes with smooth trends in the underlying price and quantity data) ${ }^{40}$ whereas using the multilateral indexes defined by (20) essentially compares the prices in any two periods through the fixed base observation that has the sample average log prices and sample average expenditure shares. Of course, with monthly or weekly data, trends in prices and quantities are often far from smooth and under these nonsmooth conditions, the chain drift problem can become severe (as we shall see later) and the use of multilateral indexes is recommended.

The difference between the direct index (19) and the corresponding multilateral index (20) simplifies to the following expression: ${ }^{41}$

(21) $\ln \mathrm{P}_{\mathrm{T}}(\mathrm{t} / \tau)-\ln \left(\rho_{\mathrm{t}} / \rho_{\tau}\right)$

\footnotetext{
${ }^{39}$ Formula (20) can be used to establish the following bilateral identity test: if $\mathrm{p}^{\mathrm{t}}=\mathrm{p}^{\tau}$ and $\mathrm{q}^{\mathrm{t}}=\mathrm{q}^{\tau}$ (which implies $\left.\mathrm{s}^{\mathrm{t}}=\mathrm{s}^{\tau}\right)$, then $\rho_{\mathrm{t}}=\rho_{\tau}$.

${ }^{40}$ See Diewert (1978) on this point.

${ }^{41}$ Formula (21) shows that if $\mathrm{p}^{\mathrm{t}}=\mathrm{p}^{\tau}$ and $\mathrm{q}^{\mathrm{t}}=\mathrm{q}^{\tau}$ (which implies $\mathrm{s}^{\mathrm{t}}=\mathrm{s}^{\tau}$ ), then $\mathrm{P}_{\mathrm{T}}(\mathrm{t} / \tau)=\rho_{\mathrm{t}} / \rho_{\tau}=1$. Formula (21) also shows that if expenditure shares are constant over time so that $\mathrm{s}_{\mathrm{tn}}=\mathrm{s}_{\mathrm{t}}$ for all $\mathrm{t}$ and $\mathrm{n}$, then $\mathrm{P}_{\mathrm{T}}(\mathrm{t} / \tau)=$ $\rho_{\mathrm{t}} / \rho_{\tau}$.
} 


$$
=\sum_{n=1}{ }^{N}(1 / 2)\left(s_{\tau n}-s_{\bullet n}\right)\left(\operatorname{lnp}_{t n}-\operatorname{lnp} \bullet_{n}\right)-\sum_{n=1}{ }^{N}(1 / 2)\left(s_{t n}-s_{\bullet n}\right)\left(\ln p_{\tau n}-\operatorname{lnp} \bullet n\right) .
$$

The above formula can be used to show that if $\mathrm{T}=2$, then $\ln \mathrm{P}_{\mathrm{T}}(2 / 1)=\ln \left(\rho_{2} / \rho_{1}\right)$ so that the direct Törnqvist bilateral index $\mathrm{P}_{\mathrm{T}}(2 / 1)$ equals the multilateral CCDI index $\rho_{2} / \rho_{1}$ if there are only two periods in the multilateral comparison.

\section{Rolling Window Multilateral Methods and the Linking Problem}

Suppose that the CCDI multilateral method explained in the previous section is used to construct a sequence of price levels, $\pi_{1}, \pi_{2}, \ldots, \pi_{\mathrm{T}}$ for $\mathrm{T}$ consecutive periods where $\mathrm{T} \geq 3$. The period t price level is defined as

(22) $\pi_{\mathrm{t}} \equiv \rho_{\mathrm{t}} / \rho_{1}$;

$$
\mathrm{t}=1, \ldots, \mathrm{T}
$$

where the logarithm of $\rho_{\mathrm{t}}$ is defined by (15) and where $\mathrm{s}_{\bullet \mathrm{n}} \equiv(1 / \mathrm{T}) \Sigma_{\mathrm{t}=1}{ }^{\mathrm{T}} \mathrm{s}_{\mathrm{tn}}$ and lnp •n $\equiv$ $(1 / T) \Sigma_{t=1}{ }^{T} \operatorname{lnp}_{\mathrm{tn}}$ for $\mathrm{n}=1, \ldots, N$. Data on period $\mathrm{T}+1$ expenditure shares $\mathrm{s}_{\mathrm{T}+1, \mathrm{n}}$ and prices $\mathrm{p}_{\mathrm{T}+1, \mathrm{n}}$ become available at the end of period $\mathrm{T}+1$ for $\mathrm{n}=1, \ldots, \mathrm{N}$. A new set of multilateral indexes can now be constructed for the window of observations that include the data for periods $2,3, \ldots, T, T+1$. Define the average expenditure share for commodity $n, s_{\bullet} *$ and the average log price $\mathrm{p}_{\bullet *} *$ for commodity $\mathrm{n}$ as follows:

(23) $\mathrm{S}_{\bullet *} \equiv(1 / \mathrm{T}) \Sigma_{\mathrm{t}=2}^{\mathrm{T}+1} \mathrm{~S}_{\mathrm{tn}} ; \ln \bullet_{n^{*}} \equiv(1 / \mathrm{T}){\Sigma_{\mathrm{t}=2}}^{\mathrm{T}+1} \ln \mathrm{p}_{\mathrm{tn}}$;

$\mathrm{n}=1, \ldots, \mathrm{N}$.

Definitions (23) can be used in order to define a new system of (unnormalized) CCDI price levels $\rho_{t^{*}}$ for the T periods in the new window; i.e., define the logarithm of $\rho_{t^{*}}$ as follows:

$$
\ln \rho_{t^{*}} \equiv \sum_{n=1}{ }^{N}(1 / 2)\left(s_{t n}+s_{\bullet} *\right)\left(\operatorname{lnp} p_{t n}-\ln p_{\bullet} *\right)
$$$$
\mathrm{t}=2, \ldots, \mathrm{T}, \mathrm{T}+1
$$

The new price levels need to be linked to the price levels generated by the original window of observations; i.e., we need to define a new price level for period $\mathrm{T}+1$ that extends the initial $\mathrm{T}$ price levels $\pi_{\mathrm{t}}$ defined by (22) for $t=1, \ldots, T$. Suppose we link the new window price levels to the initial price levels at observation $t$ where $t$ could be any observation between periods 2 and T. Let $\pi_{\mathrm{T}+1}(\mathrm{t}) \equiv\left[\rho_{\mathrm{T}+1^{*}} / \rho_{\mathrm{t}^{*}}\right]\left[\rho_{\mathrm{t}} / \rho_{1}\right]$ denote the resulting linked price level for period $\mathrm{T}+1$ that depends on choosing period $\mathrm{t}$ as link period. Thus the logarithm of this period $\mathrm{T}+1$ price level is defined as follows:

$$
\ln \pi_{\mathrm{T}+1}(\mathrm{t}) \equiv \ln \rho_{\mathrm{t}}-\ln \rho_{1}+\ln \rho_{\mathrm{T}+1^{*}}-\ln \rho_{\mathrm{t}^{*}}
$$$$
\mathrm{t}=2,3, \ldots, \mathrm{T}
$$

where the $\ln \rho_{\mathrm{t}}$ are defined by (14) and (15) and the $\ln \rho_{\mathrm{t}^{*}}$ are defined by (23) and (24). Thus there are $\mathrm{T}-1$ possible choices of period $\mathrm{t}$ which can be used in (25) to link the price level for period $\mathrm{T}+1$ to the sequence of price levels $\pi_{1}, \ldots, \pi_{\mathrm{T}}$ that were generated by the results of the initial window of observations; i.e., see definitions (22). Using the GEKS multilateral method rather than the CCDI method, Ivancic, Diewert and Fox (2009) (2011) suggested using period $\mathrm{T}$ as the linking observation. In the context of a somewhat 
different multilateral model, Krsinich (2016; 383) called this the movement splice method for linking the two windows. Krsinich (2013) (2016; 383) also suggested that a better choice of the linking observation in the context of her multilateral model was $t=2$ and she called this the window splice method. De Haan (2015a; 26) suggested that the link period $t$ should be chosen to be in the middle of the first window time span; i.e., choose $t$ $=\mathrm{T} / 2$ if $\mathrm{T}$ is an even integer or $\mathrm{t}=(\mathrm{T}+1) / 2$ if $\mathrm{T}$ is an odd integer. The Australian Bureau of Statistics $(2016 ; 12)$ called this the half splice method for linking the results of the two windows. However, without putting more structure on the underlying price and quantity data, it would seem that each choice of a linking period $t$ running from $t=2$ to $t=T$ is an equally valid choice of a period to link the two sets of price levels. Thus it would seem that we have $\mathrm{T}-1$ equally valid estimators for the period $\mathrm{T}+1$ price level, $\pi_{\mathrm{T}+1}(\mathrm{t})$ defined by (25) for $t=2,3, \ldots, T+1$, and so perhaps the "best" estimator for $\pi_{\mathrm{T}+1}$ is the mean splice, defined as the geometric mean of the $\pi_{\mathrm{T}+1}(\mathrm{t}):^{42}$

(26) $\pi_{\mathrm{T}+1}($ Mean $) \equiv\left[\Pi_{\mathrm{t}=2}^{\mathrm{T}} \pi_{\mathrm{T}+1}(\mathrm{t})\right]^{1 /(\mathrm{T}-1)}$.

In the context of very variable price data with little or no trends, choosing the mean estimator for $\pi_{\mathrm{T}+1}$ is probably a satisfactory strategy. However, we will suggest an alternative strategy below which may be superior.

Suppose the price and quantity data for period $\mathrm{T}+1$ are identical to the price and quantity data for some period $\mathrm{t}$ such that $2 \leq \mathrm{t} \leq \mathrm{T}$; i.e., we have $\mathrm{t}$ such that:

$$
\mathrm{s}_{\mathrm{T}+1, \mathrm{n}}=\mathrm{s}_{\mathrm{tn}} ; \mathrm{p}_{\mathrm{T}+1, \mathrm{n}}=\mathrm{p}_{\mathrm{tn}} ; \mathrm{n}=1, \ldots, \mathrm{N}
$$

Suppose further that we link the two windows at this observation $t$. The identity test for multilateral indexes requires that $\pi_{\mathrm{T}+1}(\mathrm{t})=\pi_{\mathrm{t}}$ where $\pi_{\mathrm{T}+1}(\mathrm{t})$ is defined by (25) and $\pi_{\mathrm{t}}$ is defined by (22). Using these definitions, we calculate $\ln \pi_{\mathrm{T}+1}(\mathrm{t})$ minus $\ln \pi_{\mathrm{t}}$ as follows:

$$
\begin{aligned}
& \text { (28) } \ln \pi_{\mathrm{T}+1}(\mathrm{t})-\ln \pi_{\mathrm{t}}=\ln \rho_{\mathrm{t}}-\ln \rho_{1}+\ln \rho_{\mathrm{T}+1^{*}}-\ln \rho_{\mathrm{t}^{*}}-\left[\ln \rho_{\mathrm{t}}-\ln \rho_{1}\right] \\
& =\ln \rho_{\mathrm{T}+1^{*}}-\ln \rho_{\mathrm{t}^{*}} \\
& =\sum_{\mathrm{n}=1}{ }^{\mathrm{N}}(1 / 2)\left(\mathrm{s}_{\mathrm{T}+1, \mathrm{n}}+\mathrm{s}_{\bullet \mathrm{n}^{*}}\right)\left(\operatorname{lnp}_{\mathrm{T}+1, \mathrm{n}}-\operatorname{lnp} \bullet_{\bullet} *\right)-\sum_{\mathrm{n}=1}{ }^{\mathrm{N}}(1 / 2)\left(\mathrm{s}_{\mathrm{tn}}+\mathrm{s}_{\bullet n^{*}}\right)\left(\operatorname{lnp}_{\mathrm{tn}}-\ln \bullet_{\bullet n^{*}}\right) \\
& =0 \quad \text { using assumptions (27). }
\end{aligned}
$$

Thus if the price and quantity data for period $\mathrm{T}+1$ are exactly equal to the price and quantity data for period $t$, then linking the windows at observation $t$ will preserve the identity test over the two windows; i.e., under these conditions it makes sense to link the two windows at period t. This logic carries over to situations where the price and quantity data of period t are closest (in some metric) to the price and quantity data of period $\mathrm{T}+1$ : it makes sense to link the windows at the observation which has the most "similar" price and quantity data. If the data are reasonably smooth, then it is likely that the most similar

\footnotetext{
${ }^{42}$ This method for linking the two windows was suggested by Ivancic, Diewert and Fox (2011; 33).
} 
price and quantity data will occur at observation $\mathrm{T}$ and thus under these conditions, movement splicing is justified. ${ }^{43}$

The exact result (28) can be extended to the case where the price data of period $\mathrm{T}+1$ is proportional to the price data of period t. Suppose the price and quantity data for period $\mathrm{T}+1$ are related to the data of period $\mathrm{t}$ (where $2 \leq \mathrm{t} \leq \mathrm{T}$ ) in the following way :

(29) $\mathrm{s}_{\mathrm{T}+1, \mathrm{n}}=\mathrm{s}_{\mathrm{tn}} ; \mathrm{p}_{\mathrm{T}+1, \mathrm{n}}=\lambda \mathrm{p}_{\mathrm{tn}} ; \mathrm{n}=1, \ldots, \mathrm{N}$

where $\lambda$ is a positive scalar. Suppose further that we link the two windows at this observation t. A proportionality test for multilateral indexes requires that $\pi_{\mathrm{T}+1}(\mathrm{t})=\lambda \pi_{\mathrm{t}}$ where $\pi_{\mathrm{T}+1}(\mathrm{t})$ is defined by (25) and $\pi_{\mathrm{t}}$ is defined by (22). It can be shown that this property also holds when the CCDI multilateral method is used for each consecutive window and the linking of the two windows is done at period t, where the data for periods $\mathrm{t}$ and $\mathrm{T}+1$ satisfy (29).

The above results suggest that linking of the two windows in a rolling window multilateral method be done at a period where the prices of period $t$ are proportional (or close to being proportional) to the prices of period $\mathrm{T}+1$. In order to implement this fifth method of linking the rolling windows, it is necessary to have measures of price proportionality between the two periods. Diewert (2009) suggested the following two measures of relative price dissimilarity between the prices of periods $t$ and $T+1:{ }^{44}$

$$
\begin{aligned}
& \text { (30) } \Delta_{\mathrm{LQ}}\left(\mathrm{p}^{\mathrm{t}}, \mathrm{p}^{\mathrm{T}+1}, \mathrm{q}^{\mathrm{t}}, \mathrm{q}^{\mathrm{T}+1}\right) \equiv \sum_{\mathrm{n}=1}{ }^{\mathrm{N}}(1 / 2)\left(\mathrm{s}_{\mathrm{T}+1, \mathrm{n}}+\mathrm{s}_{\mathrm{tn}}\right)\left[\ln \left(\mathrm{p}_{\mathrm{T}+1, \mathrm{n}} / \mathrm{P}\left(\mathrm{p}^{\mathrm{t}}, \mathrm{p}^{\mathrm{T}+1}, \mathrm{q}^{\mathrm{t}}, \mathrm{q}^{\mathrm{T}+1}\right) \mathrm{p}_{\mathrm{tn}}\right)\right]^{2} ; \\
& \text { (31) } \Delta_{\mathrm{AL}}\left(\mathrm{p}^{\mathrm{t}}, \mathrm{p}^{\mathrm{T}+1}, \mathrm{q}^{\mathrm{t}}, \mathrm{q}^{\mathrm{T}+1}\right) \\
& \left.\quad \equiv \sum_{\mathrm{n}=1} \mathrm{~N}^{\mathrm{N}}(1 / 2) \mathrm{s}_{\mathrm{T}+1, \mathrm{n}}+\mathrm{s}_{\mathrm{tn}}\right)\left\{\left(\mathrm{p}_{\mathrm{T}+1, \mathrm{n}} / \mathrm{P}\left(\mathrm{p}^{\mathrm{t}}, \mathrm{p}^{\mathrm{T}+1}, \mathrm{q}^{\mathrm{t}}, \mathrm{q}^{\mathrm{T}+1}\right) \mathrm{p}_{\mathrm{tn}}\right)+\left(\mathrm{P}\left(\mathrm{p}^{\mathrm{t}}, \mathrm{p}^{\mathrm{T}+1}, \mathrm{q}^{\mathrm{t}}, \mathrm{q}^{\mathrm{T}+1}\right) \mathrm{p}_{\mathrm{tn}} / \mathrm{p}_{\mathrm{T}+1, \mathrm{n}}\right)-2\right\}
\end{aligned}
$$

where $\mathrm{P}\left(\mathrm{p}^{\mathrm{t}}, \mathrm{p}^{\mathrm{T}+1}, \mathrm{q}^{\mathrm{t}}, \mathrm{q}^{\mathrm{T}+1}\right)$ is a bilateral superlative index number formula. ${ }^{45} \Delta_{\mathrm{LQ}}$ is the weighted log quadratic index of relative price dissimilarity and $\Delta_{\mathrm{AL}}$ is the weighted asymptotically linear index of relative price dissimilarity. Both of these measures of relative price dissimilarity will equal their lower bound of 0 if prices in periods $t$ and $T+1$ are proportional; i.e., if $\mathrm{p}^{\mathrm{T}+1}=\lambda \mathrm{p}^{\mathrm{t}}$ for some $\lambda>0$. The bigger are the measures $\Delta_{\mathrm{LQ}}$ and $\Delta_{\mathrm{AL}}$, the less proportional are the prices in the two periods. Later in our paper, we will explain exactly how these measures of relative price dissimilarity can be used to link the windows using some test data.

In the following two sections, we will discuss two additional multilateral methods that have been suggested to aggregate prices at the first stage of aggregation.

\footnotetext{
${ }^{43}$ However, if the commodity class in question is subject to frequent sales, then the data will be far from smooth.

${ }^{44}$ See Fox, Hill and Diewert (2004) for the use of dissimilarity indexes in the context of detecting data outliers.

${ }^{45}$ Later in the paper, we will choose $\mathrm{P}$ to be $\mathrm{P}_{\mathrm{T}}$, the Törnqvist formula, when we use (30) and when we use (31), we will choose $\mathrm{P}$ to be $\mathrm{P}_{\mathrm{F}}$, the Fisher ideal price index.
} 


\section{The Weighted Time Product Dummy Multilateral Method}

As usual, suppose that we have $\mathrm{T}$ time periods and $\mathrm{N}$ commodities and the price of commodity $\mathrm{n}$ in period $\mathrm{t}$ is $\mathrm{p}_{\mathrm{tn}}$ and the corresponding expenditure share is $\mathrm{s}_{\mathrm{tn}}$ for $\mathrm{n}=$ $1, \ldots, \mathrm{N}$ and $\mathrm{t}=1, \ldots, \mathrm{T}$. Suppose that prices vary in an approximately proportional manner from period to period. Thus we have the following model:

(32) $\mathrm{p}_{\mathrm{tn}}=\mathrm{a}_{\mathrm{t}} \mathrm{b}_{\mathrm{n}} \mathrm{e}_{\mathrm{tn}}$;

$\mathrm{t}=1, \ldots, \mathrm{T} ; \mathrm{n}=1, \ldots, \mathrm{N}$.

The parameter $\mathrm{a}_{\mathrm{t}}$ can be interpreted as the price level for period $\mathrm{t}, \mathrm{b}_{\mathrm{n}}$ can be interpreted as a commodity $n$ quality adjustment factor and $e_{t n}$ is a stochastic error term with mean 1 . Define the logarithms of $\mathrm{p}_{\mathrm{tn}}$ and $\mathrm{e}_{\mathrm{tn}}$ as $\mathrm{y}_{\mathrm{tn}} \equiv \operatorname{lnp}_{\mathrm{tn}}$ and $\varepsilon_{\mathrm{tn}} \equiv \ln _{\mathrm{tn}}$ for $\mathrm{t}=1, \ldots, \mathrm{T} ; \mathrm{n}=1, \ldots, \mathrm{N}$, define the logarithm of $a_{t}$ as $\alpha_{t} \equiv \ln a_{t}$ for $t=1, \ldots, T$ and define the logarithm of $b_{n}$ as $\beta_{n} \equiv$ $\operatorname{lnb}_{\mathrm{n}}$ for $\mathrm{n}=1, \ldots, \mathrm{N}$. Then taking logarithms of both sides of (32) leads to the following linear regression model:

(33) $y_{\mathrm{tn}}=\alpha_{\mathrm{t}}+\beta_{\mathrm{n}}+\varepsilon_{\mathrm{tn}}$;

$\mathrm{t}=1, \ldots, \mathrm{T} ; \mathrm{n}=1, \ldots, \mathrm{N}$.

The $\alpha_{\mathrm{t}}$ and $\beta_{\mathrm{n}}$ can be estimated by solving a least squares minimization problem. ${ }^{46}$ This is Summer's (1973) country product dummy multilateral method adapted to the time series context.

Rao (1995) ${ }^{47}$ suggested the following weighted-by-economic-importance version of Summer's method: find the $\alpha_{\mathrm{t}}$ and $\beta_{\mathrm{n}}$ which solve the following weighted least squares minimization problem:

$$
\min _{\alpha_{1}, \ldots, \alpha_{T}, \beta_{1}, \ldots, \beta_{N}} \sum_{\mathrm{t}=1}^{\mathrm{T}} \Sigma_{\mathrm{n}=1}^{\mathrm{N}} S_{\mathrm{tn}}\left(\mathrm{y}_{\mathrm{tn}}-\alpha_{\mathrm{t}}-\beta_{\mathrm{n}}\right)^{2}
$$

The first order necessary (and sufficient) conditions for solving (34) are the following $\mathrm{T}$ equations (35) and the $\mathrm{N}$ equations (36):

(36) $\sum_{\mathrm{t}=1}^{\mathrm{T}} \mathrm{s}_{\mathrm{tn}} \alpha_{\mathrm{t}}+\left(\sum_{\mathrm{t}=1}^{\mathrm{T}} \mathrm{s}_{\mathrm{tn}}\right) \beta_{\mathrm{n}}=\sum_{\mathrm{t}=1}^{\mathrm{T}} \mathrm{s}_{\mathrm{tn}} \mathrm{y}_{\mathrm{tn}}$;

$$
\begin{aligned}
& \mathrm{t}=1, \ldots, \mathrm{T} \\
& \mathrm{n}=1, \ldots, \mathrm{N} .
\end{aligned}
$$

Multiply both sides of equation $t=1$ in equations (35) by $s_{11}$, equation $t=2$ in (35) by $\mathrm{s}_{21}, \ldots$, equation $\mathrm{t}=\mathrm{T}$ in (35) by $\mathrm{s}_{\mathrm{T} 1}$, sum the resulting equations and subtract this summed equation from both sides of the first equation in (36). The resulting equation has no $\alpha_{t}$ terms. Do similar summations of equations (35) to eliminate the terms $\Sigma_{t=1}{ }^{T} s_{t n} \alpha_{t}$ in each of the equations (36). The resulting system of $\mathrm{N}$ equations is the following one:

$$
\begin{aligned}
& \Sigma_{\mathrm{t}=1}^{\mathrm{T}} \mathrm{s}_{\mathrm{t} 1} \beta_{1}-\Sigma_{\mathrm{t}=1}^{\mathrm{T}} \mathrm{s}_{\mathrm{t} 1}^{2} \beta_{1}-\Sigma_{\mathrm{t}=1}^{\mathrm{T}} \mathrm{s}_{\mathrm{t} 1} \mathrm{~s}_{\mathrm{t} 2} \beta_{2}-\Sigma_{\mathrm{t}=1}^{\mathrm{T}} \mathrm{s}_{\mathrm{t} 1} \mathrm{~s}_{\mathrm{t} 3} \beta_{3}-\ldots-\Sigma_{\mathrm{t}=1}^{\mathrm{T}} \mathrm{s}_{\mathrm{t} 1} \mathrm{~s}_{\mathrm{t} \mathrm{N}} \beta_{\mathrm{N}} \\
& =\Sigma_{\mathrm{t}=1}{ }^{\mathrm{T}} \mathrm{s}_{\mathrm{t} 1} \mathrm{y}_{\mathrm{t} 1}-\sum_{\mathrm{t}=1}{ }^{\mathrm{T}} \mathrm{s}_{\mathrm{t} 1}{ }^{2} \mathrm{y}_{\mathrm{t} 1}-\sum_{\mathrm{t}=1}{ }^{\mathrm{T}} \mathrm{S}_{\mathrm{t} 1} \mathrm{~s}_{\mathrm{t} 2} \mathrm{y}_{\mathrm{t} 2}-\sum_{\mathrm{t}=1}{ }^{\mathrm{T}} \mathrm{s}_{\mathrm{t} 1} \mathrm{~S}_{\mathrm{t} 3} \mathrm{y}_{\mathrm{t} 3}-\ldots-\sum_{\mathrm{t}=1}{ }^{\mathrm{T}} \mathrm{S}_{\mathrm{t} 1} \mathrm{~S}_{\mathrm{tN}} \mathrm{y}_{\mathrm{tN}} \text {; }
\end{aligned}
$$

\footnotetext{
${ }^{46}$ A normalization on the parameters such as $\alpha_{1}=0$ (which corresponds to $a_{1}=1$ ) is required to identify the parameters.

${ }^{47}$ See also Diewert (2004) (2005) (2012) and Rao (2005) on the WTPD method.
} 


$$
\begin{aligned}
& \sum_{\mathrm{t}=1}^{\mathrm{T}} \mathrm{S}_{\mathrm{tN}} \beta_{\mathrm{N}}-\sum_{\mathrm{t}=1}^{\mathrm{T}} \mathrm{S}_{\mathrm{tNN}} \mathrm{S}_{\mathrm{t} 1} \beta_{1}-\sum_{\mathrm{t}=1}^{\mathrm{T}} \mathrm{S}_{\mathrm{tNN}} \mathrm{S}_{\mathrm{t} 2} \beta_{2}-\sum_{\mathrm{t}=1}^{\mathrm{T}} \mathrm{S}_{\mathrm{tNN}} \mathrm{S}_{\mathrm{t} 3} \beta_{3}-\ldots-\sum_{\mathrm{t}=1}^{\mathrm{T}} \mathrm{S}_{\mathrm{tN}}{ }^{2} \beta_{\mathrm{N}} \\
& =\sum_{\mathrm{t}=1}{ }^{\mathrm{T}} \mathrm{S}_{\mathrm{tN}} \mathrm{y}_{\mathrm{tN}}-\sum_{\mathrm{t}=1}^{\mathrm{T}} \mathrm{S}_{\mathrm{tN}} \mathrm{S}_{\mathrm{t} 1} \mathrm{y}_{\mathrm{t} 1}-\sum_{\mathrm{t}=1}^{\mathrm{T}} \mathrm{S}_{\mathrm{tN}} \mathrm{S}_{\mathrm{t} 2} \mathrm{y}_{\mathrm{t} 2}-\sum_{\mathrm{t}=1}^{\mathrm{T}} \mathrm{S}_{\mathrm{tN}} \mathrm{S}_{\mathrm{t} 3} \mathrm{y}_{\mathrm{t} 3}-\ldots-\sum_{\mathrm{t}=1}{ }^{\mathrm{T}} \mathrm{S}_{\mathrm{tN}}{ }^{2} \mathrm{y}_{\mathrm{tN}} .
\end{aligned}
$$

Note that $\mathrm{s}_{\mathrm{t} 1}=1-\sum_{\mathrm{n}=2}{ }^{\mathrm{N}} \mathrm{s}_{\mathrm{tn}}, \mathrm{s}_{\mathrm{t} 2}=1-\mathrm{s}_{\mathrm{t} 1}-\sum_{\mathrm{n}=3}{ }^{\mathrm{N}} \mathrm{s}_{\mathrm{tn}} \ldots, \mathrm{s}_{\mathrm{tN}}=1-\sum_{\mathrm{n}=1}{ }^{\mathrm{N}-1} \mathrm{~s}_{\mathrm{tn}}$. Substituting these equations into the $\mathrm{N}$ equations (37) leads to the following equivalent system of equations:

$$
\begin{aligned}
& \text { (38) } \sum_{\mathrm{t}=1}^{\mathrm{T}} \mathrm{S}_{\mathrm{t} 1}\left(\mathrm{~S}_{\mathrm{t} 2}+\ldots \mathrm{S}_{\mathrm{tN}}\right) \beta_{1}-\sum_{\mathrm{t}=1}^{\mathrm{T}} \mathrm{S}_{\mathrm{t} 1} \mathrm{~S}_{\mathrm{t} 2} \beta_{2}-\sum_{\mathrm{t}=1}^{\mathrm{T}} \mathrm{S}_{\mathrm{t} 1} \mathrm{~S}_{\mathrm{t} 3} \beta_{3}-\ldots-\sum_{\mathrm{t}=1}^{\mathrm{T}} \mathrm{S}_{\mathrm{t} 1} \mathrm{~S}_{\mathrm{tN}-1} \beta_{\mathrm{N}-1}-\sum_{\mathrm{t}=1}{ }^{\mathrm{T}} \mathrm{S}_{\mathrm{t} 1} \mathrm{~S}_{\mathrm{tN}} \beta_{\mathrm{N}} \\
& =\sum_{\mathrm{t}=1}^{\mathrm{T}} \mathrm{s}_{\mathrm{t} 1} \mathrm{~s}_{\mathrm{t} 2}\left(\mathrm{y}_{\mathrm{t} 1}-\mathrm{y}_{\mathrm{t} 2}\right)+\sum_{\mathrm{t}=1}^{\mathrm{T}} \mathrm{s}_{\mathrm{t} 1} \mathrm{~s}_{\mathrm{t} 3}\left(\mathrm{y}_{\mathrm{t} 1}-\mathrm{y}_{\mathrm{t} 3}\right)+\ldots+\sum_{\mathrm{t}=1}^{\mathrm{T}} \mathrm{s}_{\mathrm{t} 1} \mathrm{~s}_{\mathrm{tN}}\left(\mathrm{y}_{\mathrm{t} 1}-\mathrm{y}_{\mathrm{tN}}\right) \text {; }
\end{aligned}
$$

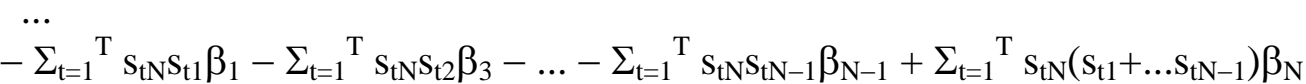

$$
\begin{aligned}
& =\sum_{\mathrm{t}=1}{ }^{\mathrm{T}} \mathrm{S}_{\mathrm{tN}} \mathrm{S}_{\mathrm{t} 1}\left(\mathrm{y}_{\mathrm{tN}}-\mathrm{y}_{\mathrm{t} 1}\right)+\sum_{\mathrm{t}=1}^{\mathrm{T}} \mathrm{S}_{\mathrm{tNN}} \mathrm{S}_{\mathrm{t} 2}\left(\mathrm{y}_{\mathrm{tN}}-\mathrm{y}_{\mathrm{t} 2}\right)+\ldots+\sum_{\mathrm{t}=1}^{\mathrm{T}} \mathrm{S}_{\mathrm{tNN}} \mathrm{S}_{\mathrm{tN}-1}\left(\mathrm{y}_{\mathrm{tN}}-\mathrm{y}_{\mathrm{tN}-1}\right) \text {. }
\end{aligned}
$$

Recall that $\mathrm{y}_{\mathrm{tn}} \equiv \operatorname{lnp}_{\mathrm{tn}}$. Thus the right hand side of the first equation in (38) is a weighted sum of the logarithmic price ratios $\ln \left(\mathrm{p}_{\mathrm{t} 1} / \mathrm{p}_{\mathrm{t} 2}\right), \ln \left(\mathrm{p}_{\mathrm{t} 1} / \mathrm{p}_{\mathrm{t} 3}\right), \ldots, \ln \left(\mathrm{p}_{\mathrm{t} 1} / \mathrm{p}_{\mathrm{tN}}\right)$. Similarly, the right hand side of the last equation in (38) is a weighted sum of the logarithmic price ratios $\ln \left(\mathrm{p}_{\mathrm{tN}} / \mathrm{p}_{\mathrm{t} 1}\right), \ln \left(\mathrm{p}_{\mathrm{tN}} / \mathrm{p}_{\mathrm{t} 2}\right), \ldots, \ln \left(\mathrm{p}_{\mathrm{tN}} / \mathrm{p}_{\mathrm{tN}-1}\right)$.

Equations (38) can be simplified if we define the following $\mathrm{TN}^{2}$ weights $\mathrm{w}_{\mathrm{tnj}}$ :

(39) $\mathrm{W}_{\mathrm{tnj}} \equiv \mathrm{S}_{\mathrm{tn}} \mathrm{S}_{\mathrm{tj}}>0$;

$\mathrm{w}_{\mathrm{tnn}} \equiv 0$;

$$
\begin{aligned}
& n \neq j ; n=1, \ldots, N ; j=1, \ldots, N ; t=1, \ldots, T \\
& n=1, \ldots, N ; t=1, \ldots, T
\end{aligned}
$$

Define the $\mathrm{N}^{2}$ weights $\mathrm{w}_{\mathrm{nj}}$ as follows: ${ }^{48}$

$$
\mathrm{n}=1, \ldots, \mathrm{N} ; \mathrm{j}=1, \ldots, \mathrm{N} \text {. }
$$

Using the above definitions, equations (38) simplify to the following $\mathrm{N}$ equations:

$$
\left(\Sigma_{\mathrm{j}=1}{ }^{\mathrm{N}} \mathrm{w}_{\mathrm{nj}}\right) \beta_{\mathrm{n}}-\Sigma_{\mathrm{j}=1}{ }^{\mathrm{N}} \mathrm{w}_{\mathrm{nj}} \beta_{\mathrm{j}}=\Sigma_{\mathrm{t}=1}^{\mathrm{T}} \sum_{\mathrm{j}=1}{ }^{\mathrm{N}} \mathrm{w}_{\mathrm{tnj}} \mathrm{y}_{\mathrm{tn}}-\sum_{\mathrm{t}=1}^{\mathrm{T}} \sum_{\mathrm{j}=1}{ }^{\mathrm{N}} \mathrm{w}_{\mathrm{tnj}} \mathrm{y}_{\mathrm{tj}} ; \quad \mathrm{n}=1, \ldots, \mathrm{N} .
$$

Equations (41) can be further simplified if we divide both sides of equation $n$ in (41) by $\Sigma_{\mathrm{j}=1}{ }^{\mathrm{N}} \mathrm{w}_{\mathrm{nj}}$ for $\mathrm{n}=1, \ldots, \mathrm{N}$. The resulting system of equations is:

(42) $\beta_{\mathrm{n}}-\Sigma_{\mathrm{j}=1}{ }^{\mathrm{N}} \mathrm{f}_{\mathrm{nj}} \beta_{\mathrm{j}}=\sum_{\mathrm{t}=1}^{\mathrm{T}} \sum_{\mathrm{j}=1}{ }^{\mathrm{N}} \mathrm{f}_{\mathrm{tnj}}\left(\mathrm{y}_{\mathrm{tn}}-\mathrm{y}_{\mathrm{tj}}\right)$;

$$
\mathrm{n}=1, \ldots, \mathrm{N}
$$

where the fractions $\mathrm{f}_{\text {nj }} \geq 0$ and $\mathrm{f}_{\text {tnj }} \geq 0$ are defined as follows: ${ }^{49}$
(43) $\mathrm{f}_{\mathrm{nj}} \equiv \mathrm{w}_{\mathrm{nj}} / \sum_{\mathrm{k}=1}{ }^{\mathrm{N}} \mathrm{W}_{\mathrm{nk}}$;
$\mathrm{n}, \mathrm{j}=1, \ldots, \mathrm{N}$;
(44) $\mathrm{f}_{\mathrm{tnj}} \equiv \mathrm{w}_{\mathrm{tnj}} / \Sigma_{\mathrm{k}=1}{ }^{\mathrm{N}} \mathrm{w}_{\mathrm{nk}}$;
$\mathrm{n}, \mathrm{j}=1, \ldots, \mathrm{N} ; \mathrm{t}=1, \ldots, \mathrm{T}$.

\footnotetext{
${ }^{48}$ Note that $\mathrm{w}_{\mathrm{nn}}=0$ for $\mathrm{n}=1, \ldots, \mathrm{N}$.

${ }^{49} \mathrm{f}_{\mathrm{nn}}=0$ for $\mathrm{n}=1, \ldots, \mathrm{N}$ and $\mathrm{f}_{\text {tnn }}=0$ for $\mathrm{n}=1, \ldots, \mathrm{N}$ and $\mathrm{t}=1, \ldots, \mathrm{T}$. The remaining fractions are positive under our assumptions that each price $\mathrm{p}_{\mathrm{tn}}$ and quantity $\mathrm{q}_{\mathrm{tn}}$ is positive for all $\mathrm{n}$ and $\mathrm{t}$.
} 
It can be verified that $\Sigma_{j=1}{ }^{N} f_{n j}=1$ for $n=1, \ldots, N$ and $\Sigma_{t=1}{ }^{T} \sum_{j=1}{ }^{N} f_{t n j}=1$ for $n=1, \ldots, N$. Let $\mathrm{F} \equiv\left[\mathrm{f}_{\mathrm{nj}}\right]$ be the $\mathrm{N}$ by $\mathrm{N}$ matrix which has element nj equal to $\mathrm{f}_{\mathrm{nj}}$ for $\mathrm{n}=1, \ldots, \mathrm{N}$ and $\mathrm{j}=$ $1, \ldots, N$. Let $f \equiv\left[f_{1}, \ldots, f_{N}\right]^{T}$ where $f_{n} \equiv \Sigma_{t=1}{ }^{T} \sum_{j=1}{ }^{N} f_{t n j}\left(y_{t n}-y_{t j}\right)$ for $n=1, \ldots, N .{ }^{50}$ Then the $N$ equations in (42) can be written using matrix notation as:

(45) $\left[\mathrm{I}_{\mathrm{N}}-\mathrm{F}\right] \beta=\mathrm{f}$

where $I_{N}$ is the $N$ by $N$ identity matrix and $\beta \equiv\left[\beta_{1}, \ldots, \beta_{N}\right]^{T}$ is the column vector of the $\beta_{n}$. Thus it would appear that the $\beta$ solution to the weighted least squares minimization problem (34) is equal to $\beta^{*} \equiv\left[\mathrm{I}_{\mathrm{N}}-\mathrm{F}\right]^{-1}$ f. However, the inverse of the matrix $\left[\mathrm{I}_{\mathrm{N}}-\mathrm{F}\right]$ does not exist since its columns are linearly dependent; i.e., we have $\left[I_{N}-F\right] 1_{N}=0_{N}$ where $1_{N}$ is a vector of ones and $0_{\mathrm{N}}$ is a vector of zeros. The solution to this problem is simple: set one of the $\beta_{\mathrm{n}}$ equal to a definite number and drop one of the equations in the system of $\mathrm{N}$ equations defined by (45). ${ }^{51}$ In our empirical work, we will choose to set $\beta_{\mathrm{N}}$ equal to 0 and to drop the last equation in (45). Under these conditions, the remaining betas can be obtained by solving equations (45). Denote the solution values to the modified system of equations as $\beta_{1^{*},} \beta_{2^{*}, \ldots,}, \beta_{\mathrm{N}-1^{*}}$ and let $\beta^{*}$ denote the column vector of all of these betas including $\beta_{\mathrm{N}^{*}}=0$. The corresponding parameters $b_{\mathrm{n}^{*}}$ which appear in equations (32) are defined as the exponentials of the $\beta_{\mathrm{n}^{*}}$; i.e., we have:

(46) $b_{n^{*}} \equiv \exp \left(\beta_{n^{*}}\right)$;

$\mathrm{n}=1, \ldots, \mathrm{N}$.

Since $\beta_{\mathrm{N}^{*}}=0, \mathrm{~b}_{\mathrm{N}^{*}}=1$. The quality adjustment parameter $\mathrm{b}_{\mathrm{n}^{*}}$ essentially converts one unit of commodity $n$ into the utility equivalent of $b_{n *}$ units of commodity $N$ for $n=1,2 \ldots ., N-1$. Thus commodity $\mathrm{N}$ acts as a numeraire commodity. ${ }^{52}$

Now that the quality adjustment parameters have been determined, the logarithm of the period t price level, $\alpha_{t *}$, can be determined using equation t in equations (35); i.e., we have: ${ }^{53}$

\footnotetext{
${ }^{50}$ Note that the elements of the matrix $\mathrm{F}$ depend on just expenditure shares whereas the elements of the vector $f$ are share weighted averages of the logarithmic price ratios $y_{t n}-y_{t j}=\ln \left(p_{t n} / p_{t j}\right)$.

${ }^{51}$ This step can be justified as follows. First note that equations (35) can be replaced by the equivalent equations: (35) ${ }^{*} \sum_{\mathrm{n}=1}{ }^{\mathrm{N}} \mathrm{s}_{\mathrm{tn}} \alpha_{\mathrm{t}}+\sum_{\mathrm{n}=1}{ }^{\mathrm{N}} \mathrm{s}_{\mathrm{tn}} \beta_{\mathrm{n}}=\Sigma_{\mathrm{n}=1}{ }^{\mathrm{N}} \mathrm{s}_{\mathrm{tn}} \mathrm{y}_{\mathrm{tn}}$ for $\mathrm{t}=1, \ldots, \mathrm{T}$. Now sum equations (35) ${ }^{*}$ for $\mathrm{t}=$ $1, \ldots, \mathrm{T}$ and note that this sum is equal to the sum of equations (36) for $\mathrm{n}=1, \ldots, \mathrm{N}$. Thus the last equation in (36) is linearly dependent on the remaining equations and can be dropped. This implies that the last equation in (38) and (45) can be dropped. Note that if we have found a solution to equations (35) ${ }^{*}$ and (36), say $\alpha_{1}{ }^{*}, \ldots, \alpha_{\mathrm{T}}{ }^{*}, \beta_{1}{ }^{*}, \ldots, \beta_{\mathrm{N}}{ }^{*}$, then $\alpha_{1}{ }^{*}+\mu, \ldots, \alpha_{\mathrm{T}}{ }^{*}+\mu, \beta_{1}{ }^{*}-\mu, \ldots, \beta_{\mathrm{N}}{ }^{*}-\mu$ is also a solution to these equations where $\mu$ is an arbitrary number. Thus a normalization on these parameters is required in order to obtain a unique solution to the minimization problem (34).

${ }^{52}$ This interpretation for the $b_{n}$ as quality adjustment factors in the context of the weighted time product dummy model follows that of Rao (2005; 574) and de Haan (2015a; 21) (2015b; 6) but this interpretation can be traced back to Summers (1973; 11): "The coefficients of the $\gamma_{\alpha}$ dummies have no significance for country price level comparisons, though they may conceivably be useful in an analysis of the relative values that purchasers in all $\mathrm{m}$ countries put on the individual items."

${ }^{53}$ Rao $(1995)(2004 ; 20)(2005 ; 577)$ derived this formula many years ago. What is new in our derivation is equations (45) which define the optimal $\beta_{\mathrm{n}}$ in a fairly simple manner.
} 
(47)

$$
\begin{aligned}
\alpha_{\mathrm{t}^{*}} & \equiv \sum_{\mathrm{n}=1}{ }^{\mathrm{N}} \mathrm{s}_{\mathrm{tn}} \mathrm{y}_{\mathrm{tn}}-\Sigma_{\mathrm{n}=1}{ }^{\mathrm{N}} \mathrm{s}_{\mathrm{tn}} \beta_{\mathrm{n}^{*}} \\
& =\sum_{\mathrm{n}=1}{ }^{N} \mathrm{~s}_{\mathrm{tn}}\left(\mathrm{y}_{\mathrm{tn}}-\beta_{\mathrm{n}^{*}}\right) .
\end{aligned}
$$

$\mathrm{t}=1, \ldots, \mathrm{T}$

Recall that $\mathrm{y}_{\mathrm{tn}}=\ln \mathrm{p}_{\mathrm{tn}}$ and $\beta_{\mathrm{n}^{*}}=\ln \left(\mathrm{b}_{\mathrm{n}^{*}}\right)$ for each $\mathrm{t}$ and $\mathrm{n}$. The period $\mathrm{t}$ (unnormalized) price level $\mathrm{a}_{\mathrm{t}^{*}}$ is the exponential of $\alpha_{\mathrm{t}}$. Thus exponentiating both sides of (47) leads to the following formula for the (unnormalized) weighted time product dummy price level for period t:

(48) $\mathrm{a}_{\mathrm{t}^{*}}=\prod_{n=1}^{N}\left(p_{t n} / b_{n^{*}}\right)^{s_{t n}}$;

$$
\mathrm{t}=1, \ldots, \mathrm{T} \text {. }
$$

Thus the unnormalized price level for period $t$ is a period $t$ expenditure share weighted geometric mean of the $\mathrm{N}$ period $\mathrm{t}$ quality adjusted prices $\mathrm{p}_{\mathrm{tn}} / \mathrm{b}_{\mathrm{n}} *$ where the logarithms of quality adjustment factors $b_{n *}$ are defined solving equations (45) after imposing a normalization on the quality adjustment factors.

Define the period $t$ normalized weighted time product dummy price level $\pi_{\mathrm{t}}$ by dividing $\mathrm{a}_{\mathrm{t}}$ by $\mathrm{a}_{1} *$ :

(49) $\pi_{\mathrm{t}} \equiv \mathrm{a}_{\mathrm{t}^{*}} / \mathrm{a}_{1 *}$;

$\mathrm{t}=1, \ldots, \mathrm{T}$.

Substituting (48) into (49) and recalling that $\mathrm{y}_{\mathrm{tn}} \equiv \operatorname{lnp}_{\mathrm{tn}}$ and $\beta_{\mathrm{n}^{*}}=\operatorname{lnb}_{\mathrm{n}^{*}}$ leads to the following expression for the logarithm of $\pi_{\mathrm{t}}$ :

(50) $\ln \pi_{\mathrm{t}}=\sum_{\mathrm{n}=1}{ }^{\mathrm{N}} \mathrm{s}_{\mathrm{tn}}\left(\mathrm{y}_{\mathrm{tn}}-\beta_{\mathrm{n}^{*}}\right)-\sum_{\mathrm{n}=1}{ }^{\mathrm{N}} \mathrm{s}_{1 \mathrm{n}}\left(\mathrm{y}_{1 \mathrm{n}}-\beta_{\mathrm{n}^{*}}\right)$;

$\mathrm{t}=1, \ldots, \mathrm{T}$.

At this point, it is useful to consider some special cases for the above multilateral indexes. Our first special case is the case where we have only two periods, so that $T=2$. In this case, Diewert (2005; 564) showed that the logarithm of $\pi_{2}$ is defined as follows;

(51) $\ln \pi_{2} \equiv \sum_{\mathrm{n}=1}{ }^{\mathrm{N}} \mathrm{S}_{\mathrm{n}} *\left(\mathrm{y}_{2 \mathrm{n}}-\mathrm{y}_{1 \mathrm{n}}\right)$

where the share weights $\mathrm{s}_{\mathrm{n}}$ are defined as the following normalized harmonic averages of the observed expenditure shares $s_{1 n}$ and $s_{2 n}$ for the two periods:

(52) $\mathrm{s}_{\mathrm{n}} \equiv \mathrm{h}\left(\mathrm{s}_{1 \mathrm{n}}, \mathrm{s}_{2 \mathrm{n}}\right) /\left[\Sigma_{\mathrm{k}=1}{ }^{\mathrm{N}} \mathrm{h}\left(\mathrm{s}_{1 \mathrm{k}}, \mathrm{s}_{2 \mathrm{k}}\right)\right]$;

$\mathrm{n}=1, \ldots, \mathrm{N}$

where $h\left(s_{1 n}, s_{2 n}\right) \equiv\left[(1 / 2) s_{1 n}{ }^{-1}+(1 / 2) s_{2 n}{ }^{-1}\right]^{-1}$. Diewert (2005; 564) noted that the bilateral price index defined by $\pi_{2}$ approximated the corresponding Törnqvist index to the second order around a point where $\mathrm{p}^{1}=\mathrm{p}^{2}$ and $\mathrm{q}^{1}=\mathrm{q}^{2} .{ }^{54}$ Thus it may appear that if there are only two periods in the window, the weighted time product dummy (WTPD) multilateral method is a perfectly satisfactory method from the viewpoint of the economic approach

\footnotetext{
${ }^{54}$ This second order approximation property will hold if $\mathrm{p}^{2}=\lambda \mathrm{p}^{1}$ and $\mathrm{q}^{2}=\mu \mathrm{q}^{1}$ where $\lambda$ and $\mu$ are arbitrary positive scalars.
} 
to index number theory. Unfortunately, second order approximation results may not be adequate in our present context where a sale for a product (i.e., a dramatic reduction in price) can increase the quantity of the sale item 1000 fold. ${ }^{55}$ Consider the following example where there are only 2 commodities and 2 periods so that $\mathrm{N}=2$ and $\mathrm{T}=2$. Suppose that the period 1 and 2 price vectors are equal to $p^{1} \equiv[1,1]$ and $p^{2} \equiv\left[1, p_{22}\right]$ and the period 1 and 2 share vectors are equal to $s^{1} \equiv[(1 / 2),(1 / 2)]$ and $s^{2} \equiv[0,1]$, where $p_{22}$ is a small positive number that is less than 1 . Thus the logarithm of $\mathrm{p}_{22}$ is less than zero; i.e., $r \equiv \operatorname{lnp}_{22}<0$. The price of commodity 2 in period 2 is so low that purchasers stop buying commodity 1 in period 2 even though the price of commodity 1 has not changed. Using formula (11) for the Törnqvist index between periods 2 and 1, the logarithm of this index is defined as follows:

$$
\begin{aligned}
\ln \mathrm{P}_{\mathrm{T}}(2 / 1) & \equiv \sum_{\mathrm{n}=1}^{2}(1 / 2)\left(\mathrm{s}_{1 \mathrm{n}}+\mathrm{s}_{2 \mathrm{n}}\right) \ln \left(\mathrm{p}_{2 \mathrm{n}} / \mathrm{p}_{1 \mathrm{n}}\right) \\
& =(1 / 2)[(1 / 2)+0] \ln (1 / 1)+(1 / 2)[(1 / 2)+1] \ln \left(\mathrm{p}_{22} / 1\right) \\
& =(3 / 4) \mathrm{r}
\end{aligned}
$$

where $\mathrm{r} \equiv \ln _{22}$ and is negative by assumption. Under our assumptions, $\mathrm{h}\left(\mathrm{s}_{11}, \mathrm{~s}_{21}\right)=$ $\mathrm{h}(1 / 2,0)=0$ and $\mathrm{h}\left(\mathrm{s}_{12}, \mathrm{~s}_{22}\right)=\mathrm{h}(1 / 2,1)=2(1 / 2) 1 /[(1 / 2)+1]=2 / 3$. Thus the sum $\mathrm{h}\left(\mathrm{s}_{11}, \mathrm{~s}_{21}\right)+$ $\mathrm{h}\left(\mathrm{s}_{12}, \mathrm{~s}_{22}\right)=\mathrm{h}\left(\mathrm{s}_{12}, \mathrm{~s}_{22}\right)=2 / 3$ and substituting these numbers into formula (51) shows that the logarithm of the WTPD normalized price level for period 2 is equal to the following expression:

$$
\text { (54) } \begin{aligned}
\ln \pi_{2} & \equiv \sum_{\mathrm{n}=1}^{2} \mathrm{~s}_{\mathrm{n}} *\left(\mathrm{y}_{2 \mathrm{n}}-\mathrm{y}_{1 \mathrm{n}}\right) \\
& =0 \ln (1 / 1)+1 \ln \left(\mathrm{p}_{22} / 1\right) \\
& =\mathrm{r} \\
& <(3 / 4) \mathrm{r} \\
& =\ln \mathrm{P}_{\mathrm{T}}(2 / 1)
\end{aligned}
$$

since $\mathrm{r}<0$ by assumption

where the last equality follows using (53) for our example. This is only a specific numerical example but it shows that price levels based on the weighted time product dummy method may have a substantial bias as compared to the price levels generated by a superlative index.

The second special case that we will consider is the case where the expenditure shares are constant in each period. This case is consistent with purchasers having Cobb-Douglas preferences for the $\mathrm{N}$ commodities under consideration. Thus assume that the data satisfy the following conditions:

(55) $\mathrm{s}_{\mathrm{tn}}=\mathrm{s}_{\mathrm{n}}$;

$\mathrm{t}=1, \ldots, \mathrm{T} ; \mathrm{n}=1, \ldots, \mathrm{N}$

Substituting conditions (55) into (50) leads to the following formula for the logarithms of the normalized WTPD price levels:

(56) $\ln \pi_{\mathrm{t}}=\Sigma_{\mathrm{n}=1}^{\mathrm{N}} \mathrm{s}_{\mathrm{n}}\left(\mathrm{y}_{\mathrm{tn}}-\mathrm{y}_{1 \mathrm{n}}\right)$;

$$
\mathrm{t}=1, \ldots, \mathrm{T} \text {. }
$$

\footnotetext{
${ }^{55}$ See de Haan and van der Grient (2011).
} 
Thus $\pi_{\mathrm{t}}=\prod_{n=1}^{N}\left(p_{t n} / p_{1 n}\right)^{s_{n}}$, a weighted geometric mean of the ratios of the period $\mathrm{t}$ prices to the period 1 prices, $\mathrm{p}_{\mathrm{tn}} / \mathrm{p}_{1 \mathrm{n}}$, using the constant expenditure shares, $\mathrm{s}_{\mathrm{n}}$, as weights.

The third special case we consider is the case where the error terms $\varepsilon_{\text {tn }}$ in equations (33) are all equal to 0 . In this case, equations (32) become the following equations:

(57) $\mathrm{p}_{\mathrm{tn}}=\mathrm{a}_{\mathrm{t}} \mathrm{b}_{\mathrm{n}}$;

$$
\mathrm{t}=1, \ldots, \mathrm{T} ; \mathrm{n}=1, \ldots, \mathrm{N}
$$

Thus in this special case, the period t price vector $\mathrm{p}^{\mathrm{t}}$ is equal to $\mathrm{a}_{\mathrm{t}} \mathrm{b}$, where $\mathrm{b}$ is the vector $\left[b_{1}, \ldots, b_{N}\right]$ and thus the price vectors are proportional to each other. As usual, we can interpret the scalar $\mathrm{a}_{\mathrm{t}}$ as the (unnormalized) period t price level. The corresponding period $t$ quantity level, $\mathrm{Q}_{\mathrm{t}}$, can be defined as period $\mathrm{t}$ value, $\Sigma_{\mathrm{n}=1}{ }^{\mathrm{N}} \mathrm{p}_{\mathrm{tn}} \mathrm{q}_{\mathrm{tn}}$, divided by the price level, $\mathrm{a}_{\mathrm{t}}$. Thus we have:

$$
\text { (58) } \begin{aligned}
\mathrm{Q}_{\mathrm{t}} & \equiv \mathrm{p}^{\mathrm{t}} \cdot \mathrm{q}^{\mathrm{t}} / \mathrm{a}_{\mathrm{t}} \\
& =\mathrm{a}_{\mathrm{t}} \mathrm{b} \cdot \mathrm{q}^{\mathrm{t}} / \mathrm{a}_{\mathrm{t}} \\
& =\mathrm{b} \cdot \mathrm{q}^{\mathrm{t}} \cdot
\end{aligned}
$$

$$
\mathrm{t}=1, \ldots, \mathrm{T}
$$$$
\text { using (57) }
$$

Thus if the error terms in equations (33) are all equal to 0 , the period t quantity aggregate, $Q_{t}$, is equal to the linear function $b \cdot q^{t}=\Sigma_{n=1}{ }^{N} b_{n} q_{t n}$ for all $t$; i.e., $Q_{t}$ is equal to a quality adjusted sum of the period t quantities purchased. Thus in the case of zero errors in equations (33), the WTPD multilateral method is consistent with purchasers of the $\mathrm{N}$ commodities maximizing a linear utility function, which implicitly assumes that the $\mathrm{N}$ commodities are perfectly substitutable after quality adjustment. A multilateral method which has this property is called an additive method. In the general case where there are nonzero error terms in equations (33), it can be seen that the WTPD multilateral method is an approximately additive method.

The problem with an additive multilateral method is that, in general, it is not consistent with the economic approach to index number theory once the number of periods is greater than two. We will attempt to explain the last point above when $\mathrm{N}=2$ with the help of a diagram. ${ }^{56}$

\footnotetext{
${ }^{56}$ This explanation is due to Marris (1984; 52) and repeated in Diewert (1999; 49). Figure 1 suggests that the longer the window length is, the more likely it is that substitution bias will increase. Thus when using an additive multilateral method, increasing the window length will reduce chain drift bias but at the cost of increasing substitution bias.
} 
Figure 1: Additive Multilateral Methods and Substitution Effects

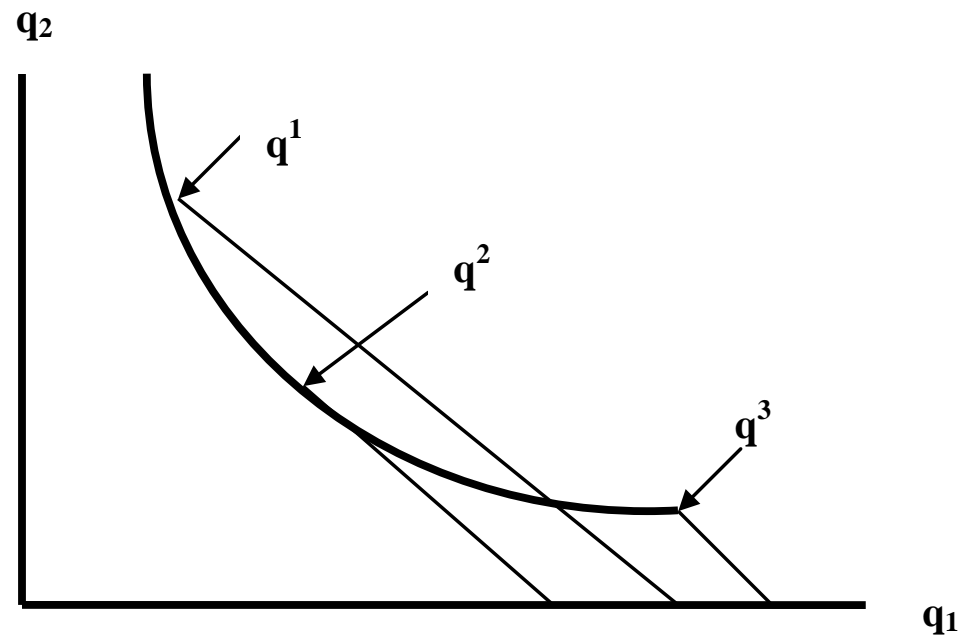

The solid curved line in Figure 1 represents an indifference curve for purchasers of the two goods under consideration. The consumption vectors that correspond to observations 1,2 and 3 are all on the same actual indifference curve and hence, the multilateral method should show the same volume for the three observations. If we use an additive method, it implies the all points should lie on a straight line. However, it is impossible for all three points in Figure 1 to be on the same straight line; see Diewert (1999). On the other hand, the indifference curve in Figure 1 can be approximated reasonably well by a flexible functional form that has a corresponding exact index number formula (such as the Fisher or Törnqvist indexes) and thus the GEKS and CCDI methods that use superlative bilateral indexes as their basic building blocks would give the right answer to a reasonable degree of approximation. The bottom line is that an additive multilateral method is not likely to be consistent with the economic approach to index number theory if the number of observations in the multiperiod comparison is greater than two. ${ }^{57}$ However, if the commodities in the commodity group under consideration are highly substitutable with each other (so that when $\mathrm{N}=2$, the indifference curve in Figure 1 approaches a straight line), then the WTPD multilateral method will be consistent with the economic approach to index number theory to a high degree of approximation.

To summarize: the WTPD multilateral method is recommended from the viewpoint of the economic approach to index number theory if:

\footnotetext{
57 "Figure 1.1 also illustrates the Gerschenkron effect: in the consumer theory context, countries whose price vectors are far from the 'international' or world average prices used in an additive method will have quantity shares that are biased upward. ... It can be seen that these biases are simply quantity index counterparts to the usual substitution biases encountered in the theory of the consumer price index. However, the biases will usually be much larger in the multilateral context than in the intertemporal context since relative prices and quantities will be much more variable in the former context. ... The bottom line on the discussion presented above is that the quest for an additive multilateral method with good economic properties (i.e., a lack of substitution bias) is a doomed venture: nonlinear preferences and production functions cannot be adequately approximated by linear functions. Put another way, if technology and preferences were always linear, there would be no index number problem and hundreds of papers and monographs on the subject would be superfluous!” W. Erwin Diewert (1999; 50).
} 
- Purchaser preferences are well approximated by Cobb-Douglas preferences.

- Purchaser preferences are well approximated by linear or additive preferences. ${ }^{58}$

We will now compare the WTPD price level for period t relative to period $\tau, \pi_{t} / \pi_{\tau}$, with the corresponding Törnqvist bilateral index, $\mathrm{P}_{\mathrm{T}}(\mathrm{t} / \tau)$, defined by (19). Using (50), we have:

(59) $\ln \left(\pi_{\mathrm{t}} / \pi_{\tau}\right)=\Sigma_{\mathrm{n}=1}{ }^{N} s_{\mathrm{tn}}\left(\ln \mathrm{ptn}_{\mathrm{tn}}-\beta_{\mathrm{n}^{*}}\right)-\sum_{\mathrm{n}=1}{ }^{N} \mathrm{~s}_{\tau \mathrm{n}}\left(\operatorname{lnp}_{\tau \mathrm{n}}-\beta_{\mathrm{n}^{*}}\right)$.

Using (19) and (59), it can be shown that:

(60) $\ln \mathrm{P}_{\mathrm{T}}(\mathrm{t} / \tau)-\ln \left(\pi_{\mathrm{t}} / \pi_{\tau}\right)=\Sigma_{\mathrm{n}=1}{ }^{\mathrm{N}}(1 / 2)\left(\mathrm{s}_{\tau \mathrm{n}}-\mathrm{s}_{\mathrm{tn}}\right)\left(\mathrm{y}_{\mathrm{tn}}+\mathrm{y}_{\tau \mathrm{n}}-2 \beta_{\mathrm{n}^{*}}\right)$

$$
=\Sigma_{\mathrm{n}=1}{ }^{\mathrm{N}}\left(\mathrm{s}_{\text {tn }}-\mathrm{s}_{\mathrm{tn}}\right)\left[(1 / 2) \ln \left(\mathrm{p}_{\mathrm{tn}} / \mathrm{b}_{\mathrm{n}^{*}}\right)+(1 / 2) \ln \left(\mathrm{p}_{\text {tn }} / \mathrm{b}_{\mathrm{n}^{*}}\right)\right]
$$

where the $b_{n^{*}}$ are defined by (46). It is difficult to determine the sign of the right hand side of (60) except in the case (55) where expenditure shares are constant across all observations in which case the right hand side of (60) is equal to zero and thus $\mathrm{P}_{\mathrm{T}}(\mathrm{t} / \tau)$ equals $\pi_{\mathrm{t}} / \pi_{\tau}$ in this case.

Using (20) and (59), it is possible to compare the logarithm of the CCDI price level for period $t$ relative to period $\tau, \ln \left(\rho_{t} / \rho_{\tau}\right)$, to the logarithm of the WTPD price level for period t relative to period $\tau, \ln \left(\pi_{t} / \pi_{\tau}\right)$ :

(61) $\ln \left(\rho_{\mathrm{t}} / \rho_{\tau}\right)-\ln \left(\pi_{\mathrm{t}} / \pi_{\tau}\right)=\sum_{\mathrm{n}=1} \mathrm{~N}(1 / 2)\left(\mathrm{s}_{\mathrm{tn}}+\mathrm{s}_{\bullet \mathrm{n}}\right)\left(\operatorname{lnp}_{\mathrm{tn}}-\ln \boldsymbol{\bullet}_{\bullet \mathrm{n}}\right)$

$$
\begin{aligned}
& -\sum_{\mathrm{n}=1}^{N}(1 / 2)\left(\mathrm{s}_{\tau \mathrm{n}}+\mathrm{s}_{\bullet_{\mathrm{n}}}\right)\left(\operatorname{lnp}_{\tau \mathrm{n}}-\operatorname{lnp} \bullet_{\bullet \mathrm{n}}\right)-\left[\sum_{\mathrm{n}=1}{ }^{\mathrm{N}} \mathrm{s}_{\mathrm{tn}}\left(\operatorname{lnp}_{\mathrm{tn}}-\beta_{\mathrm{n}^{*}}\right)-\sum_{\mathrm{n}=1}{ }^{\mathrm{N}} \mathrm{s}_{\tau \mathrm{n}}\left(\operatorname{lnp}_{\tau \mathrm{n}}-\beta_{\mathrm{n}^{*}}\right)\right] \\
& =\sum_{\mathrm{n}=1}^{\mathrm{N}}\left(\mathrm{s}_{\mathrm{tn}}-\mathrm{s}_{\bullet \mathrm{n}}\right)\left[(1 / 2) \ln \left(\mathrm{p}_{\mathrm{tn}} / \mathrm{b}_{\mathrm{n}^{*}}\right)+(1 / 2) \ln \left(\mathrm{p}_{\bullet_{\mathrm{n}}} / \mathrm{b}_{\mathrm{n}^{*}}\right)\right] \\
& -\sum_{\mathrm{n}=1}{ }^{N}\left(\mathrm{~s}_{\mathrm{tn}}-\mathrm{s}_{\bullet \mathrm{n}}\right)\left[(1 / 2) \ln \left(\mathrm{p}_{\mathrm{tn}} / \mathrm{b}_{\mathrm{n}^{*}}\right)+(1 / 2) \ln \left(\mathrm{p}_{\bullet n_{\mathrm{n}}} / \mathrm{b}_{\mathrm{n}^{*}}\right)\right] \text {. }
\end{aligned}
$$

Again, it is difficult to determine the sign of the right hand side of (61) except in the case (55) where expenditure shares are constant across all observations, in which case the right hand side of (61) is equal to zero and thus $\rho_{t} / \rho_{\tau}$ equals $\pi_{t} / \pi_{\tau}$ in this case.

\section{The Weighted Time Product Dummy Method and the Linking Problem}

Suppose that the WTPD multilateral method explained in the previous section is used to construct a sequence of price levels, $\pi_{1}, \pi_{2}, \ldots, \pi_{\mathrm{T}}$ for $\mathrm{T}$ consecutive periods where $\mathrm{T} \geq 3$. Recall that the logarithms of these price levels can be defined by equations (50), $\ln \pi_{\mathrm{t}}=$ $\alpha_{\mathrm{t}^{*}}-\alpha_{1^{*}}=\Sigma_{\mathrm{n}=1}{ }^{\mathrm{N}} \mathrm{s}_{\mathrm{tn}}\left(\mathrm{y}_{\mathrm{tn}}-\beta_{\mathrm{n}^{*}}\right)-\Sigma_{\mathrm{n}=1}{ }^{\mathrm{N}} \mathrm{s}_{1 \mathrm{n}}\left(\mathrm{y}_{1 \mathrm{n}}-\beta_{\mathrm{n}^{*}}\right)$ for $\mathrm{t}=1, \ldots, \mathrm{T}$, where the $\alpha_{1^{*}, \alpha_{2^{*}}, \ldots, \alpha_{\mathrm{T}^{*}}}$ and $\beta_{1^{*}, \ldots, \beta_{\mathrm{N}^{*}}}$ solved the weighted least squares minimization problem (34) with the normalization $\beta_{\mathrm{N}^{*}}=0$.

\footnotetext{
${ }^{58}$ In the context of the Constant Elasticity of Substitution (CES) model to be discussed later, the WTPD model is consistent with CES preferences if the elasticity of substitution is either 1 or plus infinity.
} 
Assume that data on period $\mathrm{T}+1$ expenditure shares $\mathrm{s}_{\mathrm{T}+1, \mathrm{n}}$ and prices $\mathrm{p}_{\mathrm{T}+1, \mathrm{n}}$ become available at the end of period $\mathrm{T}+1$ for $\mathrm{n}=1, \ldots, \mathrm{N}$. A new set of multilateral indexes can now be constructed for the window of observations that include the data for periods $2,3, \ldots, \mathrm{T}, \mathrm{T}+1$. The weighted least squares problem that is solved to generate the price levels for the new window of observations is the following one:

$$
\min _{\alpha_{2}, \ldots, \alpha_{T+1}, \beta_{1}, \ldots, \beta_{N}} \Sigma_{\mathrm{t}=2}^{\mathrm{T}+1} \sum_{\mathrm{n}=1}{ }^{\mathrm{N}} \mathrm{s}_{\mathrm{tn}}\left(\mathrm{y}_{\mathrm{tn}}-\alpha_{\mathrm{t}}-\beta_{\mathrm{n}}\right)^{2} .
$$

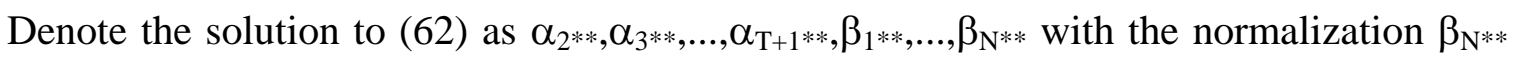
$=0$. The new set of quality adjustment coefficients $\beta_{\mathrm{n}^{* *}}$ can be obtained by solving the counterpart to the matrix equation (45) where the elements of the new $F$ matrix and $f$ vector are obtained using definitions (39) to (44) except that $t=2,3, \ldots, \mathrm{T}+1$ instead of $\mathrm{t}=$ $1,2, \ldots, \mathrm{T}$. The (unnormalized) logarithms of the price levels for the new window are defined as follows:

(63) $\alpha_{t^{* *}} \equiv \Sigma_{\mathrm{n}=1}^{\mathrm{N}} \mathrm{s}_{\mathrm{tn}}\left(\mathrm{y}_{\mathrm{tn}}-\beta_{\mathrm{n}^{* *}}\right)$

$$
\mathrm{t}=2,3, \ldots, \mathrm{T}+1 .
$$

Recall that $\mathrm{y}_{\mathrm{tn}}=\operatorname{lnp}_{\mathrm{tn}}$ and $\beta_{\mathrm{n}^{* *}}=\ln \left(\mathrm{b}_{\mathrm{n}^{* *}}\right)$ for $\mathrm{t}=2,3, \ldots, \mathrm{T}+1$ and $\mathrm{n}=1, \ldots, \mathrm{N}$. The period $\mathrm{t}$ (unnormalized) price levels $\mathrm{a}_{\mathrm{t} * *}$ are defined as the exponentials of the $\alpha_{\mathrm{t}^{* *}}$ :

(64) $\mathrm{a}_{\mathrm{t}^{* *}} \equiv e^{\alpha_{\mathrm{t} \mathrm{t}^{*}}}$;

$$
\mathrm{t}=2,3, \ldots, \mathrm{T}+1 .
$$

The new WTPD price levels need to be linked to the price levels generated by the original window of observations; i.e., we need to define a new price level for period $\mathrm{T}+1$ that extends the initial $\mathrm{T}$ normalized price levels $\pi_{\mathrm{t}}$ defined by equations (50) for $\mathrm{t}=$ $1, \ldots, \mathrm{T}$. Suppose we link the new window price levels to the initial price levels at observation $t$ where t could be any observation between periods 2 and T. Let $\pi_{\mathrm{T}+1}(\mathrm{t}) \equiv$ $\pi_{\mathrm{t}}\left[\mathrm{a}_{\mathrm{T}+1^{* *}} / \mathrm{a}_{\mathrm{t}^{* *}}\right]$ denote the resulting (normalized) linked price level for period $\mathrm{T}+1$ that depends on choosing period $t$ as link period. Thus the logarithm of this period $\mathrm{T}+1$ price level is defined as follows: ${ }^{.9}$

$$
\begin{aligned}
& \ln \pi_{\mathrm{T}+1}(\mathrm{t}) \equiv \ln \pi_{\mathrm{t}}-\ln \mathrm{a}_{\mathrm{t}^{* * *}}+\ln \mathrm{a}_{\mathrm{T}+1^{* *}} ; \quad \mathrm{t}=2,3, \ldots, \mathrm{T} \\
& =\sum_{\mathrm{n}=1}{ }^{\mathrm{N}} \mathrm{s}_{\mathrm{tn}}\left(\mathrm{y}_{\mathrm{tn}}-\beta_{\mathrm{n}^{*}}\right)-\sum_{\mathrm{n}=1}{ }^{\mathrm{N}} \mathrm{s}_{1 \mathrm{n}}\left(\mathrm{y}_{1 \mathrm{n}}-\beta_{\mathrm{n}^{*}}\right)-\alpha_{\mathrm{t}^{* *}}+\alpha_{\mathrm{T}+1^{* *}} \quad \text { using (50) and (64) } \\
& =\sum_{\mathrm{n}=1}{ }^{\mathrm{N}} \mathrm{s}_{\mathrm{tn}}\left(\mathrm{y}_{\mathrm{tn}}-\beta_{\mathrm{n}^{*}}\right)-\sum_{\mathrm{n}=1}{ }^{\mathrm{N}} \mathrm{s}_{1 \mathrm{n}}\left(\mathrm{y}_{1 \mathrm{n}}-\beta_{\mathrm{n}^{*}}\right)-\sum_{\mathrm{n}=1}{ }^{\mathrm{N}} \mathrm{s}_{\mathrm{tn}}\left(\mathrm{y}_{\mathrm{tn}}-\beta_{\mathrm{n}^{* *}}\right) \\
& +\sum_{\mathrm{n}=1}{ }^{\mathrm{N}} \mathrm{s}_{\mathrm{T}+1, \mathrm{n}}\left(\mathrm{y}_{\mathrm{T}+1, \mathrm{n}}-\beta_{\mathrm{n}^{* *}}\right) \\
& =\sum_{\mathrm{n}=1}{ }^{\mathrm{N}} \mathrm{s}_{\mathrm{T}+1, \mathrm{n}}\left(\mathrm{y}_{\mathrm{T}+1, \mathrm{n}}-\beta_{\mathrm{n}^{* *}}\right)-\sum_{\mathrm{n}=1}{ }^{\mathrm{N}} \mathrm{s}_{1 \mathrm{n}}\left(\mathrm{y}_{1 \mathrm{n}}-\beta_{\mathrm{n}^{*}}\right)+\sum_{\mathrm{n}=1}{ }^{\mathrm{N}} \mathrm{s}_{\mathrm{tn}}\left(\beta_{\mathrm{n}^{* *}}-\beta_{\mathrm{n}^{*}}\right) \text {. }
\end{aligned}
$$

Thus the choice of the linking observation $t$ between the two windows will only affect the last term in (65); i.e., the term $\Sigma_{\mathrm{n}=1}{ }^{N} \mathrm{~s}_{\mathrm{tn}}\left(\beta_{\mathrm{n}^{* *}}-\beta_{\mathrm{n}^{*}}\right)$ will in general change as $\mathrm{t}$ changes because the period t expenditure shares $\mathrm{s}_{\mathrm{tn}}$ will usually change as $\mathrm{t}$ changes. However, as the window length $\mathrm{T}$ increases, it is possible that the quality adjustment parameters will

${ }^{59}$ De Haan (2015b) essentially obtained the formula (65). 
stabilize so that $\beta_{\mathrm{n}^{* *}} \approx \beta_{\mathrm{n}^{*}}$ for $\mathrm{n}=1, \ldots, \mathrm{N} .{ }^{60}$ In this case, the last term on the right hand side of (65) will be close to 0 and it will not matter much which period is chosen as the linking period. It can also be seen that in the case where the expenditure shares are constant for all $\mathrm{T}+1$ periods, (65) simplifies to the following weighted Jevons formula:

(66) $\ln \pi_{\mathrm{T}+1}(\mathrm{t})=\sum_{\mathrm{n}=1}{ }^{\mathrm{N}} \mathrm{s}_{\mathrm{n}}\left(\mathrm{y}_{\mathrm{T}+1, \mathrm{n}}-\mathrm{y}_{1 \mathrm{n}}\right)$;

$\mathrm{t}=2,3, \ldots, \mathrm{T}$

where $s_{n}$ is the constant share for commodity $n$ for $n=1, \ldots, N$. Thus in the case of constant expenditure shares, the WTPD price level estimate for period $\mathrm{T}+1$ will be independent of the choice of the link period.

In the general case where the shares are not constant, it can be seen that we are faced with the same set of problems that were discussed in section 5: we could choose period 2, $\mathrm{T}$ or $(\mathrm{T}+1) / 2$ (if $\mathrm{T}$ is odd) as the linking period or we could take the geometric average of the $\mathrm{T}-1$ estimates for $\pi_{\mathrm{T}+1}$ defined by (65). ${ }^{61}$ In the context of very variable price data with little or no trends, choosing the mean estimator for $\pi_{\mathrm{T}+1}$ is probably a satisfactory linking strategy.

Finally, suppose the price and quantity data for period $\mathrm{T}+1$ are identical to the price and quantity data for some period t such that $2 \leq \mathrm{t} \leq \mathrm{T}$; i.e., we have $\mathrm{t}$ such that:

$\mathrm{s}_{\mathrm{T}+1, \mathrm{n}}=\mathrm{s}_{\mathrm{tn}} ; \mathrm{p}_{\mathrm{T}+1, \mathrm{n}}=\mathrm{p}_{\mathrm{tn}} ; \mathrm{n}=1, \ldots, \mathrm{N}$.

Suppose further that we link the two windows at this observation $\mathrm{t}$. The identity test for multilateral indexes requires that $\pi_{\mathrm{T}+1}(\mathrm{t})=\pi_{\mathrm{t}}$ where $\pi_{\mathrm{T}+1}(\mathrm{t})$ is defined by (65) and $\pi_{\mathrm{t}}$ is defined by (50). Using equation (65) for period t, we calculate $\ln \pi_{\mathrm{T}+1}(\mathrm{t})$ minus $\ln \pi_{\mathrm{t}}$ as follows:

$$
\begin{aligned}
\ln \pi_{\mathrm{T}+1}(\mathrm{t})-\ln \pi_{\mathrm{t}} & =\ln \mathrm{a}_{\mathrm{T}+1^{* *}}-\ln \mathrm{a}_{\mathrm{t}^{* *}} \\
& =\alpha_{\mathrm{T}+1^{* *}}-\alpha_{\mathrm{t}^{* *}} \\
& =\sum_{\mathrm{n}=1}{ }^{\mathrm{N}} \mathrm{s}_{\mathrm{T}+1, \mathrm{n}}\left(\mathrm{y}_{\mathrm{T}+1, \mathrm{n}}-\beta_{\mathrm{n}^{* *}}\right)-\Sigma_{\mathrm{n}=1}{ }^{\mathrm{N}} \mathrm{s}_{\mathrm{tn}}\left(\mathrm{y}_{\mathrm{tn}}-\beta_{\mathrm{n}^{* *}}\right) \\
& =0
\end{aligned}
$$

\footnotetext{
${ }^{60}$ This observation is likely to be true in a stable market situation where the number of varieties remains constant. However, this situation is not likely to occur in practice due to the appearance of new items and the disappearance of existing items; i.e., up to now, we have neglected the new goods problem. Thus if the window length $\mathrm{T}$ is chosen to be very large, the lack of matching items becomes a problem. Our methodology up to this point has assumed that prices $\mathrm{p}_{\mathrm{tn}}$ and shares $\mathrm{s}_{\mathrm{tn}}$ are all positive. It can be shown that our analysis of the various multilateral methods remains valid when some shares $\mathrm{s}_{\mathrm{tn}}$ are equal to zero provided that the corresponding reservation prices $p_{t n}$ remain positive; see Hicks $(1940 ; 114)$ on the concept of reservation prices. Hausman (1997) estimated these reservation prices econometrically for new breakfast cereals. For a diagram explaining the Hicks methodology, see Diewert (1996; 32). However, the estimation of reservation prices is not a practical alternative for statistical agencies. Feenstra's (1994) CES methodology avoids the estimation of reservation prices since his methodology assumes that they are infinite but in general, an estimate for the elasticity of substitution is required. A more complete treatment of the problems associated with modeling quality change is beyond the scope of this paper.

${ }^{61}$ See definition (26) which also applies in the present context but using the new definitions for the $\pi_{\mathrm{t}}$.
} 
where the last equation follows using assumptions (67). Thus if the price and quantity data for period $\mathrm{T}+1$ are exactly equal to the price and quantity data for period $t$, then linking the windows at observation $t$ will preserve the identity test over the two windows; i.e., under these conditions it makes sense to link the two windows at period t. This logic carries over to situations where the price and quantity data of period t are closest (in some metric) to the price and quantity data of period $\mathrm{T}+1$ : it makes sense to link the windows at the observation which has the most "similar" price and quantity data. ${ }^{62}$ The main advantage of this method is that it will preserve a Walsh type multiperiod identity test across the two windows. The main drawback to this method of linking is that it depends on a relative price and expenditure share similarity measure and it may be difficult to achieve consensus on exactly what the appropriate measure is.

\section{The Geary-Khamis Multilateral Method}

The GK multilateral method was introduced by Geary (1958), and Khamis (1970) showed that the equations that define the method have a positive solution under certain conditions. A modification of this method has been adapted to the time series context and is being used to construct some components of the Dutch CPI; see Chessa (2016).

The GK system of equations for $\mathrm{T}$ time periods involves the $\mathrm{T}$ (unnormalized) price levels $\mathrm{P}_{1}, \mathrm{P}_{2}, \ldots, \mathrm{P}_{\mathrm{T}}$ and a set of $\mathrm{N}$ quality adjustment factors $\mathrm{b}_{1}, \mathrm{~b}_{2}, \ldots, \mathrm{b}_{\mathrm{N}} \cdot{ }^{63}$ Let $\mathrm{p}^{\mathrm{t}}$ and $\mathrm{q}^{\mathrm{t}}$ denote the $\mathrm{N}$ dimensional price and quantity vectors for period $\mathrm{t}$ (with components $\mathrm{P}_{\mathrm{tn}}$ and $\mathrm{q}_{\mathrm{tn}}$ as usual) and let $\mathrm{s}^{\mathrm{t}}$ (with components $\mathrm{s}_{\mathrm{tn}}$ ) denote the period t expenditure share vector. Define the total consumption vector q over the entire window as the following simple sum of the period by period consumption vectors:

(69) $\mathrm{q} \equiv \sum_{\mathrm{t}=1}{ }^{\mathrm{T}} \mathrm{q}^{\mathrm{t}}$

where $\mathrm{q} \equiv\left[\mathrm{q}_{1}, \mathrm{q}_{2}, \ldots, \mathrm{q}_{\mathrm{N}}\right]$. The equations which determine the price levels $\mathrm{P}_{\mathrm{t}}$ and quality adjustment factors $b_{n}$ (up to a scalar multiple) are the following ones:

(70) $b_{\mathrm{n}}=\sum_{\mathrm{t}=1}^{\mathrm{T}}\left[\mathrm{q}_{\mathrm{tn}} / \mathrm{q}_{\mathrm{n}}\right]\left[\mathrm{p}_{\mathrm{tn}} / \mathrm{P}_{\mathrm{t}}\right]$;

(71) $P_{t}=p^{t} \cdot q^{t} / b \cdot q^{t}$;

$$
\begin{aligned}
\mathrm{n} & =1, \ldots, \mathrm{N} ; \\
\mathrm{t} & =1, \ldots, \mathrm{T}
\end{aligned}
$$

where $b \equiv\left[b_{1}, \ldots, b_{N}\right]$ is the vector of GK quality adjustment factors. The share of period t's purchases of commodity $\mathrm{n}$ in total sales of commodity $\mathrm{n}$ over all $\mathrm{T}$ periods can be defined as $\mathrm{S}_{\mathrm{tn}} \equiv \mathrm{q}_{\mathrm{tn}} / \mathrm{q}_{\mathrm{n}}$ for $\mathrm{n}=1, \ldots, \mathrm{N}$ and $\mathrm{t}=1, \ldots, \mathrm{T}$. Thus $\mathrm{b}_{\mathrm{n}} \equiv \Sigma_{\mathrm{t}=1}{ }^{\mathrm{T}} \mathrm{S}_{\mathrm{tn}}\left[\mathrm{p}_{\mathrm{tn}} / \mathrm{P}_{\mathrm{t}}\right]$ is a (real) share weighted average of the inflation adjusted prices $\mathrm{P}_{\mathrm{t}} / \mathrm{P}_{\mathrm{t}}$ for commodity $\mathrm{n}$ over all $\mathrm{T}$ periods. The period t quality adjusted sum of quantities sold, $\mathrm{b} \cdot \mathrm{q}^{\mathrm{t}}=\sum_{\mathrm{n}=1}{ }^{\mathrm{N}} \mathrm{b}_{\mathrm{n}} \mathrm{q}_{\mathrm{t}}$, is divided into the value of period $t$ sales, $\mathrm{p}^{\mathrm{t}} \cdot \mathrm{q}^{\mathrm{t}}=\Sigma_{\mathrm{n}=1}{ }^{\mathrm{N}} \mathrm{p}_{\mathrm{tn}} \mathrm{q}_{\mathrm{tn}}$, in order to obtain the period $\mathrm{t}$ (unnormalized) price level, $\mathrm{P}_{\mathrm{t}}$.

\footnotetext{
${ }^{62}$ As in section 5, the exact result (68) can be extended to the case where the price data of period $\mathrm{T}+1$ is proportional to the price data of period $t$.

${ }^{63}$ In the international context, the $b_{n}$ are known as international commodity reference prices.
} 
It can be seen that if a solution to equations (70) and (71) exists, then if all of the period price levels $\mathrm{P}_{\mathrm{t}}$ are multiplied by a positive scalar $\lambda$ say and all of the quality adjustment factors $b_{n}$ are divided by the same $\lambda$, then another solution to (70) and (71) is obtained. Hence, the $b_{n}$ and $P_{t}$ are only determined up to a scalar multiple and an additional normalization is required such as $\mathrm{P}_{1}=1$ or $\mathrm{b}_{\mathrm{N}}=1$ is required to determine a unique solution to the system of equations defined by (70) and (71). It can also be shown that only $\mathrm{N}+\mathrm{T}-1$ of the $\mathrm{N}+\mathrm{T}$ equations in (70) and (71) are independent.

Once the price levels $\mathrm{P}_{\mathrm{t}}$ have been determined, the real expenditure or volume for period $t$, $\mathrm{Q}_{\mathrm{t}}$, can be defined as the period $\mathrm{t}$ value of sales, $\mathrm{p}^{\mathrm{t}} \cdot \mathrm{q}^{\mathrm{t}}$, divided by its period $\mathrm{t}$ price level, $\mathrm{P}_{\mathrm{t}}{ }^{64}$

(72) $Q_{t}=p^{t} \cdot q^{t} / P_{t}$; $=\mathrm{b} \cdot \mathrm{q}^{\mathrm{t}}$

$\mathrm{t}=1, \ldots, \mathrm{T}$

using (71).

The second set of equations in (72) are the equations which characterize an additive method; i.e., aggregate quantity or volume in each period is a quality adjusted sum of the individual quantities. Hence an implication of the GK model is that it is consistent with utility maximizing purchasers who have a linear utility function. We encountered this situation in section 6 , in the case where the error terms $\varepsilon_{\mathrm{tn}}$ in equations (33) were all equal to 0 . In this situation, the WTPD multilateral estimate for the period t volume was also given by (72) except that the definition for the b vector in equations (58) was different. Thus the GK estimates lead to an additive system with the result that these estimates can approximate the results that are based on a superlative index if substitutability between the products in the aggregate is very high. ${ }^{65}$ Thus in general, we would expect the GK price level estimates to suffer from at least some substitution bias. Furthermore, in general, the longer is the window length $\mathrm{T}$, the bigger will be the substitution bias for at least some observations.

We now discuss alternative methods for obtaining a solution to equations (70) and (71). A traditional method for obtaining a solution is to iterate between these equations. Thus set $b=1_{N}$, a vector of ones and use equations (71) to obtain an initial sequence for the $P_{t}$. Substitute these $P_{t}$ estimates into equations (70) and obtain a sequence of $b_{n}$ estimates. Substitute these $b_{n}$ estimates into equations (71) and obtain a new sequence of $\mathrm{P}_{t}$ estimates. Continue iterating between the two systems until convergence is achieved.

An alternative method is more efficient. Following Diewert (1999; 26), substitute equations (71) into equations (70) and after some simplification, obtain the following system of equations which will determine the components of the $b$ vector:

(73) $\left[\mathrm{I}_{\mathrm{N}}-\mathrm{C}\right] \mathrm{b}=0_{\mathrm{N}}$

\footnotetext{
${ }^{64}$ Khamis (1972; 101) also derived equations (72) in the time series context.

${ }^{65}$ However, we shall soon see that the GK indexes can also approximate the results that are based on a superlative index if substitutability between products is very low.
} 
where $\mathrm{I}_{\mathrm{N}}$ is the $\mathrm{N}$ by $\mathrm{N}$ identity matrix, $0_{\mathrm{N}}$ is a vector of zeros of dimension $\mathrm{N}$ and the $\mathrm{C}$ matrix is defined as follows:

(74) $\mathrm{C} \equiv \hat{q}^{-1} \Sigma_{\mathrm{t}=1}^{\mathrm{T}} \mathrm{s}^{\mathrm{t}} \mathrm{q}^{\mathrm{tT}}$

where $\hat{q}$ is an $\mathrm{N}$ by $\mathrm{N}$ diagonal matrix with the elements of the total window purchase vector q running down the main diagonal and $\hat{q}^{-1}$ denotes the inverse of this matrix, $\mathrm{s}^{\mathrm{t}}$ is the period $t$ expenditure share column vector and $q^{t \mathbf{T}}$ is the transpose of the column vector $\mathrm{q}^{\mathrm{t}}$ and is equal to the row vector of quantities purchased during period t. Note that the $\mathrm{N}$ by $\mathrm{N}$ matrix $\mathrm{s}^{\mathrm{t}} \mathrm{q}^{\mathrm{tT}}$ has rank 1 for each $\mathrm{t}$. Let $\mathrm{q}^{\mathrm{T}}$ denote the transpose of the column vector $\mathrm{q}$. Then:

$$
\text { (75) } \begin{aligned}
\mathrm{q}^{\mathrm{T}} \mathrm{C} & =\mathrm{q}^{\mathrm{T}} \hat{q}^{-1} \sum_{\mathrm{t}=1}^{\mathrm{T}} \mathrm{s}^{\mathrm{t}} \mathrm{q}^{\mathrm{t} T} \\
& =1_{\mathrm{N}}^{\mathrm{T}} \sum_{\mathrm{t}=1}^{\mathrm{T}} \mathrm{s}^{\mathrm{t}} \mathrm{q}^{\mathrm{T} \mathbf{T}} \\
& =\sum_{\mathrm{t}=1}{ }^{\mathrm{T}} 1_{\mathrm{N}}^{\mathrm{T}} \mathrm{s}^{\mathrm{t}} \mathrm{q}^{\mathrm{t} \mathbf{T}} \\
& =\Sigma_{\mathrm{t}=1}^{\mathrm{T}} \mathrm{q}^{\mathrm{T}} \\
& =\mathrm{q}^{\mathrm{T}}
\end{aligned}
$$

since $1_{\mathrm{N}} \mathrm{s}^{\mathrm{t}}=1$ for each $\mathrm{t}$ using definition (69).

Using (75), we have $q^{T}\left[I_{N}-C\right]=q^{T}-q^{T}=0_{N}$. Thus the matrix $I_{N}-C$ is singular which implies that the $\mathrm{N}$ equations in (73) are not all independent. In particular, if the first $\mathrm{N}-1$ equations in (73) are satisfied, then the last equation in (73) will also be satisfied. It can also be seen that the $\mathrm{N}$ equations in (73) are homogeneous of degree one in the components of the vector $b$. Thus to obtain a unique b solution to (73), set $b_{N}$ equal to 1 , drop the last equation in (73) and solve the remaining $\mathrm{N}-1$ equations for $\mathrm{b}_{1}, \mathrm{~b}_{2}, \ldots, \mathrm{b}_{\mathrm{N}-1}$. This is the solution method we used in subsequent sections of this study. ${ }^{66}$

Once the vector of quality adjustment factors $\mathrm{b}$ has been determined, the period $\mathrm{t}$ (unnormalized) price and quantity levels, $\mathrm{P}_{\mathrm{t}}$ and $\mathrm{Q}_{\mathrm{t}}$, are defined using equations (71) and (72); i.e., we have $P_{t} \equiv \mathrm{p}^{\mathrm{t}} \cdot \mathrm{q}^{\mathrm{t}} / \mathrm{b} \cdot \mathrm{q}^{\mathrm{t}}$ and $\mathrm{Q}_{\mathrm{t}} \equiv \mathrm{b} \cdot \mathrm{q}^{\mathrm{t}}$ for each period $\mathrm{t}$ in the window. As usual, the sequence of normalized price levels can be defined by $\pi_{t} \equiv \mathrm{P}_{\mathrm{t}} / \mathrm{P}_{1}$ for $\mathrm{t}=1, \ldots, \mathrm{T}$.

Equations (72) show that the GK multilateral indexes will be consistent with the economic approach to index number theory provided that purchasers maximize the linear utility function, $\mathrm{f}(\mathrm{q}) \equiv \mathrm{b} \cdot \mathrm{q}=\sum_{\mathrm{n}=1}{ }^{\mathrm{N}} \mathrm{b}_{\mathrm{n}} \mathrm{q}_{\mathrm{n}}$. However, perhaps somewhat surprisingly, the GK indexes will also be consistent with the economic approach to index number theory if purchasers have Leontief or no substitution preferences. ${ }^{67}$ Thus suppose that purchasers

\footnotetext{
${ }^{66}$ In order to establish that the solution $b_{n}$ are all positive, use the argument in Diewert (1999; 27) which proceeds as follows. From (75), $\mathrm{q}$ is a strictly positive solution to $\mathrm{q}^{\mathrm{T}} \mathrm{C}=\mathrm{q}^{\mathrm{T}} \mathrm{I}_{\mathrm{N}}=1 \mathrm{q}^{\mathrm{T}}$ and hence $\mathrm{q}$ is a strictly positive left eigenvector of the strictly positive matrix $\mathrm{C}$ which corresponds to the positive eigenvalue 1 . Hence by the Perron (1907) Frobenius (1909) Theorem, $\lambda=1$ is the maximal eigenvalue of $C$ and thus $C$ also has a strictly positive right eigenvector $\mathrm{b}$ which corresponds to this positive eigenvalue. Hence $\mathrm{b}$ satisfies the equation $\mathrm{Cb}=1 \mathrm{~b}=\mathrm{I}_{\mathrm{N}} \mathrm{b}$ or $\left[\mathrm{I}_{\mathrm{N}}-\mathrm{C}\right] \mathrm{b}=0_{\mathrm{N}}$ which is (73).

${ }^{67}$ Diewert $(1999 ; 27)$ showed that linear and Leontief preferences are the only preferences for which the GK system is exact.
} 
of the $\mathrm{N}$ products have preferences which can be represented by the utility function $\mathrm{f}$ defined as follows:

(76) $f\left(q_{1}, q_{2}, \ldots, q_{N}\right) \equiv \min \left\{q_{n} / \beta_{n}: n=1, \ldots, N\right\}$

where the $\beta_{\mathrm{n}}$ are positive constants. Let $\beta \equiv\left[\beta_{1}, . ., \beta_{\mathrm{N}}\right]$ the vector of these coefficients. The unit cost function that is dual to these preferences, $c(p)$, turns out to be $c(p) \equiv \beta \cdot p$ where $p$ is the vector of prices that purchasers face. If purchasers in period t face the price vector $\mathrm{p}^{\mathrm{t}}$ and chose the quantity vector $\mathrm{q}^{\mathrm{t}}$ which maximizes the utility function $\mathrm{f}(\mathrm{q})$ defined by (76) so that period t purchaser utility is $u_{t} \equiv f\left(q^{t}\right)$, then it can be shown that $p^{t}, q^{t}$ and $u_{t}$ satisfy the following equations:

(77) $\mathrm{q}^{\mathrm{t}}=\nabla_{\mathrm{p}} \mathrm{c}\left(\mathrm{p}^{\mathrm{t}}\right) \mathrm{u}_{\mathrm{t}}=\beta \mathrm{u}_{\mathrm{t}}$

$\mathrm{t}=1, \ldots, \mathrm{T}$

where $\nabla_{\mathrm{p}} \mathrm{c}\left(\mathrm{p}^{\mathrm{t}}\right)$ is the vector of first order partial derivatives of the unit cost function $\mathrm{c}\left(\mathrm{p}^{\mathrm{t}}\right)$ $\equiv \Sigma_{\mathrm{n}=1}{ }^{\mathrm{N}} \beta_{\mathrm{n}} \mathrm{p}_{\mathrm{n}}{ }^{\mathrm{t}}$ and $\mathrm{u}_{\mathrm{t}}$ is the period t utility level. Note that equations (77) imply that the quantity vectors vary in strict proportion over the T time periods. Recall (69) where the vector of total commodity sales over the $\mathrm{T}$ periods, $\mathrm{q} \equiv \sum_{\mathrm{t}=1}^{\mathrm{T}} \mathrm{q}^{\mathrm{t}}$, was defined. It can be seen that conditions (77) imply that period t's share of commodity $n$ in total sales of commodity n over the T periods, say $\sigma_{\mathrm{tn}} \equiv \mathrm{q}_{\mathrm{tn}} / \mathrm{q}_{\mathrm{n}}$, does not depend on $\mathrm{n}$. Thus we have the existence of shares $\sigma_{\mathrm{t}}=\sigma_{\mathrm{tn}}$ for $\mathrm{n}=1, \ldots, \mathrm{n}$ and $\mathrm{t}=1, \ldots, \mathrm{T}$ such that period t's quantity vector $\mathrm{q}^{\mathrm{t}}$ is equal to $\sigma_{\mathrm{t}}$ times the vector of total sales q; i.e., we have:

(78) $\mathrm{q}^{\mathrm{t}}=\sigma_{\mathrm{t}} \mathrm{q}$;

(79) $1=\sum_{\mathrm{t}=1}^{\mathrm{T}} \sigma_{\mathrm{t}}$.

$\mathrm{t}=1, \ldots, \mathrm{T}$

We will use equations (78) and (79) to exhibit an explicit solution to equation (73). Equation (73) can be rewritten as follows:

$$
\text { (80) } \begin{aligned}
\mathrm{b} & =\mathrm{Cb} \\
& =\hat{q}^{-1} \Sigma_{\mathrm{t}=1}{ }^{\mathrm{T}} \mathrm{s}^{\mathrm{t}} \mathrm{q}^{\mathrm{T}} \mathrm{b} \\
& =\hat{q}^{-1} \Sigma_{\mathrm{t}=1}{ }^{\mathrm{T}} \mathrm{s}^{\mathrm{t}} \sigma_{\mathrm{t}} \mathrm{q}^{\mathrm{T}} \mathrm{b} \\
& =\hat{q}^{-1} \Sigma_{\mathrm{t}=1}{ }^{\mathrm{T}} \sigma_{\mathrm{t}} \mathrm{s}^{\mathrm{t}} \mathrm{q} \cdot \mathrm{b} .
\end{aligned}
$$

using definition (74) for C using (78)

We are allowed one normalization on the components of the vector b. We choose the following normalization:

(81) $b \cdot q=1$.

Equation $\mathrm{n}$ in the matrix equation (80) can be rewritten as follows if we make use of the normalization (81):

(82) $\mathrm{b}_{\mathrm{n}} \equiv \mathrm{q}_{\mathrm{n}}^{-1} \Sigma_{\mathrm{t}=1}^{\mathrm{T}} \sigma_{\mathrm{t}} \mathrm{s}_{\mathrm{tn}}$;

$$
\mathrm{n}=1, \ldots, \mathrm{N} .
$$


We need to check that the $b_{n}$ defined by (82) satisfy (81); i.e., we need to show that $q \cdot b=$ $\mathrm{q}^{\mathrm{T}} \mathrm{b}=1$. Using definitions (82), we have:

$$
\begin{aligned}
\mathrm{q}^{\mathrm{T}} \mathrm{b} & =1_{\mathrm{N}}{ }^{\mathrm{T}} \sum_{\mathrm{t}=1}{ }^{\mathrm{T}} \sigma_{\mathrm{t}} \mathrm{s}^{\mathrm{t}} \\
& =\sum_{\mathrm{t}=1}{ }^{\mathrm{T}} \sigma_{\mathrm{t}} 1_{\mathrm{N}} \mathrm{T}^{\mathrm{t}} \mathrm{s}^{\mathrm{t}} \\
& =\sum_{\mathrm{t}=1}^{\mathrm{T}} \sigma_{\mathrm{t}} \\
& =1
\end{aligned}
$$$$
\text { since } 1_{N}{ }^{T} s^{t}=\Sigma_{n=1}{ }^{N} s_{t n}=1 \text { for } t=1, \ldots, T
$$$$
\text { using (79). }
$$

Thus the $b_{n}$ defined by (82) satisfy equations (70) subject to the normalization (81) and these $b_{n}$ can be used to define the period $t$ (unnormalized) price levels $P_{t}$ using equations (71); i.e., define $P_{t} \equiv p^{t} \cdot q^{t} / b \cdot q^{t}$ for $t=1, \ldots, T$. Finally, the sequence of normalized price levels can be defined by $\pi_{t} \equiv P_{t} / P_{1}$ for $t=1, \ldots, T$. Thus the GK price levels are consistent with purchasers having either linear or Leontief preferences over their purchases of the $\mathrm{N}$ commodities.

When $T=2$, Geary $(1958 ; 98)$ showed that $\pi_{2} \equiv \mathrm{P}_{2} / \mathrm{P}_{1}$ is equal to the following expression:

$$
\mathrm{P}_{2} / \mathrm{P}_{1} \equiv\left[\Sigma_{\mathrm{n}=1}{ }^{\mathrm{N}} \mathrm{h}\left(\mathrm{q}_{1 \mathrm{n}}, \mathrm{q}_{2 \mathrm{n}}\right) \mathrm{p}_{2 \mathrm{n}}\right] /\left[\Sigma_{\mathrm{n}=1}{ }^{\mathrm{N}} \mathrm{h}\left(\mathrm{q}_{1 \mathrm{n}}, \mathrm{q}_{2 \mathrm{n}}\right) \mathrm{p}_{1 \mathrm{n}}\right] \equiv \mathrm{P}_{\mathrm{GK}}\left(\mathrm{p}^{1}, \mathrm{p}^{2}, \mathrm{q}^{1}, \mathrm{q}^{2}\right)
$$

where $\mathrm{h}\left(\mathrm{q}_{1 \mathrm{n}}, \mathrm{q}_{2 \mathrm{n}}\right) \equiv 2 \mathrm{q}_{1 \mathrm{n}} \mathrm{q}_{2 \mathrm{n}} /\left[\mathrm{q}_{1 \mathrm{n}}+\mathrm{q}_{2 \mathrm{n}}\right]$ is the harmonic mean of $\mathrm{q}_{1 \mathrm{n}}$ and $\mathrm{q}_{2 \mathrm{n}}$. The GK bilateral price index $\mathrm{P}_{\mathrm{GK}}$ can be compared to the Walsh $(1901 ; 398)(1921 ; 97)$ bilateral price index, $\mathrm{P}_{\mathrm{W}}$, defined as follows:

$$
\mathrm{P}_{\mathrm{W}}\left(\mathrm{p}^{1}, \mathrm{p}^{2}, \mathrm{q}^{1}, \mathrm{q}^{2}\right) \equiv\left[\Sigma_{\mathrm{n}=1}{ }^{\mathrm{N}}\left(\mathrm{q}_{1 \mathrm{n}} \mathrm{q}_{2 \mathrm{n}}\right)^{1 / 2} \mathrm{p}_{2 \mathrm{n}}\right] /\left[\sum_{\mathrm{n}=1}{ }^{\mathrm{N}}\left(\mathrm{q}_{1 \mathrm{n}} \mathrm{q}_{2 \mathrm{n}}\right)^{1 / 2} \mathrm{p}_{1 \mathrm{n}}\right] \text {. }
$$

The Geary-Khamis and Walsh bilateral price indexes are both basket indexes; i.e., they price out a basket of commodities using the prices of period 2 in the numerator and the prices of period 1 in the denominator. The basket coefficient for commodity $\mathrm{n}$ is the geometric average $\left(\mathrm{q}_{1 \mathrm{n}} \mathrm{q}_{2 \mathrm{n}}\right)^{1 / 2}$ for the Walsh index and the harmonic average $\mathrm{h}\left(\mathrm{q}_{1 \mathrm{n}}, \mathrm{q}_{2 \mathrm{n}}\right)$ for the Geary-Khamis index. Diewert (1976; 133-134) showed that the Walsh index is a superlative index and thus it should handle substitution effects in a satisfactory manner. It is straightforward to show ${ }^{68}$ that $\mathrm{P}_{\mathrm{GK}}\left(\mathrm{p}^{1}, \mathrm{p}^{2}, \mathrm{q}^{1}, \mathrm{q}^{2}\right)$ approximates $\mathrm{P}_{\mathrm{W}}\left(\mathrm{p}^{1}, \mathrm{p}^{2}, \mathrm{q}^{1}, \mathrm{q}^{2}\right)$ to the second order around any strictly positive point where $p^{1}=p^{2}>>0_{N}$ and $q^{1}=q^{2}>>0_{N}$ and thus for small or moderate variations in prices and quantities, the two indexes will be close to each other. However, in the scanner data context where there are sales of products, the variations in prices and quantities can be huge going from one period to the next if the period length is a month or less and thus the GK index can differ considerably from a superlative bilateral price index under these conditions. We will illustrate this point with a numerical example.

Suppose $\mathrm{N}=2$ and $\mathrm{T}=2$. Suppose that the period 1 and 2 price and quantity vectors are equal to $\mathrm{p}^{1} \equiv\left[\mathrm{p}_{11}, \mathrm{p}_{12}\right] \equiv[2,2] ; \mathrm{p}^{2} \equiv\left[\mathrm{p}_{21}, \mathrm{p}_{22}\right] \equiv[2,17 / 16] ; \mathrm{q}^{1} \equiv\left[\mathrm{q}_{11}, \mathrm{q}_{12}\right] \equiv[8,8] ; \mathrm{q}^{2} \equiv$

\footnotetext{
${ }^{68}$ This result can be established using the techniques in Diewert (1978; 897). Thus $\mathrm{P}_{\mathrm{GK}}$ is a pseudosuperlative index.
} 
$\left[\mathrm{q}_{21}, \mathrm{q}_{22}\right] \equiv[1,16] .{ }^{69}$ Thus in period 1 , both products sell at the price 2 and 8 units of each product are purchased in the market under consideration. In period 2, item 2 goes on sale at roughly one half of the non-sale price and sales of this product jump to 16 units while the price of product one remains unchanged and sales of it fall to 1 unit. Using these price and quantity vectors and definitions (84) and (85), it can be shown that $\mathrm{P}_{\mathrm{GK}}\left(\mathrm{p}^{1}, \mathrm{p}^{2}, \mathrm{q}^{1}, \mathrm{q}^{2}\right)=$ 0.598 and $\mathrm{P}_{\mathrm{W}}\left(\mathrm{p}^{1}, \mathrm{p}^{2}, \mathrm{q}^{1}, \mathrm{q}^{2}\right)=0.625$. Thus the superlative Walsh index is 4.5 percentage points above the corresponding Geary-Khamis index for this very reasonable example. ${ }^{70}$ Thus it is likely that the existence of discounted prices will cause the GK index to have a downward bias in the periods when the discounts took place as compared to a superlative index. For a discussion of the test performance of the GK and Fisher bilateral indexes, see Diewert (1999). ${ }^{71}$

In summary: from the viewpoint of the economic approach to index number theory, we cannot endorse the use of the GK multilateral index in the time series context because it is exactly consistent with the economic approach only if purchaser preferences are either linear so that all commodities in the class of commodities under consideration are perfect substitutes or if purchaser preferences are Leontief, where there is a complete lack of substitutability between the commodities. The GK system is dominated by the WTPD multilateral system because the latter system is exact not only for linear preferences but also for Cobb-Douglas preferences.

\section{Constant Elasticity of Substitution Preferences}

There is another index number formula that is used in the first stage of price aggregation by economists, marketing researchers and statistical agencies and that is the Constant Elasticity of Substitution (CES) functional form. ${ }^{72}$ We will use this functional form in subsequent sections of this paper in order to generate some artificial data sets. Thus in the present section, some of the properties of this functional form are explained.

Using the economic approach to index number theory, it is assumed that purchaser preferences can be represented by a utility function $\mathrm{f}(\mathrm{q})$ or by the unit cost function $\mathrm{c}(\mathrm{p})$ which corresponds to the utility function. The CES unit cost function has the following functional form:

\footnotetext{
${ }^{69}$ These prices and quantities are consistent with purchasers maximizing the utility function $\mathrm{f}\left(\mathrm{q}_{1}, \mathrm{q}_{2}\right) \equiv \mathrm{q}_{1}+$ $\mathrm{q}_{2}+(1 / 2) \mathrm{q}_{1}{ }^{1 / 2} \mathrm{q}_{2}{ }^{1 / 2}$. Diewert (1976; 133-135) showed that the Walsh price index defined by (77) is exactly equal to the true cost of living index for these preferences, which is equal to $c\left(\mathrm{p}^{2}\right) / \mathrm{c}\left(\mathrm{p}^{1}\right)$ where $\mathrm{c}$ is the unit cost function which is dual to the utility function $\mathrm{f}\left(\mathrm{q}_{1}, \mathrm{q}_{2}\right)$ defined above.

${ }^{70}$ The Fisher ideal index for this example is equal to 0.654 which is $9.3 \%$ above $\mathrm{P}_{\mathrm{GK}}$ for this example.

${ }^{71}$ Diewert (1999; 27-28) summarized the test performance of $\mathrm{P}_{\mathrm{GK}}$ defined by (76) as follows: "The Fisher bilateral price index satisfies all twenty of the tests listed by Diewert (1992; 214-221), while the GearyKhamis bilateral price index fails six of these tests: PT7 (homogeneity of degree zero in current period quantities), PT8 (homogeneity of degree zero in base period prices), PT13 (price reversal or price weights symmetry), PT16 (the Paasche and Laspeyres bounding test), PT19 (monotonicity in base period quantities) and PT20 (monotonicity in current period quantities). The failure of bilateral test PT13 is not important, but the failure of the other tests is troubling."

${ }^{72}$ See Feenstra (1994) for an excellent exposition on how the CES functional form can be used to measure the gains from the introduction of new goods and services. The Bureau of Labor Statistics (2014) has recently decided to use this functional form to construct elementary indexes for at least some strata.
} 
(86)

$$
\begin{aligned}
\mathrm{c}\left(\mathrm{p}_{1}, \ldots, \mathrm{p}_{\mathrm{N}}\right) & \equiv\left[\sum_{\mathrm{n}=1}^{\mathrm{N}} \alpha_{\mathrm{n}} \mathrm{p}_{\mathrm{n}}{ }^{1-\sigma}\right]^{1 /(1-\sigma)} & & \text { if } \sigma \geq 0 \text { and } \sigma \neq 1 \\
& \equiv \prod_{\mathrm{n}=1}{ }^{N} p_{n}^{\alpha_{n}} & & \text { if } \sigma=1
\end{aligned}
$$

where $\sigma$ and the $\alpha_{n}$ are positive parameters. with $\sum_{n=1}{ }^{N} \alpha_{n}=1$. The unit cost function defined by (86) corresponds to a Constant Elasticity of Substitution (CES) utility function which was introduced into the economics literature by Arrow, Chenery, Minhas and Solow (1961). The parameter $\sigma$ is the elasticity of substitution; when $\sigma=0$, the unit cost function defined by (86) becomes linear in prices and hence corresponds to a fixed coefficients or Leontief utility function which exhibits 0 substitutability between all commodities. When $\sigma=1$, the corresponding aggregator or utility function is a CobbDouglas function. When $\sigma$ approaches $+\infty$, the corresponding aggregator function $f$ approaches a linear aggregator function which exhibits infinite substitutability between each pair of inputs. The CES unit cost function defined by (86) is not a fully flexible functional form (unless the number of commodities $\mathrm{N}$ being aggregated is 2) but it is frequently used to aggregate commodities in a group of commodities which are thought to be highly substitutable with each other.

Given a twice continuously differentiable cost function $\mathrm{c}(\mathrm{p})=\mathrm{c}\left(\mathrm{p}_{1}, \ldots, \mathrm{p}_{\mathrm{N}}\right)$, the elasticity of substitution between commodities $i$ and $j$ (where $i \neq j$ ) is defined as follows:

$$
\sigma_{i j} \equiv c(p) c_{i j}(p) / c_{i}(p) c_{j}(p)
$$

where $\mathrm{c}_{\mathrm{i}}(\mathrm{p}) \equiv \partial \mathrm{c}(\mathrm{p}) / \partial \mathrm{p}_{\mathrm{i}}$ denotes the first order partial derivative of $\mathrm{c}(\mathrm{p})$ with respect to $\mathrm{p}_{\mathrm{i}}$ and $\mathrm{c}_{\mathrm{ij}}(\mathrm{p}) \equiv \partial^{2} \mathrm{c}(\mathrm{p}) / \partial \mathrm{p}_{\mathrm{i}} \partial \mathrm{p}_{\mathrm{j}}$ denotes the second order partial derivative of $\mathrm{c}(\mathrm{p})$ with respect to $\mathrm{p}_{\mathrm{i}}$ and $\mathrm{p}_{\mathrm{j}}$. When $\sigma_{\mathrm{ij}}$ is evaluated using the CES unit cost function defined by (86), it is found that $\sigma_{i j}$ equals the parameter $\sigma$ for all pairs of commodities $i$ and $j$; i.e., the elasticity of substitution is a constant for all pairs of commodities.

Suppose that we are given the price vectors $\mathrm{p}^{\mathrm{t}} \equiv\left[\mathrm{p}_{\mathrm{t} 1}, \ldots, \mathrm{p}_{\mathrm{tN}}\right]$ for $\mathrm{t}=1, . ., \mathrm{T}$. Then if purchasers have CES preferences and are minimizing the costs of achieving their utility levels in each period, it will turn out that the components of their period t expenditure share vectors $\mathrm{s}^{\mathrm{t}} \equiv\left[\mathrm{s}_{\mathrm{t} 1}, \ldots, \mathrm{S}_{\mathrm{tN}}\right]$ for $\mathrm{t}=1, \ldots, \mathrm{T}$ will be equal to the following expressions:

(88) $\mathrm{s}_{\mathrm{tn}}=\alpha_{\mathrm{n}} \mathrm{p}_{\mathrm{tn}}^{1-\sigma} /\left[\Sigma_{\mathrm{i}=1}{ }^{\mathrm{N}} \alpha_{\mathrm{i}} \mathrm{P}_{\mathrm{ti}}{ }^{1-\sigma}\right]$;

$$
\mathrm{n}=1, \ldots, \mathrm{N} ; \mathrm{t}=1, \ldots, \mathrm{T} \text {. }
$$

Thus given the price vectors $p^{t}$, the vector of positive parameters $\alpha \equiv\left[\alpha_{1}, \ldots, \alpha_{N}\right]$ whose components sum to unity and the nonnegative parameter $\sigma$ where $\sigma \neq 1$, then the share vectors $s^{t}$ can be computed using equations (88) for $t=1, \ldots, T$. If in addition, we are given total expenditures on the $\mathrm{N}$ commodities for period $\mathrm{t}$, say $\mathrm{e}_{\mathrm{t}}>0$ for $\mathrm{t}=1, \ldots, \mathrm{T}$, then we can compute the components of the CES quantity vector for period $t$, say $\mathrm{q}^{\mathrm{t}}=\left[\mathrm{q}_{\mathrm{t} 1}, \ldots, \mathrm{q}_{\mathrm{t} N}\right]$ for $\mathrm{t}$ $=1, \ldots, \mathrm{T}$ using the following equations:

(89) $\mathrm{q}_{\mathrm{tn}} \equiv \mathrm{e}_{\mathrm{t}} \mathrm{s}_{\mathrm{tn}} / \mathrm{p}_{\mathrm{tn}}$;

$\mathrm{n}=1, \ldots, \mathrm{N} ; \mathrm{t}=1, \ldots, \mathrm{T}$. 
Finally, the CES (unnormalized) period t price levels, $\mathrm{P}_{\mathrm{t}}$, are computed as follows:

(90) $\mathrm{P}_{\mathrm{t}} \equiv \mathrm{c}\left(\mathrm{p}^{\mathrm{t}}\right)=\left[\sum_{\mathrm{n}=1}{ }^{\mathrm{N}} \alpha_{\mathrm{n}} \mathrm{Ptn}^{1-\sigma}\right]^{1 /(1-\sigma)}$; $\mathrm{t}=1, \ldots, \mathrm{T}$.

The corresponding CES (unnormalized) period t quantity levels are defined as follows:

(91) $Q_{t} \equiv e_{t} / P_{t}=p^{t} \cdot q^{t} / P_{t}$; $\mathrm{t}=1, \ldots, \mathrm{T}$.

Of course, the CES normalized price levels can be defined as $\pi_{t} \equiv \mathrm{P}_{\mathrm{t}} / \mathrm{P}_{1}$ for $\mathrm{t}=1, \ldots, \mathrm{T}$. We will use this method for constructing an artificial data set that is consistent with CES preferences in the following section.

\section{The Construction of an Artificial Data Set Using CES Preferences}

The Australian Bureau of Statistics (2016) and the Dutch Central Bureau of Statistics ${ }^{73}$ have done extensive computations using scanner data in order to compare alternative methods for aggregating prices at the first stage of aggregation. A problem with these comparisons is that it is not known which method is closest to the "truth". We will attempt to address this problem, at least in part, by constructing an artificial data set that is exactly consistent with purchasers having CES preferences over a group of related items for a number of time periods. We will then determine how well the various multilateral methods studied earlier in this paper approximate the "true" indexes.

Recall that the CES unit cost function was defined by (86) in the previous section. We now assume that $\mathrm{T}=12$ and $\mathrm{N}=4$. We assume that the parameters $\alpha_{\mathrm{n}}$ which appear in (86) are defined as follows: $\alpha \equiv\left[\alpha_{1}, \alpha_{2}, \alpha_{3}, \alpha_{4}\right] \equiv[0.2,0.2,0.2,0.4]$. The elasticity of substitution parameter $\sigma$ will take on the values $0,0.5,1,2,4,10$ and 20. In the scanner data context, it is likely that $\sigma$ is between 1 and $5 .{ }^{74}$

In order to calculate the period t (unnormalized) CES price level $\mathrm{P}_{t} \equiv \mathrm{c}\left(\mathrm{p}^{\mathrm{t}}\right)$, where $\mathrm{c}(\mathrm{p})$ is defined by (86), we require information on the period $t$ vector of prices, $\mathrm{p}^{\mathrm{t}} \equiv$ $\left[\mathrm{p}_{\mathrm{t} 1}, \mathrm{p}_{\mathrm{t} 2}, \mathrm{p}_{\mathrm{t} 3}, \mathrm{p}_{\mathrm{t} 4}\right]$ for $\mathrm{t}=1, \ldots, 12$. These prices are listed in Table 3 below. Once the unnormalized CES price levels $\mathrm{P}_{\mathrm{t}}$ have been constructed, the normalized CES price levels can be calculated as $\pi_{\mathrm{CES}}{ }^{\mathrm{t}} \equiv \mathrm{P}_{t} / \mathrm{P}_{1}$ for $\mathrm{t}=1, \ldots, 12$. In order to calculate the CES quantity vectors that match up with the given CES price vectors, we also require information on total expenditures $e_{t}$ on the four commodities for each period t. These exogenously given expenditures are also listed in Table 3.

\footnotetext{
${ }^{73}$ See de Haan and van der Grient (2011) and de Haan (2015a).

${ }^{74}$ See the empirical evidence on the magnitude of $\sigma$ using Australian scanner data in Ivancic, Diewert and Fox (2010).
} 
Table 3: Price and Expenditure Data for the Artificial Data Set

\begin{tabular}{cccccc}
\hline $\mathbf{t}$ & $\mathbf{p}_{\mathbf{t} 1}$ & $\mathbf{p}_{\mathbf{t} 2}$ & $\mathbf{p}_{\mathbf{t} 3}$ & $\mathbf{p}_{\mathbf{t} 4}$ & $\mathbf{e}_{\mathbf{t}}$ \\
\hline 1 & 2.00 & 1.00 & 1.00 & 0.50 & 10 \\
2 & 1.75 & 0.50 & 0.95 & 0.55 & 13 \\
3 & 1.60 & 1.05 & 0.90 & 0.60 & 11 \\
4 & 1.50 & 1.10 & 0.85 & 0.65 & 12 \\
5 & 1.45 & 1.12 & 0.40 & 0.70 & 15 \\
6 & 1.40 & 1.15 & 0.80 & 0.75 & 13 \\
7 & 1.35 & 1.18 & 0.75 & 0.70 & 14 \\
8 & 1.30 & 0.60 & 0.72 & 0.65 & 17 \\
9 & 1.25 & 1.20 & 0.70 & 0.70 & 15 \\
10 & 1.20 & 1.25 & 0.40 & 0.75 & 18 \\
11 & 1.15 & 1.28 & 0.70 & 0.75 & 16 \\
12 & 1.10 & 1.30 & 0.65 & 0.80 & 17 \\
\hline
\end{tabular}

The prices of commodities 1 and 3 trend downward throughout the sample period while the prices of commodities 2 and 4 trend upward. The trends in commodities 1 and 4 are very smooth but the trends in commodities 2 and 3 are interrupted by sales: item 2 goes on sale in periods 2 and 8 and item 3 goes on sale in periods 5 and 10 . Total expenditures $\mathrm{e}_{t}$ on the commodity group trend upwards except in the four periods after a sale when aggregate expenditures fall a bit.

For each value of the elasticity of substitution $\sigma$, we can evaluate the period t expenditure share vectors $\mathrm{s}^{\mathrm{t}} \equiv\left[\mathrm{s}_{\mathrm{t} 1}, \mathrm{~S}_{\mathrm{t} 2}, \mathrm{~S}_{\mathrm{t}}, \mathrm{S}_{\mathrm{t}}\right]$ using the $\mathrm{p}^{\mathrm{t}}$ vectors that are listed in Table 3 and equations (88) in the previous section. Once the share vectors have been constructed, the components of the corresponding quantity vectors $\mathrm{q}^{\mathrm{t}} \equiv\left[\mathrm{q}_{\mathrm{t} 1}, \mathrm{q}_{\mathrm{t} 2}, \mathrm{q}_{\mathrm{t} 3}, \mathrm{q}_{\mathrm{t} 4}\right]$ can be constructed using equations (89) in the previous section.

Once the set of twelve price vectors $\mathrm{p}^{\mathrm{t}}$ and twelve quantity vectors $\mathrm{q}^{\mathrm{t}}$ have been constructed for the alternative $\sigma$ values, we can compare the period t chained Fisher, chained Törnqvist, Weighted Time Product Dummy, Geary-Khamis, GEKS and CCDI normalized price levels $\left(\pi_{\mathrm{FCH}}{ }^{\mathrm{t}}, \pi_{\mathrm{TCH}}{ }^{\mathrm{t}}, \pi_{\mathrm{WTPD}}{ }^{\mathrm{t}}, \pi_{\mathrm{GK}}{ }^{\mathrm{t}}, \pi_{\mathrm{GEKS}}{ }^{\mathrm{t}}, \pi_{\mathrm{CCDI}}{ }^{\mathrm{t}}\right.$ respectively) to the corresponding true CES normalized price level, $\pi_{\mathrm{CES}}{ }^{\mathrm{t}}$. These alternative indexes are evaluated for $\sigma$ equal to $0,0.5,1,2,4,10$ and 20 and are listed in Table A1 of the Appendix, and plotted in Figure 2 for the considered values of $\sigma$ up to $10{ }^{75}$

\footnotetext{
${ }^{75}$ To simplify programming, $\sigma=1.001$ was actually used throughout for the " $\sigma=1$ ” case.
} 
Figure 2: Alternative Price Levels for Different Methods and Elasticities of Substitution
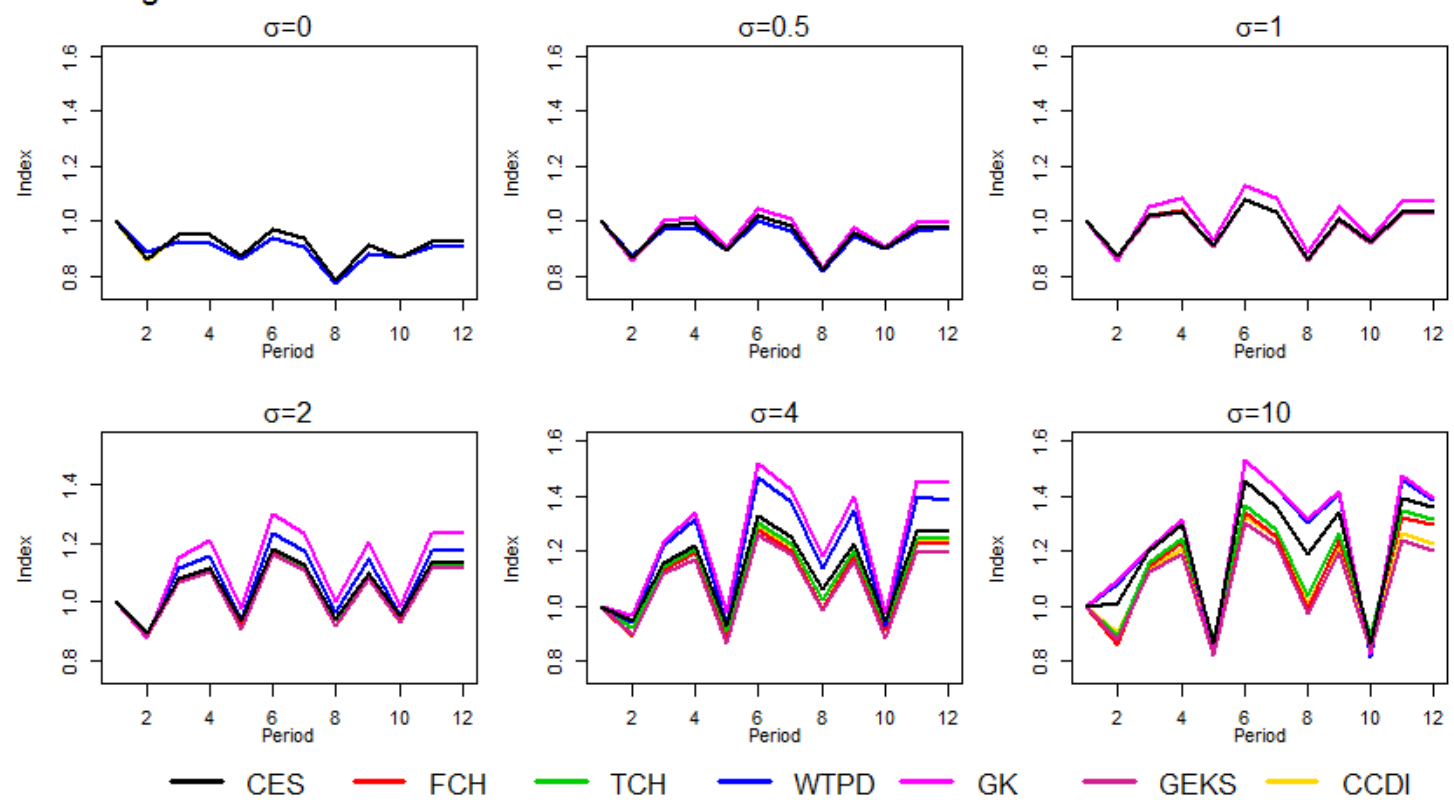

It can be seen that when $\sigma=0$, the CES, chained Fisher (FCH), GK and GEKS indexes all coincide. Furthermore the chained Törnqvist (TCH) and CCDI indexes are so close to the CES that they cannot be distinguished from each other in Figure 2. The only outliers in this case are the WTPD indexes which lie below the other indexes after period 2. Preferences which allow for no substitution between products are not realistic, but the results provide a check on our computations.

For $\sigma=0.5$, the GK indexes have a modest upwards bias while the WTPD indexes have a modest downward bias as compared to the true cost of living index. The remaining indexes are all very close to the CES price levels and cannot be distinguished separately in Figure 2.

In theory, when $\sigma=1$ the chained Törnqvist, CCDI and WTPD price levels should be exactly equal to the corresponding CES price levels and this expectation is borne out. The chained Fisher and GEKS indexes are also very close to the corresponding CES indexes and cannot be distinguished from each other in Figure 2. The GK price levels turn out to be substantially above the other indexes after period 2 .

When $\sigma=2$, the GK price levels are substantially above the corresponding WTPD levels after period 2 and the WTPD price levels are well above the CES price levels. Thus these indexes have substantial amounts of substitution bias for our numerical example. The chained Törnqvist and CCDI price levels are very close to the corresponding CES price levels while the chained Fisher and GEKS price levels end up being slightly below the CES price levels. 
When $\sigma=4$, the GK and WTPD price levels are substantially above the CES price levels for most observations. ${ }^{76}$ Thus these indexes have substantial amounts of substitution bias for our numerical example in this case. The chained Törnqvist and CCDI price levels are 2-3\% under the corresponding CES price levels at the end of the sample period while the chained Fisher and GEKS price levels end up being 4-5\% below the CES price levels at the end of the sample period. Thus none of our approximations to the true CES indexes end up being very close at the end of the sample period but the upward bias in the GK and WTPD indexes is very large indeed (13.8\% and $8.8 \%$ respectively).

When $\sigma=10$, the WTPD and GK price levels are virtually identical ${ }^{77}$ and these indexes turn out to give the best approximation to the true CES indexes although for many observations, they lie well above the corresponding true indexes. The remaining indexes lie below the CES indexes, with the chained Törnqvist and chained Fisher indexes coming the closest to the corresponding CES indexes.

From Table A1 of the Appendix, when $\sigma=20$, the WTPD and GK price levels are again virtually identical. ${ }^{78}$ For most observations, these price levels are either very close to the corresponding CES price levels or are above them, although at the end of the sample they are slightly below. The remaining indexes are generally substantially below the CES price levels. Thus for very high elasticities of substitution, the WTPD and GK methods provide the best approximation to CES preferences as might be expected.

In summary: for elasticities of substitution in the most likely range of 1 to 4 , the four methods based on the use of bilateral superlative indexes approximate CES preferences reasonably well with the chained Törnqvist generally doing the best. The GK indexes have substantial upward biases in all cases while the WTPD indexes also have substantial upward biases when $\sigma$ equals 2 or 4 , but they are unbiased when $\sigma=1$.

\section{An Artificial Data Set Using CES Preferences Adjusted for Product Sales}

The CES indexes which were constructed in the previous section did not suffer from a chain drift problem; i.e., if prices and quantities in any two periods were exactly the same, the CES index levels for those two periods would also be the same. However, in actual practice, the assumptions which the Konüs (1924) true cost of living methodology relies on are not met: when a commodity goes on sale at say one half of its regular price, consumers tend to purchase amounts that not only satisfy their needs for the sale period but also they stock up to partially satisfy their needs for the subsequent period. This violates a basic assumption that is used in the economic approach to index number

\footnotetext{
${ }^{76}$ The vector of WTPD quality adjustment factors is $b_{\text {WTPD }} \equiv[1.84,1.26,0.93,1.00]$ and the vector of GK quality adjustment factors is $\mathrm{b}_{\mathrm{GK}} \equiv[1.78,1.16,0.87,1.00]$.

${ }^{77}$ The new vector of WTPD quality adjustment factors is $b_{\mathrm{WTPD}} \equiv[1.66,0.93,0.98,1.00]$ and the vector of GK quality adjustment factors is $\mathrm{b}_{\mathrm{GK}} \equiv[1.64,0.92,0.97,1.00]$. Thus the two additive methods are converging to the same preferences as $\sigma$ becomes large.

${ }^{78}$ The new vector of WTPD quality adjustment factors is $b_{\text {WTPD }} \equiv[1.64,0.91,0.99,1.00]$ and the vector of GK quality adjustment factors is $b_{\mathrm{GK}} \equiv[1.64,0.91,0.99,1.00]$. Thus the two additive methods have converged to the same preferences when $\sigma=20$.
} 
theory; i.e., the economic approach to index number theory assumes that purchases of goods made during a period coincide with the consumption of these purchased goods within the period. As was explained earlier, this stockpiling activity will cause chained superlative indexes to drift downwards. ${ }^{79}$ To model this situation, we will use the price and expenditure data listed in Table 3 and the assumption of CES preferences for varying $\sigma$ as in the previous section but the quantity data for commodities that go on sale will be adjusted. Thus commodity 2 goes on sale in periods 2 and 8 . For periods 3 and 9, we take the predicted quantities for these items that are generated by the CES model described in the previous section and we somewhat arbitrarily adjust these quantities downward to half of the predicted levels that were generated by the CES model. Similarly, commodity 3 goes on sale in periods 5 and 10. Again, for periods 6 and 11, we adjust the quantities of these commodities to half of the predicted levels that were generated by the CES model in the previous section. Thus for periods $t=3,6,9$ and 11 and for each alternative value of $\sigma$, we have a new $\mathrm{q}^{\mathrm{t}}$ vector and so for these periods, we need to define a new level of expenditure $e_{t} \equiv p^{t} \cdot q^{t}$ and new expenditure shares $s_{t n} \equiv p_{t n} q_{t n} / e_{t}$ for $t=3,6,9$ and 11 and $n=1,2,3,4$. Thus for the eight periods $1,2,4,5,7,8,10$ and 12 , the unnormalized and normalized CES price levels, $\mathrm{P}_{\mathrm{t}}$ and $\pi_{\mathrm{CES}}{ }^{\mathrm{t}} \equiv \mathrm{P}_{\mathrm{t}} / \mathrm{P}_{1}$ for the new data set, are the same as in the previous section. For periods 3, 6, 9 and 11, there are no CES price levels but for convenience, in Table A2 and Figure 3, we simply use the normalized CES price levels $\pi_{\mathrm{CES}}{ }^{\mathrm{t}}$ from the previous section for all periods.

Once the new set of twelve price vectors $p^{t}$ and twelve quantity vectors $q^{t}$ have been constructed for the alternative $\sigma$ values, ${ }^{80}$ we can compare the period $t$ chained Fisher, chained Törnqvist, fixed base Fisher, fixed base Törnqvist, Weighted Time Product Dummy, Geary-Khamis, GEKS and CCDI normalized price levels $\left(\pi_{\mathrm{FCH}}{ }^{\mathrm{t}}, \pi_{\mathrm{TCH}}{ }^{\mathrm{t}}, \pi_{\mathrm{FFB}}{ }^{\mathrm{t}}\right.$, $\pi_{\mathrm{TFB}}{ }^{\mathrm{t}}, \pi_{\mathrm{WTPD}}{ }^{\mathrm{t}}, \pi_{\mathrm{GK}}{ }^{\mathrm{t}}, \pi_{\mathrm{GEKS}}{ }^{\mathrm{t}}, \pi_{\mathrm{CCDI}}{ }^{\mathrm{t}}$ respectively) to the corresponding true CES normalized price level, $\pi_{\text {CES }}{ }^{t}$, for all periods except periods $3,6,9$ and 11 . These alternative indexes are evaluated for $\sigma$ equal to $0,0.5,1,2,4$, and 10 and are listed in Table A2 of the Appendix, and plotted in Figure 3.

Using this adjusted data set, the chained Fisher and chained Törnqvist indexes have substantial downward biases as compared to the corresponding true CES indexes (excluding periods 1, 3, 6, 9 and 11). The new data set illustrates that superlative indexes are indeed subject to substantial downward chain drift when products are sold at substantially discounted prices.

\footnotetext{
${ }^{79}$ Szulc (1983) (1987) was perhaps the first modern price statistician to note the chain drift problem in the context of sales. However, Persons $(1921 ; 110)$ using his data set on crop production noted the downward drift of Fisher chained indexes relative to a Fisher index that measured price change directly between periods 1 and $\mathrm{T}$ and he also applied Walsh's $(1901 ; 389)$ multiperiod identity test to demonstrate this downward drift. Frisch (1936; 9) noted Persons' research in his survey paper on index numbers.

${ }^{80}$ The new $\mathrm{p}^{\mathrm{t}}$ and $\mathrm{q}^{\mathrm{t}}$ will coincide with the $\mathrm{p}^{\mathrm{t}}$ and $\mathrm{q}^{\mathrm{t}}$ that were used in the previous section except for periods $3,6,9$ and 11 , we use new $q^{t}$ vectors as defined above.
} 
Figure 3: Alternative Price Levels for Sales Adjusted Data
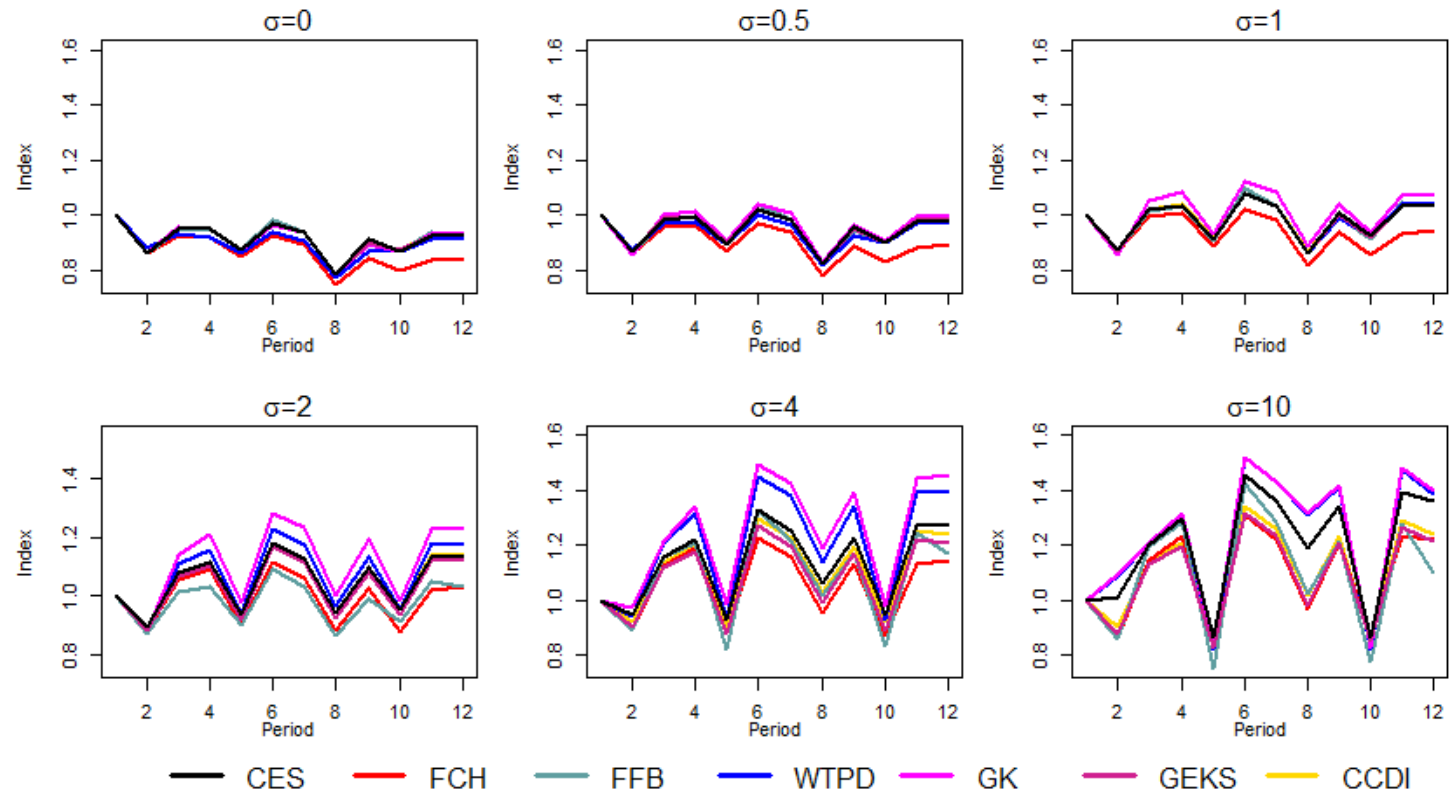

From Figure 3 (and Table A2 of the Appendix), for $\sigma=0$, it can be seen that the fixed base Fisher (FFB) and GK price levels coincide with the CES price levels for all periods except periods 3, 6, 9 and 11 where the CES indexes are not well defined for the new data. ${ }^{81}$ The fixed base Törnqvist (not plotted in Figure 3), GEKS and CCDI price levels are very close to the corresponding CES price levels. The WTPD price levels have a small amount of downward bias while the chained Fisher and the chained Törnqvist (not plotted in Figure 3) price levels have substantial downward biases.

When $\sigma=0.5$, the fixed base Fisher (and fixed base Törnqvist), GEKS and CCDI price levels are all very close to the corresponding CES price levels. The GK indexes are slightly above and the WTPD indexes are slightly below the corresponding CES index levels. The two chained superlative indexes end up well below the other indexes; i.e., the chain drift problem for superlative indexes is severe for this artificial data set. We move on to the more applicable $\sigma$ equals 1,2 and 4 results.

When $\sigma=1$, the two chained superlative indexes have a large downward bias compared to the target CES index. The GK price levels are substantially above the corresponding CES price levels. The remaining indexes are all fairly close to their CES counterparts. The fixed base Törnqvist indexes are exactly equal to their CES counterparts (except for observations 3, 6, 9 and 11 when the CES indexes are not applicable); see Table A2.

When $\sigma=2$, the fixed base Törnqvist and CCDI price levels are very close to their CES counterpart price levels. The GEKS price level for period 12 ends up 1.5\% below the

\footnotetext{
${ }^{81}$ Recall that we are using the CES normalized price levels from the previous section for all periods in the present section in order to simplify the charts for this section.
} 
corresponding CES price level while the fixed base Fisher price level ends up 2.5\% below the target index. The chained Fisher and chained Törnqvist indexes end up 9.0\% and $11.5 \%$ below the target index in period 12 while the WTPD and GK price levels for period 12 end up 3.2\% and 8.5\% above the CES price level.

When $\sigma=4$, the CCDI indexes are closest to their CES counterparts and the CCDI price level for period 12 ends up 2.7\% below the corresponding CES level. The fixed base Törnqvist and GEKS price levels end up 4.4\% and 5.5\% below the CES price level at period 12. The fixed base Fisher, the chained Törnqvist and the chained Fisher indexes all have substantial downward biases and end up 8.3\%, $10.2 \%$ and $10.3 \%$ below the corresponding CES price level for period 12. The WTPD and GK indexes have substantial upward biases and end up $9.0 \%$ and 14.2\% above the corresponding CES price level at period 12 .

When $\sigma=10$, all of the alternative indexes have some significant biases for some periods. The WTPD and GK price levels are close to each other and are substantially above their CES counterparts for many observations. These price levels end up being only $1.7 \%$ and 2.5\% above the corresponding CES price level for period 12. The worst performing indexes are the fixed base Fisher and fixed base Törnqvist indexes which end up 19.4\% and $16.8 \%$ below the CES price level for period 12. The chained Fisher and Törnqvist indexes end up 10.2\% and 9.4\% below the CES price level for period 12. Finally the GEKS and CCDI price levels end up $11.0 \%$ and $9.1 \%$ below the CES price level for period 12. However, it should be kept in mind that in most empirical applications, the elasticity of substitution will be well below 10 .

Some tentative conclusions that can be drawn from the material presented in this section are as follows:

- Chained superlative indexes are not useful target indexes for a CPI when dealing with aggregating scanner data where discounted prices are prevalent.

- The CCDI multilateral method worked best overall for our numerical example for elasticities of substitution in the range $0 \leq \sigma \leq 4$.

- GK indexes had substantial upward biases relative to the corresponding CES true cost of living price levels for elasticities of substitution in the range $1 \leq \sigma \leq 4$.

- Weighted Time Product Dummy indexes will work well if $\sigma=1$ or if $\sigma \geq 10$ but for our example, they had substantial upward biases for elasticities of substitution in the range $2 \leq \sigma \leq 4$.

We turn now to an examination of the problems associated with linking the results from one window of observations to another subsequent window.

\section{Single Window versus Linked CCDI Price Levels}

In this section, using the sales adjusted data, we draw on the results in section 5 and compare the single window $\pi_{\mathrm{CCDI}}{ }^{\mathrm{t}}$ price levels which were listed in the previous section for various data sets that depended on the elasticity of substitution $\sigma$ with the 
corresponding CCDI price levels that use linked windows. The single window results were based on a window that consisted of all 12 observations. These CCDI price levels of course depended on $\sigma$ and we denote their period 12 values as $\pi_{\text {CCDI }}^{12}(\sigma)$ in this section. In this section, for each of our $\sigma$ values, we will form two windows of length 11 . The first such window will consist of the data for periods 1-11 and the second window will consist of the data for periods 2-12. In keeping with CPI methodology which does not allow revisions to occur for the flagship CPI, we assume that the final linked series for periods 1 to 11 will consist of the CCDI normalized price levels using the first window of length 11. The linked in CPI for period 12 will be formed by using equations (25) in section 5 to link in the results from the second window by choosing the link periods $t=2,3, \ldots, 11$. Denote these alternative linked normalized price levels for period 12 by $\pi_{\mathrm{L}}{ }^{12}(\mathrm{t}, \sigma)$ for choice of link period $t=2,3, \ldots, 11$. Define the geometric mean of these ten alternative period 12 price levels as $\pi_{\mathrm{L}}^{12}($ Mean, $\sigma)$.

We first compare the period 12 linked normalized price levels $\pi_{\mathrm{L}}{ }^{12}(\mathrm{t}, \sigma)$ to the period 12 single window normalized price level, $\pi_{\mathrm{CCDI}}{ }^{12}(\sigma)$. Define the differences between these period 12 price levels as follows:

$$
\mathrm{D}(\mathrm{t}, \sigma) \equiv \pi_{\mathrm{L}}^{12}(\mathrm{t}, \sigma)-\pi_{\mathrm{CCDI}}^{12}(\sigma)
$$$$
\mathrm{t}=2,3, \ldots, 11 ; \sigma=0,0.5,1,2,4,10
$$

We also define the difference between the period 12 single window CCDI price level for each $\sigma, \pi_{\mathrm{CCDI}}{ }^{12}(\sigma)$, and the mean period 12 price level using the geometric mean of the 10 alternative link periods, $\pi_{\mathrm{L}}{ }^{12}$ (Mean, $\left.\sigma\right)$, as follows:

$$
\mathrm{D}(\text { Mean, } \sigma) \equiv \pi_{\mathrm{L}}^{12}(\text { Mean, } \sigma)-\pi_{\mathrm{CCDI}}^{12}(\sigma)
$$$$
\sigma=0,0.5,1,2,4,10
$$

If these differences are large in magnitude, then this indicates a chain drift problem with the use of successive CCDI linked windows. ${ }^{82}$ Table 4 lists these differences.

For $\sigma$ in the range $0 \leq \sigma \leq 2$, it can be seen that the differences in the period 12 CCDI price levels due to the choice of alternative link periods are small. Choosing the link period to be period 4 or 10 leads to virtually zero differences but the differences are also small when periods 2, 5, 7 or 8 are chosen. Choosing the mean of the ten period specific estimates also leads to a fairly low difference between the single window period 12 CCDI price level and the two window linked period 12 price levels.

The differences are much larger when the true cost of living index elasticity of substitution is equal to 4 or 10 . It can be seen that the differences are smallest when the linking period is chosen to be periods 2, 5 or 10 . Note that sales occurred during each of these periods. When $\sigma=10$, the period 12 linked CCDI price level is always at least 1 percentage point above its single window CCDI price level for period 12 and for the choice of period 6 as the link observation, it is 3 percentage points above.

\footnotetext{
${ }^{82}$ If the Törnqvist bilateral indexes satisfied the circularity test exactly, then these differences would all be 0 and there would be no chain drift problem with the use of chained Törnqvist indexes. However, as was seen in the previous section, the circularity test does not hold exactly and there is a chain drift problem.
} 
Table 4: Differences at Period 12, $\mathrm{D}(\mathrm{t}, \sigma)$, between the Single Window CCDI Price Levels and the Linked CCDI Price Levels as Functions of the Linking Period $t$ and the Elasticity of Substitution $\sigma$

\begin{tabular}{rrrrrrr}
\hline $\mathbf{t}$ & $\mathbf{D}(\mathbf{t , 0 )}$ & $\mathbf{D}(\mathbf{t}, \mathbf{0 . 5})$ & $\mathbf{D}(\mathbf{t}, \mathbf{1})$ & $\mathbf{D}(\mathbf{t}, \mathbf{2})$ & $\mathbf{D}(\mathbf{t}, \mathbf{4})$ & $\mathbf{D}(\mathbf{t}, \mathbf{1 0})$ \\
\hline 2 & 0.00030 & 0.00014 & 0.00021 & 0.00067 & 0.00212 & 0.01004 \\
3 & -0.00197 & -0.00149 & -0.00098 & 0.00050 & 0.00567 & 0.02197 \\
4 & -0.00001 & 0.00011 & 0.00021 & 0.00098 & 0.00603 & 0.02640 \\
5 & -0.00029 & 0.00000 & 0.00021 & 0.00006 & -0.00222 & 0.01370 \\
6 & 0.00154 & 0.00206 & 0.00265 & 0.00442 & 0.01035 & 0.03114 \\
7 & 0.00002 & 0.00011 & 0.00021 & 0.00092 & 0.00537 & 0.02639 \\
8 & 0.00041 & 0.00022 & 0.00021 & 0.00125 & 0.00645 & 0.02581 \\
9 & -0.00177 & -0.00137 & -0.00098 & 0.00014 & 0.00451 & 0.02312 \\
10 & -0.00015 & 0.00003 & 0.00021 & 0.00010 & -0.00202 & 0.01647 \\
11 & 0.00151 & 0.00204 & 0.00265 & 0.00432 & 0.00946 & 0.02675 \\
\hline Mean & -0.00004 & 0.00019 & 0.00046 & 0.00133 & 0.00457 & 0.02216 \\
\hline
\end{tabular}

We now compare the period 12 linked normalized price levels $\pi_{\mathrm{L}}{ }^{12}(\mathrm{t}, \sigma)$ to the period 12 true cost of living index, $\pi_{\mathrm{CES}}{ }^{12}(\sigma)$. Define the biases between these period 12 price levels as follows:

(94) $\mathrm{B}(\mathrm{t}, \sigma) \equiv \pi_{\mathrm{L}}^{12}(\mathrm{t}, \sigma)-\pi_{\mathrm{CES}}{ }^{12}(\sigma)$;

$$
\mathrm{t}=2,3, \ldots, 11 ; \sigma=0,0.5,1,2,4,10 \text {. }
$$

We also define the difference between the period 12 CES price level for each $\sigma, \pi_{\mathrm{CES}}{ }^{12}(\sigma)$, and the mean period 12 price level using the geometric mean of the ten alternative link periods, $\pi_{\mathrm{L}}^{12}$ (Mean, $\sigma$ ), as follows:

(95) $\mathrm{B}($ Mean, $\sigma) \equiv \pi_{\mathrm{L}}{ }^{12}($ Mean, $\sigma)-\pi_{\mathrm{CES}}{ }^{12}(\sigma)$;

$$
\sigma=0,0.5,1,2,4,10 \text {. }
$$

For each $\sigma$, these differences measure the bias in the various two window CCDI period 12 price levels compared to the corresponding period 12 true cost of living indexes, $\pi_{\mathrm{CES}}{ }^{12}(\sigma)$. Table 5 lists these differences. It can be seen that the bias in the two window CCDI price levels at period 12 for elasticities of substitution in the range $0 \leq \sigma \leq 4$ fairly small for all choices of the linking point but smallest if periods 2, 4, 5, 7, 8 or 10 are chosen. Note that the bias is largest in magnitude if periods 3, 6, 9 or 11 are chosen as the linking observations. These 4 periods are the periods that immediately follow a sale. Since in real life, a sale could occur during any period, this result indicates that it will be difficult to come up with a general rule as to which period in the first window is the "best" period to choose in terms of minimizing bias. Under these circumstances, choosing the mean splice method may be a conservative strategy which would avoid large biases. 
Table 5: Biases at Period 12, $B(t, \sigma)$, as a Functions of the Linking Period $t$ and the Elasticity of Substitution $\sigma$

\begin{tabular}{rrrrrrr}
\hline $\mathbf{t}$ & $\mathbf{B}(\mathbf{t}, \mathbf{0})$ & $\mathbf{B}(\mathbf{t}, \mathbf{0 . 5})$ & $\mathbf{B}(\mathbf{t}, \mathbf{1})$ & $\mathbf{B}(\mathbf{t}, \mathbf{2})$ & $\mathbf{B}(\mathbf{t}, \mathbf{4})$ & $\mathbf{B}(\mathbf{t}, \mathbf{1 0})$ \\
\hline 2 & -0.00002 & 0.00068 & 0.00249 & 0.00187 & -0.03189 & -0.11420 \\
3 & -0.00230 & -0.00094 & 0.00130 & 0.00169 & -0.02833 & -0.10227 \\
4 & -0.00034 & 0.00065 & 0.00249 & 0.00218 & -0.02797 & -0.09784 \\
5 & -0.00061 & 0.00054 & 0.00249 & 0.00126 & -0.03622 & -0.11054 \\
6 & 0.00122 & 0.00260 & 0.00494 & 0.00562 & -0.02365 & -0.09310 \\
7 & -0.00031 & 0.00065 & 0.00249 & 0.00212 & -0.02864 & -0.09785 \\
8 & 0.00008 & 0.00076 & 0.00249 & 0.00244 & -0.02756 & -0.09843 \\
9 & -0.00210 & -0.00083 & 0.00130 & 0.00134 & -0.02949 & -0.10112 \\
10 & -0.00048 & 0.00057 & 0.00249 & 0.00130 & -0.03603 & -0.10777 \\
11 & 0.00118 & 0.00258 & 0.00494 & 0.00551 & -0.02455 & -0.09749 \\
\hline Mean & -0.00037 & 0.00073 & 0.00274 & 0.00253 & -0.02944 & -0.10208 \\
\hline
\end{tabular}

Table 5 shows that for large elasticities of substitution, the bias pattern has shifted: linking at observations 6 and 11 now reduces the bias. When $\sigma=10$, the bias is greatest in magnitude when the linking observation is chosen to be observations 2, 5 or 10 . Note that observations 2, 5 and 10 are periods when sales occurred.

Our conclusion at this point is that no clear pattern emerged as to which observation in the window was the "best" one for linking the second window to the first. Until more conclusive evidence on this problem is obtained, it seems advisable to use the mean splice.

\section{Relative Price Similarity Linking}

As was suggested in Section 5, it is likely that price comparisons between two periods will be more accurate if the structure of relative prices is more similar. In the context of making comparisons of prices across countries, this method of linking countries with the most similar structure of relative prices has been pursued by Hill (1997) (1999a) (1999b) (2009), Diewert (2013b) and Hill, Rao, Shankar and Hajargasht (2017). Hill (2001) (2004) also pursued this similarity of relative prices approach in the time series context. A key aspect of this methodology is the choice of the measure of similarity (or dissimilarity) of the relative price structures of two countries. Various measures of the similarity or dissimilarity of relative price structures have been proposed by Allen and Diewert (1981), Kravis, Heston and Summers (1982; 104-106), Hill (1997) (2009), Sergeev (2001) (2009), Aten and Heston (2009) and Diewert (2009). ${ }^{83}$

\footnotetext{
${ }^{83}$ See Diewert (2009) for a discussion of the relative merits of the various measures. Diewert suggested and favoured the measures defined by (96) and (97) below. It can be shown that these two functions of the prices and quantities pertaining to the two periods under consideration approximate each other to the second order around a point where the two price vectors are equal and the two quantity vectors are equal. For our empirical example, the dissimilarity measures defined by (96) and (97) were indeed fairly close to each other for each value of $\sigma$.
} 
We will use the two measures of relative price dissimilarity defined by (30) and (31), $\Delta_{\mathrm{AL}}$ (the weighted asymptotic linear index of relative price dissimilarity), and $\Delta_{\mathrm{LQ}}$ (the weighted log quadratic index). ${ }^{84}$ For convenience, these two measures are defined as follows:

(96) $\Delta_{\mathrm{AL}}\left(\mathrm{p}^{\mathrm{r}}, \mathrm{p}^{\mathrm{t}}, \mathrm{q}^{\mathrm{r}}, \mathrm{q}^{\mathrm{t}}\right) \equiv \sum_{\mathrm{n}=1}{ }^{\mathrm{N}}(1 / 2)\left(\mathrm{s}_{\mathrm{rn}}+\mathrm{s}_{\mathrm{tn}}\right)\left\{\left(\mathrm{p}_{\mathrm{tn}} / \mathrm{P}\left(\mathrm{p}^{\mathrm{r}}, \mathrm{p}^{\mathrm{t}}, \mathrm{q}^{\mathrm{r}}, \mathrm{q}^{\mathrm{t}}\right) \mathrm{p}_{\mathrm{rn}}\right)+\left(\mathrm{P}\left(\mathrm{p}^{\mathrm{r}}, \mathrm{p}^{\mathrm{t}}, \mathrm{q}^{\mathrm{r}}, \mathrm{q}^{\mathrm{t}}\right) \mathrm{p}_{\mathrm{rn}} / \mathrm{p}_{\mathrm{tn}}\right)-2\right\}$; (97) $\Delta_{\mathrm{LQ}}\left(\mathrm{p}^{\mathrm{r}}, \mathrm{p}^{\mathrm{t}}, \mathrm{q}^{\mathrm{r}}, \mathrm{q}^{\mathrm{t}}\right) \equiv \sum_{\mathrm{n}=1}{ }^{\mathrm{N}}(1 / 2)\left(\mathrm{s}_{\mathrm{rn}}+\mathrm{s}_{\mathrm{tn}}\right)\left[\ln \left(\mathrm{p}_{\mathrm{tn}} / \mathrm{P}\left(\mathrm{p}^{\mathrm{r}}, \mathrm{p}^{\mathrm{t}}, \mathrm{q}^{\mathrm{r}}, \mathrm{q}^{\mathrm{t}}\right) \mathrm{p}_{\mathrm{rn}}\right)\right]^{2}$

where $p^{r}, q^{r}, s^{r}$ and $p^{t}, q^{t}, s^{t}$ are the price, quantity and share vectors for periods $r$ and $s$ respectively. These measures turn out to be nonnegative and the bigger they are, the more dissimilar are the relative prices for periods $r$ and $t$. Note that the measures defined by (96) and (97) require that a bilateral index formula, $\mathrm{P}\left(\mathrm{p}^{\mathrm{r}}, \mathrm{p}^{\mathrm{t}}, \mathrm{q}^{\mathrm{r}}, \mathrm{q}^{\mathrm{t}}\right)$, be specified so that these measures can be calculated. For the asymptotic linear measure of relative price dissimilarity, we will use the Fisher price index $\mathrm{P}_{\mathrm{F}}$ defined by (4) and for the $\log$ quadratic measure, we will use the Törnqvist index $\mathrm{P}_{\mathrm{T}}$ defined by (5) as the bilateral indexes that appear in (96) and (97) respectively.

We use the same price and quantity data that were used in the previous two sections. Using these data, the dissimilarity measures $\Delta_{\mathrm{AL}}\left(\mathrm{p}^{\mathrm{r}}, \mathrm{p}^{\mathrm{t}}, \mathrm{q}^{\mathrm{r}}, \mathrm{q}^{\mathrm{t}}\right)$ defined by (96) using the Fisher bilateral price index as our $\mathrm{P}\left(\mathrm{p}^{\mathrm{r}}, \mathrm{p}^{\mathrm{t}}, \mathrm{q}^{\mathrm{r}}, \mathrm{q}^{\mathrm{t}}\right)$ are calculated for $\mathrm{r}=1, \ldots, 12$ and for $\mathrm{t}=$ $1, \ldots, 12$. The $\Delta_{\mathrm{AL}}\left(\mathrm{p}^{1}, \mathrm{p}^{\mathrm{t}}, \mathrm{q}^{1}, \mathrm{q}^{\mathrm{t}}\right)$ are listed in the column of Table 6 under the heading $\Delta_{\mathrm{AL} 1 \mathrm{t}}$, The $\Delta_{\mathrm{AL}}\left(\mathrm{p}^{2}, \mathrm{p}^{\mathrm{t}}, \mathrm{q}^{2}, \mathrm{q}^{\mathrm{t}}\right)$ are listed in Table 6 under the heading $\Delta_{\mathrm{AL} 2 \mathrm{t}}$, and so on. Note that when $\mathrm{r}=\mathrm{t}, \Delta_{\mathrm{ALtt}}=0$ for each $\mathrm{t}$ as expected. Note also that the matrix of measures listed in Table 6 is symmetric so that $\Delta_{\mathrm{ALrt}}=\Delta_{\mathrm{ALtr}}$ for all $\mathrm{r}$ and $\mathrm{t}$.

Table 6: Asymptotic Linear Measures of Price Dissimilarity for $\sigma=0$

\begin{tabular}{rcccccccccccc}
\hline $\mathbf{t}$ & $\Delta_{\text {AL1t }}$ & $\Delta_{\text {AL2t }}$ & $\Delta_{\text {AL3t }}$ & $\Delta_{\text {AL4t }}$ & $\Delta_{\text {AL5t }}$ & $\Delta_{\text {AL6t }}$ & $\Delta_{\text {AL7t }}$ & $\Delta_{\text {AL8t }}$ & $\Delta_{\text {AL9t }}$ & $\Delta_{\text {AL10t }}$ & $\Delta_{\text {AL11t }}$ & $\Delta_{\text {AL12t }}$ \\
\hline 1 & 0.000 & 0.064 & 0.027 & 0.051 & 0.179 & 0.102 & 0.099 & 0.096 & 0.130 & 0.255 & 0.180 & 0.221 \\
2 & 0.064 & 0.000 & 0.070 & 0.119 & 0.282 & 0.166 & 0.184 & 0.053 & 0.187 & 0.384 & 0.288 & 0.324 \\
3 & 0.027 & 0.070 & 0.000 & 0.004 & 0.105 & 0.025 & 0.025 & 0.042 & 0.039 & 0.140 & 0.068 & 0.096 \\
4 & 0.051 & 0.119 & 0.004 & 0.000 & 0.074 & 0.008 & 0.009 & 0.046 & 0.018 & 0.096 & 0.038 & 0.058 \\
5 & 0.179 & 0.282 & 0.105 & 0.074 & 0.000 & 0.040 & 0.048 & 0.126 & 0.049 & 0.016 & 0.049 & 0.058 \\
6 & 0.102 & 0.166 & 0.025 & 0.008 & 0.040 & 0.000 & 0.001 & 0.049 & 0.004 & 0.046 & 0.015 & 0.025 \\
7 & 0.099 & 0.184 & 0.025 & 0.009 & 0.048 & 0.001 & 0.000 & 0.064 & 0.002 & 0.052 & 0.011 & 0.022 \\
8 & 0.096 & 0.053 & 0.042 & 0.046 & 0.126 & 0.049 & 0.064 & 0.000 & 0.064 & 0.170 & 0.112 & 0.126 \\
9 & 0.130 & 0.187 & 0.039 & 0.018 & 0.049 & 0.004 & 0.002 & 0.064 & 0.000 & 0.043 & 0.004 & 0.013 \\
10 & 0.255 & 0.384 & 0.140 & 0.096 & 0.016 & 0.046 & 0.052 & 0.170 & 0.043 & 0.000 & 0.026 & 0.027 \\
11 & 0.180 & 0.288 & 0.068 & 0.038 & 0.049 & 0.015 & 0.011 & 0.112 & 0.004 & 0.026 & 0.000 & 0.003 \\
12 & 0.221 & 0.324 & 0.096 & 0.058 & 0.058 & 0.025 & 0.022 & 0.126 & 0.013 & 0.027 & 0.003 & 0.000 \\
\hline
\end{tabular}

For each representative elasticity of substitution $\sigma$ that we have chosen, we will construct relative price similarity linked normalized price levels, $\pi_{A L}{ }^{t}(\sigma)$. As each new observation becomes available, we link the current observation to the most similar previous

\footnotetext{
${ }^{84}$ This measure is a weighted generalization of the nonproportionality measure suggested by Allen and Diewert (1981; 433).
} 
observation. Thus for $\sigma=0$, we use the measures listed in Table 6 . We set $\pi_{\mathrm{AL}}{ }^{1}(0)$ equal to 1 . For period 2, we set $\pi_{\mathrm{AL}}{ }^{2}(0) \equiv \mathrm{P}_{\mathrm{F}}\left(\mathrm{p}^{1}, \mathrm{p}^{2}, \mathrm{q}^{1}, \mathrm{q}^{2}\right)$, the Fisher price index for period 2 relative to period 1 . For period 3 , we look at the first two entries in the column in Table 6 that has the heading $\Delta_{\mathrm{ALt3}}$. The smaller of these two numbers, 0.027 , occurs at $\mathrm{t}=1$, so we use the Fisher formula to link the prices of period 3 directly to the prices of period 1; i.e., we set $\pi_{\mathrm{AL}}{ }^{3}(0) \equiv \mathrm{P}_{\mathrm{F}}\left(\mathrm{p}^{1}, \mathrm{p}^{3}, \mathrm{q}^{1}, \mathrm{q}^{3}\right)$. For period 4 , we look at the first 3 entries in the column in Table 6 that has the heading $\Delta_{\text {ALt } 4}$. The smallest of these numbers, 0.004 , occurs at $t=3$, so we link the period 4 price level to the price level of period 3 using the Fisher price index for period 4 relative to period 3 . Hence the period 4 normalized price level is $\pi_{\mathrm{AL}}{ }^{4}(0) \equiv \mathrm{P}_{\mathrm{F}}\left(\mathrm{p}^{3}, \mathrm{p}^{4}, \mathrm{q}^{3}, \mathrm{q}^{4}\right) \pi_{\mathrm{AL}}{ }^{3}(0)$. For period 5, we look at the first 4 entries in the column in Table 19 that has the heading $\Delta_{\text {ALt5 }}$. The smallest of these numbers, 0.074 , occurs at $t=4$, so we link the period 5 price level to the price level of period 4 using the Fisher price index for period 5 relative to period 4 . Thus the period 5 normalized price level is $\pi_{\mathrm{AL}}{ }^{5}(0) \equiv \mathrm{P}_{\mathrm{F}}\left(\mathrm{p}^{4}, \mathrm{p}^{5}, \mathrm{q}^{4}, \mathrm{q}^{5}\right) \pi_{\mathrm{AL}}{ }^{4}(0)$. For period 6 , we look at the first 5 entries in the column in Table 19 that has the heading $\Delta_{\text {ALt6. }}$ The smallest of these numbers, 0.008 , occurs at $t=4$, so we link the period 6 price level to the price level of period 4 using the Fisher price index for period 6 relative to period 4. Thus the period 6 normalized price level is $\pi_{\mathrm{AL}}{ }^{6}(0) \equiv \mathrm{P}_{\mathrm{F}}\left(\mathrm{p}^{4}, \mathrm{p}^{6}, \mathrm{q}^{4}, \mathrm{q}^{6}\right) \pi_{\mathrm{AL}}{ }^{4}(0)$. Continue this sequential process until all 12 of the price similarity linked price levels $\pi_{\mathrm{AL}}{ }^{\mathrm{t}}(0)$ have been defined. These price levels are listed in Table A2 of the Appendix; see the column with the heading $\pi_{\mathrm{AL}}{ }^{\mathrm{t}}$.

It can be seen that the price similarity linked price levels $\pi_{\mathrm{AL}}{ }^{\mathrm{t}}$ are quite close to the corresponding target CES price levels, $\pi_{\mathrm{CES}}{ }^{\mathrm{t}}$ but not as close as the CCDI price levels, $\pi_{\mathrm{CCDI}}{ }^{\mathrm{t}}$, when $\sigma=0$. Define the mean absolute difference between the $\pi_{\mathrm{CES}}{ }^{\mathrm{t}}$ and the corresponding $\pi_{\mathrm{AL}}{ }^{\mathrm{t}}$ as the average bias, $\mathrm{B}_{\mathrm{AL}}$ and define the mean absolute differences between the other approximating indexes in a similar manner. Then it turns out that the CCDI and GEKS indexes have the smallest average biases at 0.18 and 0.19 percentage points whereas the price similarity linked indexes $\pi_{\mathrm{AL}}{ }^{\mathrm{t}}$ have an average bias of 0.58 percentage points. The average absolute differences with the $\pi_{\mathrm{CES}}{ }^{\mathrm{t}}$ for the other indexes are listed in Table 7 below.

We turn now to the Log Quadratic measures of relative price dissimilarity defined by (97). Again, we use the same price and quantity data that were used in the previous two sections. Using these data, the dissimilarity measures $\Delta_{\mathrm{LQ}}\left(\mathrm{p}^{\mathrm{r}}, \mathrm{p}^{\mathrm{t}}, \mathrm{q}^{\mathrm{r}}, \mathrm{q}^{\mathrm{t}}\right)$ defined by (97) using the Törnqvist bilateral price index as our $\mathrm{P}\left(\mathrm{p}^{\mathrm{r}}, \mathrm{p}^{\mathrm{t}}, \mathrm{q}^{\mathrm{r}}, \mathrm{q}^{\mathrm{t}}\right)$ are calculated for $\mathrm{r}=1, \ldots, 12$; $\mathrm{t}=1, \ldots, 12$. The resulting dissimilarity measures $\Delta_{\mathrm{LQ}}\left(\mathrm{p}^{\mathrm{r}}, \mathrm{p}^{\mathrm{t}}, \mathrm{q}^{\mathrm{r}}, \mathrm{q}^{\mathrm{t}}\right)$ for $\sigma=0$ are listed in Table 21 below. Note that when $r=t, \Delta_{\text {LQtt }}=0$ for each $\mathrm{t}$ as expected. Note also that the matrix of measures listed in Table 21 is symmetric so that $\Delta_{\mathrm{LQrt}}=\Delta_{\mathrm{LQtr}}$ for all $\mathrm{r}$ and $\mathrm{t}$. Finally, we note that the alternative dissimilarity measures listed in Tables 6 and 7 are fairly similar. 
Table 7: Log Quadratic Measures of Price Dissimilarity for $\sigma=0$

\begin{tabular}{rcccccccccccc}
\hline $\mathrm{t}$ & $\Delta_{\mathrm{LQ11}}$ & $\Delta_{\mathrm{LQ21}}$ & $\Delta_{\mathrm{LQ3t}}$ & $\Delta_{\mathrm{LQ4t}}$ & $\Delta_{\mathrm{LQ5t}}$ & $\Delta_{\mathrm{LQ6t}}$ & $\Delta_{\mathrm{LQ7t}}$ & $\Delta_{\mathrm{LQ8t}}$ & $\Delta_{\mathrm{LQ9t}}$ & $\Delta_{\mathrm{LQ10t}}$ & $\Delta_{\mathrm{LQ11t}}$ & $\Delta_{\mathrm{LQ12t}}$ \\
\hline 1 & 0.000 & 0.063 & 0.027 & 0.050 & 0.174 & 0.101 & 0.098 & 0.095 & 0.128 & 0.248 & 0.177 & 0.217 \\
2 & 0.063 & 0.000 & 0.068 & 0.116 & 0.268 & 0.161 & 0.178 & 0.052 & 0.180 & 0.364 & 0.276 & 0.311 \\
3 & 0.027 & 0.068 & 0.000 & 0.004 & 0.102 & 0.025 & 0.025 & 0.041 & 0.039 & 0.137 & 0.068 & 0.096 \\
4 & 0.050 & 0.116 & 0.004 & 0.000 & 0.071 & 0.008 & 0.009 & 0.045 & 0.018 & 0.094 & 0.038 & 0.058 \\
5 & 0.174 & 0.268 & 0.102 & 0.071 & 0.000 & 0.039 & 0.047 & 0.122 & 0.048 & 0.016 & 0.048 & 0.057 \\
6 & 0.101 & 0.161 & 0.025 & 0.008 & 0.039 & 0.000 & 0.001 & 0.049 & 0.004 & 0.045 & 0.014 & 0.025 \\
7 & 0.098 & 0.178 & 0.025 & 0.009 & 0.047 & 0.001 & 0.000 & 0.063 & 0.002 & 0.051 & 0.011 & 0.022 \\
8 & 0.095 & 0.052 & 0.041 & 0.045 & 0.122 & 0.049 & 0.063 & 0.000 & 0.063 & 0.164 & 0.109 & 0.123 \\
9 & 0.128 & 0.180 & 0.039 & 0.018 & 0.048 & 0.004 & 0.002 & 0.063 & 0.000 & 0.042 & 0.004 & 0.013 \\
10 & 0.248 & 0.364 & 0.137 & 0.094 & 0.016 & 0.045 & 0.051 & 0.164 & 0.042 & 0.000 & 0.026 & 0.027 \\
11 & 0.177 & 0.276 & 0.068 & 0.038 & 0.048 & 0.014 & 0.011 & 0.109 & 0.004 & 0.026 & 0.000 & 0.003 \\
12 & 0.217 & 0.311 & 0.096 & 0.058 & 0.057 & 0.025 & 0.022 & 0.123 & 0.013 & 0.027 & 0.003 & 0.000 \\
\hline
\end{tabular}

For each representative elasticity of substitution $\sigma$, we construct relative price similarity linked normalized price levels, $\pi_{\mathrm{LQ}}{ }^{\mathrm{t}}(\sigma){ }^{85}$ For $\sigma=0$, as each new observation becomes available, we link the current observation to the most similar previous observation as was done when we constructed the price levels $\pi_{\mathrm{AL}}{ }^{\mathrm{t}}(0)$, except that we now use the dissimilarity measures listed in Table 21 instead of those listed in Table 19. The resulting sequence of price similarity linked price levels $\pi_{\mathrm{LQ}}{ }^{\mathrm{t}}(0)$ is listed under the heading $\pi_{\mathrm{LQ}}{ }^{t}$ in Table 20 above. It can be seen that the price similarity linked price levels $\pi_{\mathrm{LQ}}{ }^{\mathrm{t}}$ are fairly close to the corresponding target CES price levels, $\pi_{\mathrm{CES}}{ }^{\mathrm{t}}$, when $\sigma=0$ with an average absolute difference of 0.62 percentage points. Thus the approximation of the Log Quadratic price similarity linked index $\pi_{\mathrm{LQ}}{ }^{t}(0)$ to the target CES index is similar to the approximation of the Asymptotic Linear price similarity linked index $\pi_{\mathrm{AL}}{ }^{t}(0)$ to $\pi_{\mathrm{CES}}{ }^{t}$ and both of these approximations are not as good as the approximations provided by the GEKS and CCDI indexes when the elasticity of substitution is 0 .

We can construct counterparts to Tables 6 and 7 for $\sigma$ equal to 0.5, 1, 2, 4 and 10 and form the price similarity linked indexes $\pi_{\mathrm{AL}}{ }^{t}(\sigma)$ and $\pi_{\mathrm{LQ}}{ }^{\mathrm{t}}(\sigma)$ for these values of $\sigma$ using the above linking methodology. The resulting price levels are listed in Table A2 of the Appendix. In Table 8, we list the mean absolute difference between our ten approximating indexes to the corresponding true cost of living indexes, $\pi_{\mathrm{CES}}{ }^{t}(\sigma)$ for each of our representative $\sigma$ values. However, we exclude periods 3, 6, 9 and 11 from this comparison because the true cost of living is not defined for these observations.

\footnotetext{
${ }^{85}$ As $\sigma$ changes, the prices do not change but the expenditure shares change. Hence the measures of relative price dissimilarity change as $\sigma$ changes. We have not listed all of the counterpart tables to Tables 19 and 21 but we note that for fixed $\sigma$, the AL and LQ dissimilarity measures were quite similar.
} 
Table 8: Mean Absolute Differences in Percentage Points between $\pi_{\mathrm{CES}}{ }^{t}(\sigma)$ and Ten Approximating Indexes as Functions of the Elasticity of Substitution $\sigma$

\begin{tabular}{lllllllllll}
\hline$\sigma$ & $\mathrm{B}_{\mathrm{FCH}}$ & $\mathrm{B}_{\mathrm{TCH}}$ & $\mathrm{B}_{\mathrm{FFB}}$ & $\mathrm{B}_{\mathrm{TFB}}$ & $\mathrm{B}_{\mathrm{WTPD}}$ & $\mathrm{B}_{\mathrm{GK}}$ & $\mathrm{B}_{\mathrm{GEKS}}$ & $\mathrm{B}_{\mathrm{CCDI}}$ & $\mathrm{B}_{\mathrm{AL}}$ & $\mathrm{B}_{\mathrm{LQ}}$ \\
\hline 0 & 3.78 & 4.77 & 0.00 & 0.11 & 1.66 & 0.00 & 0.12 & 0.08 & 0.55 & 0.63 \\
0.5 & 3.89 & 4.84 & 0.12 & 0.04 & 0.89 & 1.19 & 0.05 & 0.17 & 0.47 & 0.43 \\
1 & 4.06 & 4.81 & 0.46 & 0.00 & 0.00 & 2.58 & 0.17 & 0.29 & 0.53 & 0.27 \\
2 & 4.81 & 4.75 & 1.91 & 0.37 & 2.19 & 5.68 & 1.40 & 0.10 & 1.07 & 0.47 \\
4 & 6.84 & 5.65 & 5.96 & 3.41 & 5.37 & 8.90 & 4.98 & 2.47 & 2.69 & 1.61 \\
10 & 9.08 & 7.68 & 10.83 & 9.19 & 4.91 & 5.01 & 9.57 & 7.83 & 6.05 & 5.08 \\
\hline
\end{tabular}

When $\sigma=0$, the fixed base Fisher and GK indexes are exactly equal to the CES indexes. The fixed base Törnqvist, CCDI and GEKS indexes are all very close to the true cost of living index. When $\sigma=0.5$, GEKS does best followed closely by the fixed base Fisher and CCDI indexes. When $\sigma=1$, the fixed base Törnqvist and WTPD price levels are exactly equal to the corresponding CES price levels. The GEKS, CCDI and LQ price similarity linked price levels are all fairly close to the corresponding CES price levels. For $\sigma=2$, The CCDI price levels are very close to the corresponding CES price levels followed by the fixed base Törnqvist and the log quadratic price similarity linked indexes (LQ indexes). The GK price levels are on average furthest from the corresponding CES price levels when $\sigma=2$ and 4 . For $\sigma=4$, the LQ indexes are closest to the corresponding true cost of living indexes followed by the CCDI and Asymptotic Linear price similarity linked indexes (AL indexes). Finally, for $\sigma=10$, the WTPD, GK and LQ indexes are the clear winners.

The results in this section can be summed up as follows:

- The Chained Fisher and Chained Törnqvist indexes performed poorly for all elasticities of substitution.

- The Weighted Time Product Dummy indexes worked well for our numerical example when the elasticity of substitution $\sigma$ was equal to 1 or 10 but they did not work well when $\sigma$ was equal to 2 or 4 .

- The Geary-Khamis indexes worked well when $\sigma=0$ or 10 but poorly when $\sigma=1$, 2 or 4.

- For $0 \leq \sigma \leq 1 / 2$, the Fixed Base Fisher, Fixed Base Törnqvist, GEKS and CCDI indexes all worked well. However the cases where $\sigma \geq 1$ are the cases of interest.

- For $1 \leq \sigma \leq 2$, the CCDI indexes performed well.

- The LQ price similarity linked indexes performed the best by a substantial margin for $\sigma=4$ and the LQ generally performed well for $1 \leq \sigma \leq 10$.

In applications of multilateral methods using scanner data at the elementary level of aggregation, it is likely that the elasticity of substitution is greater than one so the very 
limited results in this section support the use of the CCDI and Log Quadratic price similarity linked indexes in this context. ${ }^{86}$

We have not directly addressed the possibility of using the price dissimilarity measures for choosing the period for linking windows in applying multilateral methods. However, we can make some observations on this from the price dissimilarity measures of tables 6 and 7. Using the Log Quadratic measures from Table 7, $\Delta_{\mathrm{LQ12t}}$ suggests the optimality of using period 11 as the link period for updating an initial 11 period window as period 12 data becomes available, with the smallest dissimilarity value being 0.003 . This suggests that the movement splice updating method is optimal, i.e. using the immediately prior period as the linking period. However, if we have, say, an initial 10 period window, as period 11 data becomes available, $\Delta_{\text {LQ11t }}$ suggests the linking period should be period 9, which means that movement splice updating is not optimal.

The length of the initial window in this example is not relevant. What it demonstrates is that it is not necessarily the case that, for any window length, the previous period is the optimal linking period. Again, in the absence of additional information, this suggests the use of the mean splice.

\section{Conclusion}

The dot points at the end of the previous section will not be repeated here but they could serve as the main conclusions from this study. However, there are two important limitations of our study:

- The conclusions of this study are based on only a single artificial data set example. More research into how the different multilateral methods perform under different conditions is needed.

- We have assumed that all prices and quantities are positive over all periods. Our results will still be valid if some quantities are zero in some periods but the assumption of positive prices cannot be entirely relaxed. Many of the multilateral methods depend on taking the logarithms of prices and if prices are 0 in some periods, this can cause the multilateral method to be undefined. But more fundamentally, the economic approach to index number theory can deal with new and disappearing commodities using the shadow price approach due to Hicks (1940) which can in theory generate positive reservation prices to go along with the associated zero quantities. However, it will be difficult for statistical agencies to estimate these reservation prices.

\footnotetext{
${ }^{86}$ We have not recommended the use of the Sato-Vartia formula to compute price indexes that are consistent with CES preferences because a limitation of the CES functional form is that the degree of substitutability between every pair of commodities is constrained to be the same. Methods like GEKS, CCDI or similarity linking are based on the use of superlative bilateral index number formulae as building blocks and thus these methods will allow for an arbitrary pattern of substitutability between each commodity pair.
} 
An important result in our study is that linking the price and quantity data for a new period to the data of previous periods by using a price dissimilarity measure is the only multilateral method that is consistent with Walsh's powerful multiperiod identity test; i.e., if the price data for the new period is equal to or proportional to the price data of a previous period, then the price level for the new period will be equal to or proportional to the price level of the previous period. The drawback to the use of this multilateral method is that it requires agreement on how to measure the degree of price dissimilarity. For our sales adjusted data sets, we found that the Log Quadratic measure of price dissimilarity worked well. It remains to be seen whether this result will hold up under other conditions.

In the meantime, for elasticities of substitution in reasonable ranges that are expected to be found empirically, overall our results suggest the use of the CCDI index, combined with a new method, the mean splice, for updating. 


\section{References}

Allen, R.C. and W.E. Diewert (1981), "Direct versus Implicit Superlative Index Number Formulae”, Review of Economics and Statistics 63, 430-435.

Alterman, W.F.., W.E. Diewert and R.C. Feenstra (1999), International Trade Price Indexes and Seasonal Commodities, Bureau of Labor Statistics, Washington D.C.

Armknecht, P. and M. Silver (2013), "Post-Laspeyres: The Case for a New Formula for Compiling Consumer Price Indexes”, Review of Income and Wealth, forthcoming.

Arrow, K.J., H.B. Chenery, B.S. Minhas and R.M. Solow (1961), "Capital-Labor Substitution and Economic Efficiency", Review of Economics and Statistics 63, 225-250.

Aten, B. and A. Heston (2009), "Chaining Methods for International Real Product and Purchasing Power Comparisons: Issues and Alternatives”, pp. 245-273 in Purchasing Power Parities of Currencies: Recent Advances in Methods and Applications, D.S. Prasada Rao (ed.), Cheltenham UK: Edward Elgar.

Australian Bureau of Statistics (2016), "Making Greater Use of Transactions Data to Compile the Consumer Price Index", Information Paper 6401.0.60.003, November 29, Canberra: ABS.

Balk, B.M. (1981), “A Simple Method for Constructing Price Indices for Seasonal Commodities”, Statistische Hefte 22 (1), 1-8.

Balk, B.M. (1996), “A Comparison of Ten Methods for Multilateral International Price and Volume Comparisons”, Journal of Official Statistics 12, 199-222.

Balk, B.M. (2008), Price and Quantity Index Numbers, New York: Cambridge University Press.

Baltas, G. (2001), “Utility-consistent Brand Demand Systems with Endogenous Category Consumption: Principles and Marketing Applications”, Decision Sciences 32, 399-421.

Bureau of Labor Statistics (2014), “New CPI Estimation System to be Introduced”, Release, October 21, Washington D.C. http://www.bls.gov/cpi/cpinewest.htm

Caves D.W., Christensen, L.R. and Diewert, W.E. (1982), 'Multilateral comparisons of output, input, and productivity using superlative index numbers', Economic Journal 92, 73-86.

Chessa, A.G. (2016), “A New Methodology for Processing Scanner Data in the Dutch CPI”, Eurona 1/2016, 49-69.

Clements, K.W., H.Y. Izan and E.A. Selvanathan (2006), "Stochastic Index Numbers: A Review”, International Statistical Review 74, 235-270.

Davies, G.R. (1924), “The Problem of a Standard Index Number Formula”, Journal of the American Statistical Association 19, 180-188.

de Haan, J. (2008), "Reducing Drift in Chained Superlative Price Indexes for Highly Disaggregated Data”, paper presented at the EMG Workshop 2008, University of New South Wales, Sydney, Australia, December 10-12.

de Haan, J. (2015a), “A Framework for Large Scale Use of Scanner Data in the Dutch CPI”, Paper presented at the 14th meeting of the Ottawa Group, May 22, Tokyo. http://www.stat.go.jp/english/info/meetings/og2015/pdf/t6s11p33_pap.pdf 
de Haan, J. (2015b), "Rolling Year Time Dummy Indexes and the Choice of Splicing Method", Room Document at the 14th meeting of the Ottawa Group, May 22, Tokyo. http://www.stat.go.jp/english/info/meetings/og2015/pdf/t1s3room

de Haan, J. and H.A. van der Grient (2011), "Eliminating Chain drift in Price Indexes Based on Scanner Data", Journal of Econometrics 161, 36-46.

Diewert, W.E. (1976), "Exact and Superlative Index Numbers", Journal of Econometrics 4, 114-145.

Diewert, W.E. (1978), "Superlative Index Numbers and Consistency in Aggregation”, Econometrica 46, 883-900.

Diewert, W.E. (1993), “The Early History of Price Index Research”, pp. 33-65 in Essays in Index Number Theory, Volume 1, W.E. Diewert and A.O. Nakamura (eds.), Amsterdam: North-Holland.

Diewert, W.E. (1995), On the Stochastic Approach to Index Numbers”, Discussion Paper 95-31, Department of Economics, University of British Columbia, Vancouver, Canada.

Diewert, W.E. (1996), “Comments on CPI Biases”, Business Economics 32:2, 30-35.

Diewert, W.E. (1999), "Axiomatic and Economic Approaches to International Comparisons”, pp. 13-87 in International and Interarea Comparisons of Income, Output and Prices, A. Heston and R.E. Lipsey (eds.), Studies in Income and Wealth, Volume 61, Chicago: The University of Chicago Press.

Diewert, W.E. (2004), "On the Stochastic Approach to Linking the Regions in the ICP”, Department of Economics, Discussion Paper 04-16, University of British Columbia, Vancouver, B.C., Canada, V6T 1 Z1.

Diewert, W.E. (2005), "Weighted Country Product Dummy Variable Regressions and Index Number Formulae”, The Review of Income and Wealth 51:4, 561-571.

Diewert, W.E. (2009), “Similarity Indexes and Criteria for Spatial Linking”, pp. 183-216 in Purchasing Power Parities of Currencies: Recent Advances in Methods and Applications, D.S. Prasada Rao (ed.), Cheltenham, UK: Edward Elgar.

Diewert, W.E. (2012), Consumer Price Statistics in the UK, Government Buildings, Cardiff Road, Newport, UK, NP10 8XG: Office for National Statistics. http://www.ons.gov.uk/ons/guide-method/userguidance/prices/cpi-and-rpi/index.html

Diewert, W.E. (2013a), "An Empirical Illustration of Index Construction using Israeli Data on Vegetables" paper presented at the $13^{\text {th }}$ Meeting of the Ottawa Group On Prices, May 1-3, Copenhagen, Denmark.

Diewert, W.E. (2013b), "Methods of Aggregation above the Basic Heading Level within Regions”, pp. 121-167 in Measuring the Real Size of the World Economy: The Framework, Methodology and Results of the International Comparison Program-ICP, Washington D.C.: The World Bank.

Diewert, W.E., Y. Finkel and Y. Artsev (2009), "Empirical Evidence on the Treatment of Seasonal Products: The Israeli Experience”, pp. 53-78 in Price and Productivity Measurement: Volume 2: Seasonality, W.E. Diewert, B.M. Balk, D. Fixler, K.J. Fox and A.O. Nakamura (eds.), Victoria, Canada: Trafford Press.

Diewert, W.E., M. Huwiler and U. Kohli (2009), Swiss Journal of Economics and Statistics 145(2), 127-135.

Drechsler, L. (1973), "Weighting of Index Numbers in Multilateral International Comparisons", Review of Income and Wealth 19,17-34. 
Eltetö, Ö., and Köves, P. (1964), “On a Problem of Index Number Computation Relating to International Comparisons”, (in Hungarian), Statisztikai Szemle 42, 507-518.

Feenstra, R.C. (1994), "New Product Varieties and the Measurement of International Prices”, American Economic Review 84, 157-177.

Feenstra, R.C. and M.D. Shapiro (2003), "High-Frequency Substitution and the Measurement of Price Indexes”, pp. 123-146 in Scanner Data and Price Indexes, Robert C. Feenstra and Matthew D. Shapiro (eds.), Studies in Income and Wealth Volume 64, Chicago: The University of Chicago Press.

Fisher, I. (1911), The Purchasing Power of Money, London: Macmillan.

Fisher, I. (1922), The Making of Index Numbers, Boston: Houghton-Mifflin.

Fox, K.J., R.J., Hill and W.E. Diewert (2004), "Identifying Outliers in Multi-Output Models", Journal of Productivity Analysis 22, 73-94.

Frisch, R. (1936), "Annual Survey of General Economic Theory: The Problem of Index Numbers", Econometrica 4, 1-39.

Frobenius, G. (1909), “Über Matrizen aus positiven Elementen”, Sitzungberichte der königlich preussischen Akademie der Wissenschaften, Part 1, 514-518.

Geary, R.G. (1958), "A Note on Comparisons of Exchange Rates and Purchasing Power between Countries", Journal of the Royal Statistical Society Series A 121, 97-99.

Gini, C. (1931), “On the Circular Test of Index Numbers”, Metron 9:9, 3-24.

Hanbury, J., T. Watanabe and D.E. Weinstein (2013), "How Much do Official Price Indexes Tell us about Inflation”, paper presented at the Economic Measurement Group Workshop Asia 2013, Tokyo, Japan, October 16.

Hausman, J. (1997), "Valuation of New Goods Under Perfect and Imperfect Competition”, pp. 209-237 in The Economics of New Goods, T. Bresnahan and R. Gordon (eds.), NBER Studies in Income and Wealth, Volume 58, Chicago: The University of Chicago Press.

Hicks, J.R. (1940), “The Valuation of the Social Income”, Economica 7, 105-140.

Hill, R.J. (1997), "A Taxonomy of Multilateral Methods for Making International Comparisons of Prices and Quantities", Review of Income and Wealth 43(1), 4969.

Hill, R.J. (1999a), “Comparing Price Levels across Countries Using Minimum Spanning Trees”, The Review of Economics and Statistics 81, 135-142.

Hill, R.J. (1999b), "International Comparisons using Spanning Trees", pp. 109-120 in International and Interarea Comparisons of Income, Output and Prices, A. Heston and R.E. Lipsey (eds.), Studies in Income and Wealth Volume 61, NBER, Chicago: The University of Chicago Press.

Hill, R.J. (2001), “Measuring Inflation and Growth Using Spanning Trees”, International Economic Review 42, 167-185.

Hill, R.J. (2004), "Constructing Price Indexes Across Space and Time: The Case of the European Union”, American Economic Review 94, 1379-1410.

Hill, R.J. (2009), "Comparing Per Capita Income Levels Across Countries Using Spanning Trees: Robustness, Prior Restrictions, Hybrids and Hierarchies”, pp. 217-244 in Purchasing Power Parities of Currencies: Recent Advances in Methods and Applications, D.S. Prasada Rao (ed.), Cheltenham UK: Edward Elgar. 
Hill, R.J., D.S. Prasada Rao, S. Shankar and R. Hajargasht (2017), "Spatial Chaining as a Way of Improving International Comparisons of Prices and Real Incomes”, paper presented at the Meeting on the International Comparisons of Income, Prices and Production, Princeton University, May 25-26.

Hill, T.P. (1988), "Recent Developments in Index Number Theory and Practice", OECD Economic Studies 10, 123-148.

Hill, T.P. (1993), "Price and Volume Measures”, pp. 379-406 in System of National Accounts 1993, Eurostat, IMF, OECD, UN and World Bank, Luxembourg, Washington, D.C., Paris, New York, and Washington, D.C.

Huang, N., W. Wimalaratne and B. Pollard (2017), "The Effects of the Frequency and Implementation Lag of Basket Updates on the Canadian CPI”, Journal of Official Statistics, forthcoming.

ILO/IMF/OECD/UNECE/Eurostat/The World Bank (2004), Consumer Price Index Manual: Theory and Practice, Peter Hill (ed.), Geneva: International Labour Office.

Ivancic, L., W.E. Diewert and K.J. Fox (2009), "Scanner Data, Time Aggregation and the Construction of Price Indexes", Discussion Paper 09-09, Department of Economics, University of British Columbia, Vancouver, Canada.

Ivancic, L., W.E. Diewert and K.J. Fox (2010), "Using a Constant Elasticity of Substitution Index to estimate a Cost of Living Index: from Theory to Practice", Australian School of Business Research Paper No. 2010 ECON 15, University of New South Wales, Sydney 2052 Australia

Ivancic, L., W.E. Diewert and K.J. Fox (2011), "Scanner Data, Time Aggregation and the Construction of Price Indexes", Journal of Econometrics 161, 24-35.

Inklaar, R. and W.E. Diewert (2016), "Measuring Industry Productivity and CrossCountry Convergence", Journal of Econometrics 191, 426-433.

Khamis, S.H. (1970), "Properties and Conditions for the Existence of a New Type of Index Number”, Sankhya B 32, 81-98.

Khamis, S.H. (1972), "A New System of Index Numbers for National and International Purposes”, Journal of the Royal Statistical Society Series A 135, 96-121.

Kravis, I.B., A. Heston and R. Summers (1982), World Product and Income: International Comparisons of Real Gross Product, Statistical Office of the United Nations and the World Bank, Baltimore: The Johns Hopkins University Press.

Krsinich, F. (2015), "Implementation of Consumer Electronics Scanner Data in the New Zealand CPI", Statistics New Zealand. Paper presented at the New Zealand Association of Economists conference, Wellington, New Zealand, 3 July.

Johansen, I. and R. Nygaard (2011), "Dealing with Bias in the Norwegian Superlative Price Index of Food and Non-alcoholic Beverages", Paper presented at the Twelfth meeting of the Ottawa Group, May 4-6, Wellington, New Zealand.

Konüs, A.A. (1924), "The Problem of the True Index of the Cost of Living”, translated in Econometrica 7, (1939), 10-29.

Konüs, A.A. and S.S. Byushgens (1926), "K probleme pokupatelnoi cili deneg”, Voprosi Konyunkturi 2, 151-172.

Krsinich, F. (2011), "Price Indexes from Scanner Data: A Comparison of Different Methods”, Paper presented at the twelfth meeting of the Ottawa Group, May 4-6, Wellington, New Zealand. 
Krsinich, F. (2013), “Using the Rolling Year Time Product Dummy Method for Quality Adjustment in the Case of Unobserved Characteristics”, Ottawa Group 2013 Meeting, Copenhagen, Denmark, May 1-3.

Krsinich, F. (2016), “The FEWS Index: Fixed Effects with a Window Splice', Journal of Official Statistics 32, 375-404.

Laspeyres, E. (1871), “Die Berechnung einer mittleren Waarenpreissteigerung”, Jahrbücher für Nationalökonomie und Statistik 16, 296-314.

Lehr, J. (1885), Beitrage zur Statistik der Preise, Frankfurt: J.D. Sauerlander.

Lowe, J. (1823), The Present State of England in Regard to Agriculture, Trade and Finance, second edition, London: Longman, Hurst, Rees, Orme and Brown.

Marris, R. (1984), "Comparing the Incomes of Nations: A Critique of the International Comparison Project”, Journal of Economic Literature 22:1, 40-57.

Marshall, A. (1887), "Remedies for Fluctuations of General Prices', Contemporary Review 51, 355-375.

Paasche, H. (1874), “Über die Preisentwicklung der letzten Jahre nach den Hamburger Borsennotirungen”, Jahrbücher für Nationalökonomie und Statistik 12, 168-178.

Perron, O. (1907), "Grundlagen für eine Theorie des Jacobischen Kettenbruchalgorithmus”, Mathematische Annalen 64, 1-76.

Persons, W.M. (1921), "Fisher's Formula for Index Numbers”, Review of Economics and Statistics 3:5, 103-113.

Rao, D.S. Prasada (1995), “On the Equivalence of the Generalized Country-ProductDummy (CPD) Method and the Rao-System for Multilateral Comparisons”, Working Paper No. 5, Centre for International Comparisons, University of Pennsylvania, Philadelphia.

Rao, D.S. Prasada (2004), “The Country-Product-Dummy Method: A Stochastic Approach to the Computation of Purchasing Power parities in the ICP”, paper presented at the SSHRC Conference on Index Numbers and Productivity Measurement, June 30-July 3, 2004, Vancouver, Canada.

Rao, D.S. Prasada (2005), “On the Equivalence of the Weighted Country Product Dummy (CPD) Method and the Rao System for Multilateral Price Comparisons”, Review of Income and Wealth 51:4, 571-580.

Sato, K. (1976), “The Ideal Log Change Index Number”, Review of Economics and Statistics 78, 121-126.

Selvanathan, E.A. and D.S. Prasada Rao (1994), Index Numbers: A Stochastic Approach, Ann Arbor: The University of Michigan Press.

Sergeev, S. (2001), “Measures of the Similarity of the Country's Price Structures and their Practical Application”, Conference on the European Comparison Program, U. N. Statistical Commission. Economic Commission for Europe, Geneva, November 12-14, 2001.

Sergeev, S. (2009), “Aggregation Methods Based on Structural International Prices”, pp. 274-297 in Purchasing Power Parities of Currencies: Recent Advances in Methods and Applications, D.S. Prasada Rao (ed.), Cheltenham UK: Edward Elgar.

Summers, R. (1973), “International Comparisons with Incomplete Data”, Review of Income and Wealth 29:1, 1-16.

Szulc, B.J. (1964), "Indices for Multiregional Comparisons”, (in Polish), Przeglad Statystyczny 3, 239-254. 
Szulc, B.J. (1983), “Linking Price Index Numbers,” pp. 537-566 in Price Level Measurement, W.E. Diewert and C. Montmarquette (eds.), Ottawa: Statistics Canada.

Szulc, B.J. (1987), "Price Indices below the Basic Aggregation Level”, Bulletin of Labour Statistics 2, 9-16.

Theil, H. (1967), Economics and Information Theory, Amsterdam: North-Holland Publishing.

Törnqvist, L. (1936), “The Bank of Finland's Consumption Price Index”, Bank of Finland Monthly Bulletin 10, 1-8.

Törnqvist, L. and E. Törnqvist (1937), Vilket är förhällandet mellan finska markens och svenska kronans köpkraft?”, Ekonomiska Samfundets Tidskrift 39, 1-39 reprinted as pp. 121-160 in Collected Scientific Papers of Leo Törnqvist, Helsinki: The Research Institute of the Finnish Economy, 1981.

van der Grient, H.A. and J. de Haan (2011), "Scanner Data Price Indexes: The 'Dutch Method" versus Rolling Year GEKS", paper presented at the $12^{\text {th }}$ Meeting of the Ottawa Group, May 4-6, Wellington, New Zealand.

Vartia, Y.O. (1976), “Ideal Log-Change Index Numbers”, Scandinavian Journal of Statistics 3, 121-126.

Walsh, C.M. (1901), The Measurement of General Exchange Value, New York: Macmillan and Co.

Walsh, C. M. (1921), “Discussion”, Journal of the American Statistical Association 17, 537-544. 
Appendix

Table A1: Alternative Price Levels for Different Methods and Elasticities of Substitution

\begin{tabular}{|c|c|c|c|c|c|c|c|}
\hline & $\pi_{\mathrm{CES}}{ }^{\mathrm{t}}$ & $\pi_{\mathrm{FCH}}{ }^{\mathrm{t}}$ & $\pi_{\mathrm{TCH}}{ }^{\mathrm{t}}$ & $\pi_{\text {WTPD }}{ }^{t}$ & $\pi_{\mathrm{GK}}{ }^{\mathrm{t}}$ & $\pi_{\mathrm{GEKS}} \mathrm{t}^{\mathrm{s}}$ & $\pi_{\mathrm{CCDI}}{ }^{\mathrm{t}}$ \\
\hline \multicolumn{8}{|c|}{ Alternative Price Levels when $\sigma=0$} \\
\hline 1 & 1.0000 & 1.0000 & 1.0000 & 1.0000 & 1.0000 & 1.0000 & 1.0000 \\
\hline 2 & 0.8600 & 0.8600 & 0.8585 & 0.8830 & 0.8600 & 0.8600 & 0.8571 \\
\hline 3 & 0.9500 & 0.9500 & 0.9515 & 0.9227 & 0.9500 & 0.9500 & 0.9507 \\
\hline 4 & 0.9500 & 0.9500 & 0.9515 & 0.9179 & 0.9500 & 0.9500 & 0.9506 \\
\hline 5 & 0.8740 & 0.8740 & 0.8726 & 0.8612 & 0.8740 & 0.8740 & 0.8724 \\
\hline 6 & & 0.9700 & 0.9705 & 0.9367 & 0.9700 & 0.9700 & 9705 \\
\hline 7 & 0.9360 & 360 & & & 0.9360 & 0.9360 & 366 \\
\hline 8 & 0.7840 & 340 & 0.7829 & 0.7717 & 0.7840 & 0.7840 & 7832 \\
\hline 9 & 0.9100 & 0.9100 & & & 0.9100 & 0.9100 & 9106 \\
\hline 10 & 0.8700 & 0.8700 & 0.8698 & 0.8645 & 0.8700 & 0.8700 & 8689 \\
\hline 11 & 0.9260 & 0.9260 & 0.9268 & 0.9040 & 0.9260 & 0.9260 & 0.9265 \\
\hline 12 & 0.9300 & 0.9300 & 0.9308 & 0.9144 & 0.9300 & 0.9300 & 0.9303 \\
\hline \multicolumn{8}{|c|}{ Alternative Price Levels when $\sigma=0.5$} \\
\hline 1 & & 1.0000 & 1.0000 & 1.0000 & 1.0000 & & 0000 \\
\hline 2 & 0.8 & & & & & & 633 \\
\hline 3 & 0. & 0.9 & 34 & & & 31 & 831 \\
\hline 4 & 0 . & 23 & 18 & & 26 & 15 & 915 \\
\hline 5 & 0.8951 & 35 & 46 & 98 & 0. & 31 & 3944 \\
\hline 6 & 1.0223 & 1.0221 & 1.0223 & 1.0033 & 1.0458 & 1.0221 & 1.0222 \\
\hline 7 & 0.9831 & 0.9829 & 0.9831 & & 1.0053 & 829 & 0.9831 \\
\hline 8 & 0.8213 & 0.8200 & & & & 202 & 8209 \\
\hline 9 & & & & & & & \\
\hline 10 & & & & & & & 983 \\
\hline 11 & 70 & 70 & & & & 66 & 768 \\
\hline 12 & 0.9817 & 0.9818 & 0.9817 & 0.9719 & 0.9966 & 311 & 9815 \\
\hline \multicolumn{8}{|c|}{ Alternative Price Levels when $\sigma=1$} \\
\hline 1 & 1.0000 & 1.0000 & 1.0000 & 1.0000 & 1.0000 & 1.0000 & 0000 \\
\hline 2 & 0.8716 & 0.8675 & 0.8716 & $0 . \varepsilon$ & 0.8 & 668 & 8716 \\
\hline 3 & 1.0172 & 1.0183 & 1.0172 & 1.0172 & 1. & 160 & 0172 \\
\hline 4 & 1.0346 & 1.0357 & 1.0 & & 1. & 29 & 346 \\
\hline 5 & & & & & & & אל \\
\hline 6 & & & & & & & 771 \\
\hline 7 & & & & & & & 321 \\
\hline 8 & 0. & & & & & 70 & 616 \\
\hline 9 & 1.0058 & 47 & 1.0 & $1 .($ & 26 & 33 & 1.0058 \\
\hline 10 & 0.9244 & 0.9205 & 0.9244 & 0.9244 & 0.9373 & 0.9172 & 0.9244 \\
\hline 11 & 1.0301 & 1.0285 & 1.0301 & 1.0301 & 1.0 & 1.0270 & 1.0301 \\
\hline 12 & 1.0355 & 1.0339 & 1.0355 & 1.0355 & 1.0717 & 1.0316 & 1.0355 \\
\hline \multicolumn{8}{|c|}{ Alternative Price Levels when $\sigma=2$} \\
\hline 1 & $1 .($ & 1.0000 & 00 & 1.0000 & & & 000 \\
\hline 2 & 0.8953 & 0.8801 & & & & & 0.8927 \\
\hline 3 & & & & & & & 0775 \\
\hline 4 & 1.1151 & & & & & & 1.1126 \\
\hline 5 & & & & & & 0.9086 & 0.9312 \\
\hline 6 & 1.1817 & 76 & 1. & 1.2 & 1.3023 & 843 & 1.1783 \\
\hline 7 & 1.1248 & 1.1114 & 1.1223 & 1.1738 & 1.2364 & 1.1090 & 1.1217 \\
\hline 8 & 0.9418 & 0.9207 & 0.9380 & 0.9647 & 1.0013 & 0.9205 & 0.9378 \\
\hline 9 & & 374 & 961 & & 1.2068 & 1.0818 & 1.0950 \\
\hline 10 & 0.9559 & 0.9387 & 0.9527 & 0.9558 & 0.9842 & 0.9270 & 0.9502 \\
\hline 11 & 1.1312 & 1.1186 & 1.1288 & 1.1742 & 1.2348 & 1.1125 & 1.1276 \\
\hline 12 & 1.1370 & 1.1243 & 1.1346 & 1.1738 & 1.2325 & 1.1153 & 1.1328 \\
\hline
\end{tabular}


Table A1 (cont.): Alternative Price Levels for Different Methods and Elasticities of Substitution

\begin{tabular}{|c|c|c|c|c|c|c|c|}
\hline $\mathbf{t}$ & $\pi_{\mathrm{CES}}{ }^{\mathrm{t}}$ & $\pi_{\mathrm{FCH}}{ }^{\mathrm{t}}$ & $\pi_{\mathrm{TCH}}{ }^{t}$ & $\pi_{\text {WTPD }}{ }^{t}$ & $\pi_{G K}{ }^{t}$ & $\pi_{\text {GEKS }}{ }^{t}$ & $\pi_{\mathrm{CCDI}}{ }^{\mathrm{t}}$ \\
\hline \multicolumn{8}{|c|}{ Alternative Price Levels when $\sigma=4$} \\
\hline 1 & 1.0000 & 1.0000 & 1.0000 & 1.0000 & 1.0000 & 1.0000 & 1.0000 \\
\hline 2 & 0.9465 & 0.8924 & 0.9196 & 0.9406 & 0.9670 & 0.8988 & 220 \\
\hline 3 & 1.1558 & 337 & & & 298 & & \\
\hline 4 & 1.2209 & 1.1972 & 1.2090 & 1.3145 & 1.3389 & 1.1704 & זרי \\
\hline 5 & 0.9305 & 0.8881 & 0.9078 & 0.9336 & 0.9771 & 0.8661 & 0.8931 \\
\hline 6 & 1.3293 & 1.2745 & 1.3000 & 1.4674 & 1.5194 & 1.2610 & 1.2915 \\
\hline 7 & 1.2529 & 1.2013 & 1.2253 & 1.3772 & 1.4222 & 1.1910 & 1.2185 \\
\hline 8 & 1.0640 & 0.9890 & 1.0254 & & & 0.9830 & 0205 \\
\hline 9 & 1.2259 & & & & & 627 & 09 \\
\hline 10 & 0.9453 & 32 & 0.9 & & 0.9726 & 0.8832 & 888 \\
\hline 11 & 1.2728 & 44 & 1. & & & 22 & 39 \\
\hline 12 & 1.2745 & 1.2260 & 1.2484 & 1.3870 & 1.4509 & 1.1954 & \\
\hline \multicolumn{8}{|c|}{ Alternative Price Levels when $\sigma=10$} \\
\hline 1 & 1.0000 & 1.0000 & 1.0000 & 1.0000 & 1.0000 & 1.0000 & 0000 \\
\hline 2 & 1.0088 & 0.8565 & 0.8885 & 1.0 & 1.0912 & 0.8752 & 9010 \\
\hline 3 & 1.1981 & 439 & 1.1568 & & & 66 & 376 \\
\hline 4 & 1.2933 & & & & & & \\
\hline 5 & & & & & & & \\
\hline 6 & 1.2 & & & & & & \\
\hline 7 & 1. & & & & 00 & 56 & 90 \\
\hline 8 & 1.1896 & 35 & 31 & 1. & 41 & 41 & 25 \\
\hline 9 & 1.3380 & 86 & 1.2629 & 1.4 & 51 & 962 & 218 \\
\hline 10 & 0.8636 & 0.8923 & 0.8921 & 0.8 & 0.8275 & 0.8383 & 0.8429 \\
\hline 11 & 1.3934 & 1.3216 & 1.3 & & 26 & 372 & 558 \\
\hline 12 & 1.3618 & 1.2935 & 1.3172 & 1.3827 & 1.3942 & 1.1997 & \\
\hline \multicolumn{8}{|c|}{ Alternative Price Levels when $\sigma=20$} \\
\hline 1 & 1.0000 & 1.0000 & 1.0000 & & 1.0000 & 00 & 000 \\
\hline 2 & 1.0218 & & & & & 37 & 408 \\
\hline 3 & & & & & & & \\
\hline 4 & 1.2998 & 1.2269 & 1.2 & 1.3 & 1.3 & 1.1855 & 1.1949 \\
\hline 5 & 0.8297 & 0.8727 & 0.8787 & 0.8 & 0.8 & 0.8104 & 0.8144 \\
\hline 6 & 1.4892 & 1.3172 & 1.3387 & 1.5141 & 1.5146 & 1.3048 & 1.3226 \\
\hline 7 & 1.3907 & 1.2301 & 1.2502 & 1.4129 & 1.4133 & 1.2272 & 1.2427 \\
\hline 8 & 1.2197 & 0.9157 & 0.9478 & 1.3126 & 1.3125 & 0.9169 & 0.9427 \\
\hline 9 & 1.3704 & 1.2186 & 1.2376 & 1.4038 & 1.4062 & 1.1960 & 1.2165 \\
\hline 10 & 0.8297 & 0.8762 & 0.8721 & 0.8065 & 0.8107 & 0.8320 & 0.8349 \\
\hline 11 & 1.4194 & 1.3645 & 1.3836 & 1.4418 & 1.4461 & 1.2258 & 1.2475 \\
\hline 12 & 1.3456 & 1.3028 & 1.3198 & 1.3204 & 1.3260 & 1.1755 & 1.1876 \\
\hline
\end{tabular}


Table A2: Price Levels for the Sales Adjusted Data

\begin{tabular}{|c|c|c|c|c|c|c|c|c|c|c|c|}
\hline $\mathrm{t}$ & $\pi_{\mathrm{CES}}{ }^{\mathrm{t}}$ & $\pi_{\mathrm{FCH}}{ }^{\mathrm{t}}$ & $\pi_{\mathrm{TCH}}{ }^{t}$ & $\pi_{\mathrm{FFB}}{ }^{\mathrm{t}}$ & $\pi_{\mathrm{TFB}}{ }^{\mathrm{t}}$ & $\pi_{\text {WTPD }}{ }^{t}$ & $\pi_{\mathrm{GK}}{ }^{\mathrm{t}}$ & $\pi_{\mathrm{GEKS}}{ }^{\mathrm{t}}$ & $\pi_{\mathrm{CCDI}}{ }^{\mathrm{t}}$ & $\pi_{\mathrm{AL}}{ }^{\mathrm{t}}$ & $\pi_{L Q}{ }^{t}$ \\
\hline \multicolumn{12}{|c|}{ Alternative Price Levels when $\sigma=0$} \\
\hline 1 & 1.0000 & 1.0000 & 1.0000 & 1.0000 & 1.0000 & 1.0000 & 1.0000 & 1.0000 & 1.0000 & 1.0000 & 1.0000 \\
\hline 2 & 0.8600 & 0.8600 & 0.8585 & 0.8600 & 0.8585 & 0.8828 & 0.8600 & 0.8624 & 0.8612 & 0.8600 & 0.8585 \\
\hline 3 & 0.9500 & 0.9232 & 0.9169 & 0.9444 & 0.9450 & 0.9296 & 0.9559 & 0.9524 & 0.9531 & 0.9444 & 0.9450 \\
\hline 4 & 0.9500 & 0.9205 & 0.9141 & 0.9500 & 0.9502 & 0.9179 & 0.9500 & 0.9495 & 0.9505 & 0.9416 & 0.9421 \\
\hline 5 & 0.8740 & 0.8468 & 0.8384 & 0.8740 & 0.8712 & 0.8615 & 0.8740 & 0.8759 & 0.8751 & 0.8663 & 8640 \\
\hline 6 & 0.9700 & 0.9216 & 0.9091 & 0.9794 & 0.9813 & 0.9357 & 0.9654 & 0.9688 & 0.9691 & 0.9651 & 0.9657 \\
\hline 7 & 0.9360 & 0.8904 & 0.8784 & 0.9360 & 0.9364 & 0.9042 & 0.9360 & 0.9354 & 0.9364 & 0.9325 & 0.9330 \\
\hline 8 & 0.7840 & 0.7458 & 0.7343 & 0.7840 & 0.7858 & 0.7715 & 0.7840 & 0.7863 & 0.7863 & 0.7942 & 0.7965 \\
\hline 9 & 0.9100 & 0.8394 & 0.8224 & 0.8937 & 0.8956 & 0.8659 & 0.8937 & 0.9010 & 0.9008 & 0.9036 & 0.9041 \\
\hline 10 & 0.8700 & 0.7970 & 0.7789 & 0.8700 & 0.8680 & 0.8648 & 0.8700 & 0.8706 & 0.8703 & 0.8623 & 0.8600 \\
\hline 11 & 0.9260 & 0.8350 & 0.8140 & 0.9385 & 0.9398 & 0.9103 & 0.9286 & 0.9272 & 0.9279 & 0.9168 & 0.9172 \\
\hline 12 & & 0.8412 & 0.8201 & 0.9300 & 0.9299 & 0.9144 & 0.9300 & & & & 9241 \\
\hline \multicolumn{12}{|c|}{ Alternative Price Levels when $\sigma=0.5$} \\
\hline 1 & 1.0000 & 1.0000 & 1.0000 & 1.0000 & 1.0000 & 1.0000 & 1.0000 & 1.0000 & .0000 & 1.0000 & 1.0000 \\
\hline 2 & 0.8639 & 0.8626 & 0.8635 & 0.8626 & 0.8635 & 0.8751 & 0.8527 & 0.8644 & 0.8672 & 0.8626 & 8635 \\
\hline 3 & 0.9831 & 0.9574 & 0.9493 & 0.9790 & 0.9796 & 0.9718 & 1.0020 & 849 & 0.9851 & 0.9790 & 796 \\
\hline 4 & 0.9915 & 0.9634 & 0.9552 & 0.9915 & 0.9915 & 0.9735 & 1.0126 & 916 & 0.9921 & 0.9852 & 0.9857 \\
\hline 5 & 0.8951 & 0.8674 & 0.8615 & 0.8919 & 0.8940 & 0.8900 & 0.9045 & 0.8963 & 0.8984 & 0.8870 & 0.8891 \\
\hline 6 & 1.0223 & 0.9712 & 0.9578 & 1.0354 & 1.0364 & & & 1.0220 & 1.0218 & 206 & 1.0211 \\
\hline 7 & 0.9831 & 0.9351 & 0.9223 & & & & & & 338 & & 832 \\
\hline 8 & 213 & 801 & 0. & & & & & & & & 365 \\
\hline 9 & 0.9570 & 0.8861 & 0.8677 & 7 & 47 & 0.9 & & 96 & 90 & 39 & 544 \\
\hline 10 & 0.8990 & 0.8261 & 0.8086 & 60 & 79 & 0.8 & 52 & 992 & 013 & 0.8907 & 3929 \\
\hline 11 & 0.9770 & 0.8825 & 0.8597 & 923 & & & & & 799 & & 0.9724 \\
\hline 12 & 0.9817 & 0.8901 & 0.8671 & 0.9806 & 0.9813 & 0.9719 & 0.9965 & 16 & 0.9822 & & 9808 \\
\hline \multicolumn{12}{|c|}{ Alternative Price Levels when $\sigma=1$} \\
\hline 1 & 1.0000 & 1.0000 & 1.0000 & 1.0000 & 1.0000 & 1.0000 & 1.0000 & 1.0000 & 1.0000 & 1.0000 & 1.0000 \\
\hline 2 & 0.8716 & 0.8675 & 0.8716 & 0.8675 & 0.8716 & & & & 0.8754 & 0.8675 & 0.8716 \\
\hline 3 & 1.0172 & & & & & & & & 186 & & 1.0154 \\
\hline 4 & & & & & & & & & & & 11 \\
\hline 5 & 0.9137 & 0.8838 & 0.8 & 0. & 0.5 & 0.5 & 0. & 06 & 90 & 31 & 0.9106 \\
\hline 6 & 1.0771 & 1.0225 & 1.0107 & 1.0931 & 50 & 1.0 & 1.1 & 756 & 1.0777 & 1.0787 & 1.0795 \\
\hline 7 & 1.0321 & 0.9810 & 0.9697 & 305 & 1.0321 & 1.0322 & 1.0818 & 1.0312 & 1.0339 & 1.0349 & 1.0357 \\
\hline 8 & 0.8616 & 0.8159 & 0.8094 & 0.8633 & 0.8616 & 0.8616 & 0.8864 & 0.8605 & 0.8659 & 0.8559 & 0.8578 \\
\hline 9 & 1.0058 & 0.9345 & 0.9171 & 0.9917 & 0.9960 & 0.9906 & 1.0356 & 0.9982 & 1.0001 & 1.0062 & 1.0069 \\
\hline 10 & 0.9244 & 0.8512 & 0.8371 & 0.9129 & 0.9244 & 0.9244 & 375 & 0.9208 & 0.9290 & 0.9135 & 0.9213 \\
\hline 11 & 1.0301 & 0.9318 & 0.9096 & 1.0463 & & & & 321 & 0352 & 0294 & 0302 \\
\hline 12 & 1.0355 & 0.9407 & 0.9184 & 1.0298 & 1.0355 & 1.0355 & 1.0717 & 36 & 1.0378 & 92 & 1.0402 \\
\hline \multicolumn{12}{|c|}{ Alternative Price Levels when $\sigma=$} \\
\hline & 1. & & S & & & & & & & 0 & 00 \\
\hline 2 & 0.8953 & 0.8801 & 0.8926 & & & & & & 0.8960 & 0.8801 & 0.8926 \\
\hline 3 & 1.0794 & 1.0561 & 1.0517 & 1.0782 & 1.0800 & 1.1080 & 1.1395 & 1.0700 & 1.0781 & 1.0782 & 1.0800 \\
\hline 4 & 1.1151 & 1.0904 & 1.0859 & 1.1111 & 1.1144 & 1.1589 & 1.2102 & 1.1047 & 1.1153 & 1.1133 & 1.1151 \\
\hline 5 & 0.9366 & 0.8974 & 0.9088 & 0.8920 & 0.9277 & 0.9439 & 0.9793 & 0.9154 & 0.9390 & 0.9163 & 0.9332 \\
\hline 6 & 1.1817 & 1.1151 & 1.1123 & 1.1983 & 1.2063 & 1.2257 & 1.2850 & 1.1684 & 1.1812 & 1.1885 & 1.1903 \\
\hline 7 & 1.1248 & 1.0626 & 1.0598 & 1.1142 & 1.1229 & 1.1739 & 1.2373 & 1.1126 & 1.1256 & 1.1325 & 1.1342 \\
\hline 8 & 0.9418 & 0.8802 & 0.8857 & 0.9382 & 0.9411 & 0.9651 & 1.0039 & 0.9251 & 0.9432 & 0.9356 & 0.9383 \\
\hline 9 & 1.0981 & 1.0224 & 1.0129 & 1.0763 & 1.0896 & 1.1309 & 1.1913 & 1.0809 & 1.0934 & 1.1039 & 1.1056 \\
\hline 10 & 0.9559 & 0.8787 & 0.8757 & 0.9094 & 462 & & 0.9861 & 336 & 0.9579 & 0.9347 & 0.9523 \\
\hline 11 & & & & & & & 1.2290 & 1.1222 & 1.1370 & 1.1378 & 1.1397 \\
\hline 12 & 1.1370 & 1.0320 & 1.0178 & 1.1085 & 1.1315 & 1.1738 & 1.2336 & 1.1204 & 1.1382 & 1.1500 & 1.1521 \\
\hline
\end{tabular}


Table A2 (cont.): Price Levels for the Sales Adjusted Data

\begin{tabular}{|c|c|c|c|c|c|c|c|c|c|c|c|}
\hline t & $\pi_{\mathrm{CES}} \mathrm{t}^{\mathrm{s}}$ & $\pi_{\mathrm{FCH}}{ }^{\mathrm{t}}$ & $\pi_{\mathrm{TCH}}{ }^{\mathrm{t}}$ & $\pi_{\mathrm{FFB}}{ }^{\mathrm{t}}$ & $\pi_{\mathrm{TFB}} \mathrm{t}^{\mathrm{s}}$ & $\pi_{\text {WTPD }}{ }^{t}$ & $\pi_{\mathrm{GK}}$ & $\pi_{\text {GEKS }}{ }^{t}$ & $\pi_{\mathrm{CCDI}}$ & $\pi_{\mathrm{AL}}{ }^{\mathrm{t}}$ & $\pi_{\mathrm{LQ}}{ }^{t}$ \\
\hline \multicolumn{12}{|c|}{ Alternative Price Levels when $\sigma=4$} \\
\hline 1 & 1.0000 & 1.0000 & 1.0000 & 1.0000 & 1. & 1.0000 & 1.0000 & 1.0000 & 1.0000 & 1.0000 & 1.0000 \\
\hline 2 & 0.9465 & 24 & & 0.8924 & 96 & & 35 & 06 & & & 96 \\
\hline 3 & 58 & 36 & & & & & 71 & & & 339 & 560 \\
\hline 4 & 1.2209 & 68 & & 1. & & & 05 & 750 & & 187 & 212 \\
\hline 5 & 0.9305 & 0.8804 & 0.8972 & 0.8200 & 0.8608 & 347 & 0.9833 & 0.8758 & 0.9035 & 0.9041 & 9170 \\
\hline 6 & 1.3293 & 1.2284 & 1.2414 & 1.3299 & 1.3486 & & 1.4947 & 1.2698 & 1.2978 & 1.3390 & 3419 \\
\hline 7 & 1.2529 & 1.1584 & & 1.2126 & & & & & & & 2653 \\
\hline 8 & 1.0640 & & & & & & & & & & 281 \\
\hline 9 & 1. & & & & & & & & & & 373 \\
\hline 10 & 3 & 0 & 0 & 8 & 77 & & 0. & 32 & & 83 & 315 \\
\hline 1 & 1.2728 & 28 & 38 & 1.2487 & 77 & 2 & 1. & 98 & 03 & 56 & 2885 \\
\hline 22 & 1.2745 & 433 & 146 & 1.1691 & 1.2180 & 1.3887 & 1.4560 & 1.2050 & 05 & 75 & 1.3007 \\
\hline \multicolumn{12}{|c|}{ Alternative Price Levels when $\sigma=10$} \\
\hline 1 & 1.0000 & 1.0000 & 1.0000 & 1.0000 & 1.0000 & 1.0 & 1.0000 & 1.0000 & & 000 & 000 \\
\hline 2 & 1.0088 & 0.8565 & 0.8 & 0.8565 & 85 & 6 & 1.0 & 68 & 25 & 65 & 885 \\
\hline 3 & 1.1981 & 1.1434 & 1.1562 & 1.1971 & 74 & & 1.2 & 05 & & 71 & 974 \\
\hline 4 & & & & 47 & & & & & 00 & 916 & 1.2921 \\
\hline 5 & 0.8 & & & & & & & & & 16 & 085 \\
\hline 6 & & & & & & & & & & & 649 \\
\hline 7 & & & & 1.2 & & & & & & 76 & 1.3692 \\
\hline 8 & 396 & & & 1.0239 & 85 & & & 09 & 90 & 48 & 1.0368 \\
\hline 9 & 1.3380 & 1.2082 & 1.2246 & 1.2114 & 1.2462 & 88 & 1.4152 & 1.2058 & 1.2308 & 1.3464 & 1.3481 \\
\hline 10 & 0.8636 & 0.8703 & 0.8650 & 0.7762 & 0.7776 & 0.8 & 0.8291 & 0.8501 & 0.8549 & 0.9122 & 0.9091 \\
\hline 1 & 1.3934 & 1.2356 & 1.2468 & 1.2805 & 1.3252 & 1.4768 & 1.4828 & 1.2620 & 1.2892 & 1.4097 & 1.4115 \\
\hline 12 & 1.5010 & 1.2 & $1 . \angle 350$ & 1.0903 & 1.1325 & 1.3857 & 1.0905 & 1.2120 & 1.2376 & 1.3950 & 1.3966 \\
\hline
\end{tabular}

